\title{
Providing NIST Supervisors with a Continuous Learning Program
}

\author{
David Griffith \\ Susan Heller-Zeisler \\ Joy Herman \\ Andrew Jackson \\ Janine Kerns \\ Donna Kimball \\ William E. Wallace \\ Brian A. Weiss
}



NISTIR 7776

\title{
Providing NIST Supervisors with a Continuous Learning Program
}

\author{
David Griffith \\ Information Technology Laboratory \\ Susan Heller-Zeisler \\ Office of the Director \\ Joy Herman \\ Office of Workforce Management
}

Andrew Jackson

Center for Neutron Research

Janine Kerns

Office of the Financial Resource Management

Donna Kimball

Material Measurement Laboratory

William E. Wallace

Material Measurement Laboratory

Brian A. Weiss

Engineering Laboratory

This publication is available free of charge from:

http://dx.doi.org/10.6028/NIST.IR.7776

April 2011

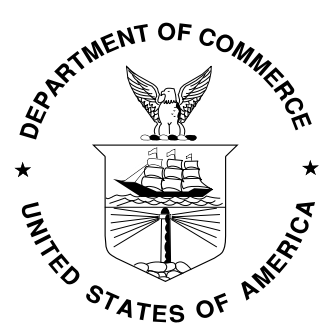

U.S. Department of Commerce Gary Locke, Secretary

National Institute of Standards and Technology Patrick D. Gallagher, Director 



\title{
Providing NIST Supervisors with a Continuous Learning Program
}

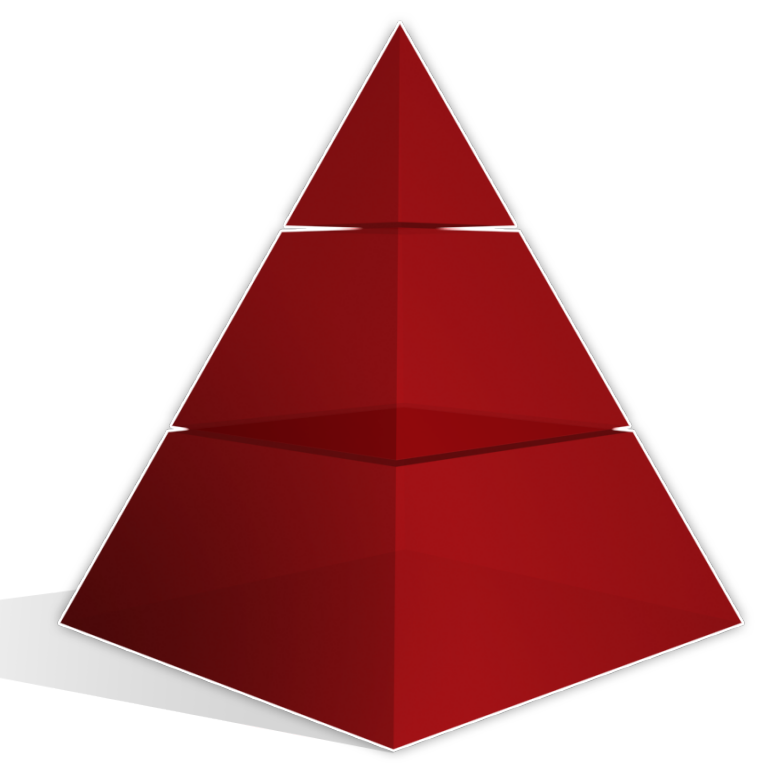

\author{
Building the Next Generation 7 \\ Special Study Group Project
}

March 2010 - October 2010

\section{Final Report}

\section{November 1, 2010}

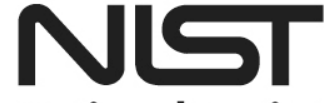

National Institute of Standards and Technology U.S. Department of Commerce

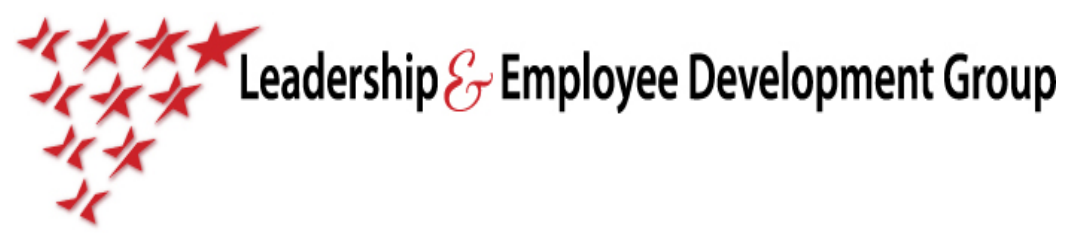


Any mention of commercial products within this report is for information only; it does not imply recommendation or endorsement by NIST. 


\section{Acknowledgments}

The Building the Next Generation Class 7 (BTNG7) Special Study Group members would like to thank the Chief Human Capital Officer, Michael Culpepper, and the NIST Leadership and Employee Development Group (LED), in particular Debora Clough, for entrusting this assignment to us. Their guidance and encouragement was essential to obtaining and processing the data reported here.

We also would like to thank William Ott and David Seiler of the Physical Measurement Laboratory (PML) for their valuable information and advice regarding the 1998 report, "Survey of Leadership and Managerial Development Needs at NIST."

We kindly thank all of the participants for their valuable input and thoughtful commentary, which, through the survey results and conversations, provided the foundation for this report.

Finally, the Special Study Group would like to extend a heartfelt thank you to our guide and mentor through this project, Michael Martin of the LED Group. We sincerely wish Mike and the LED group continued success and growth for the outstanding NIST New Leader Program and the NIST Building the Next Generation Program. 



\section{Table of Contents}

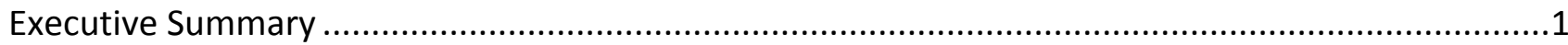

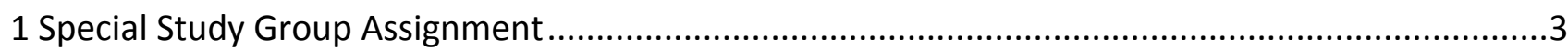

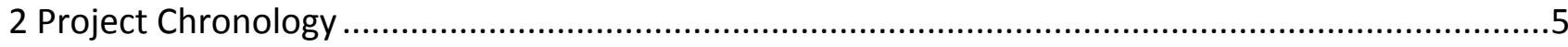

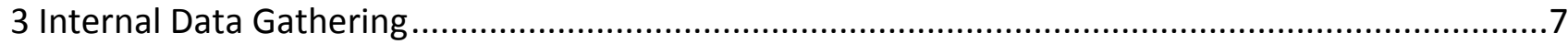

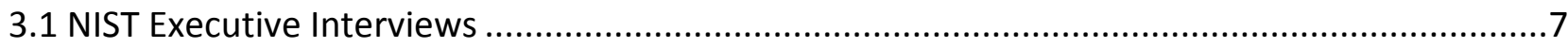

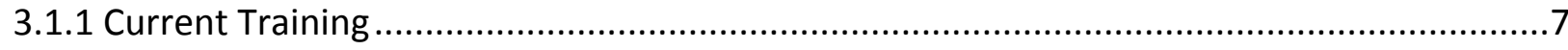

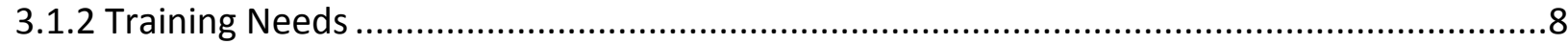

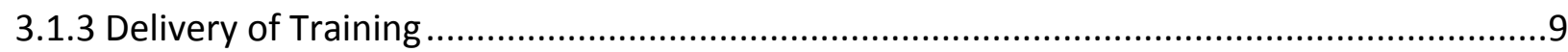

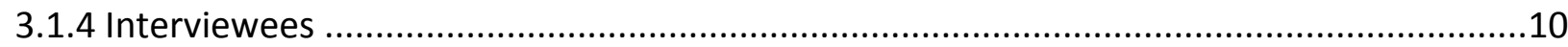

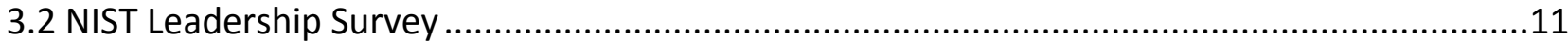

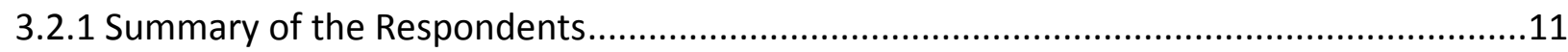

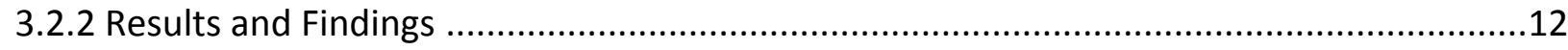

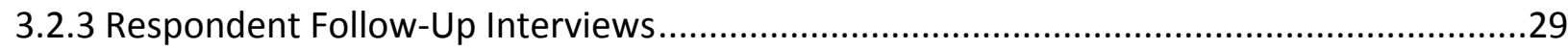

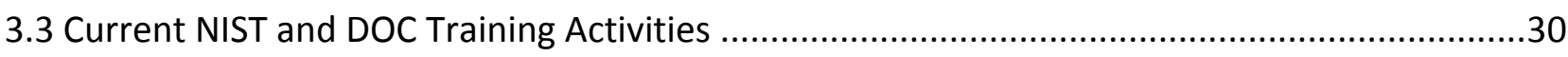

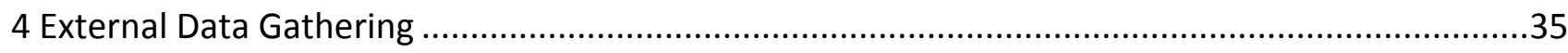

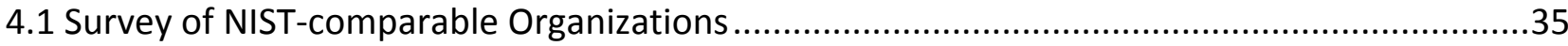

4.1.1 Summaries of Organizations Surveyed ............................................................35

4.1.1.1 Counterpart National Metrology Institutes and International Organizations ..............35

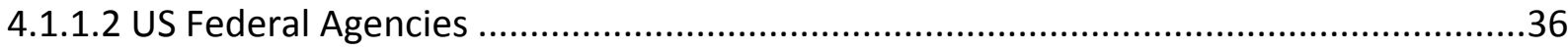

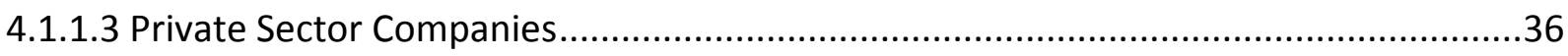

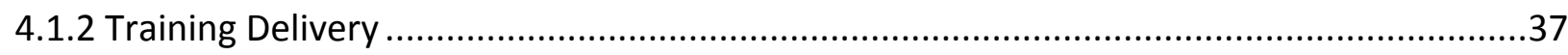

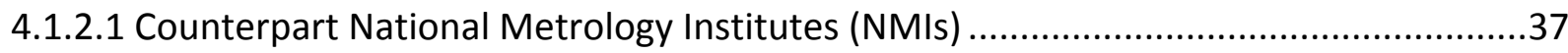

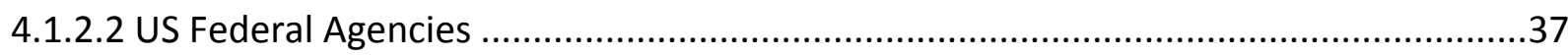

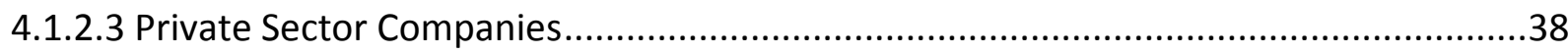

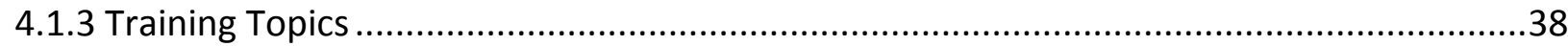

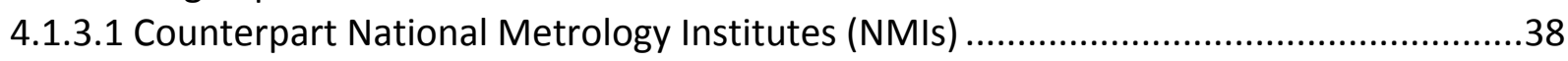

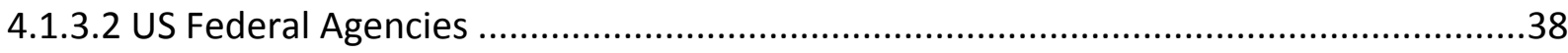

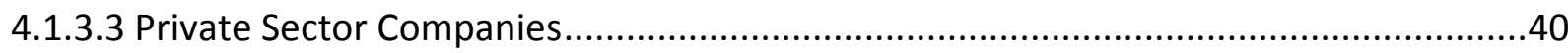

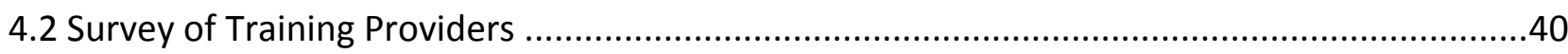

4.2.1 Summaries of Training Providers Surveyed ..............................................................40

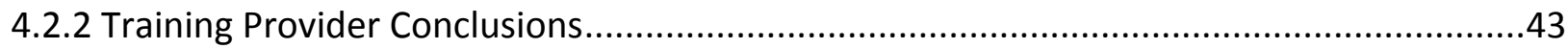

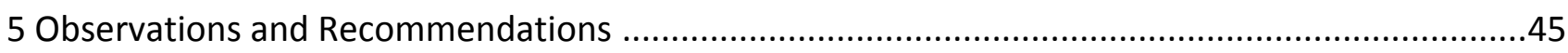

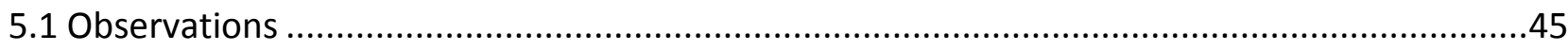

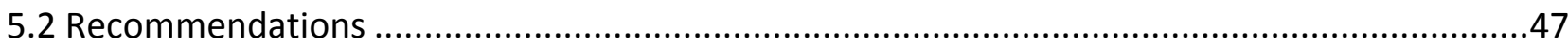

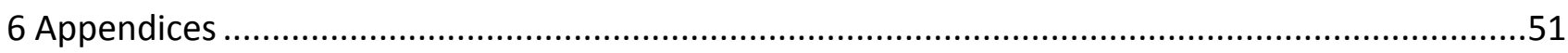

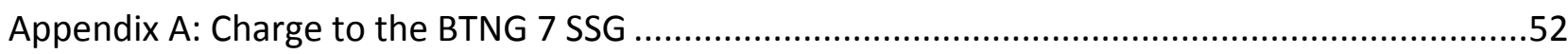

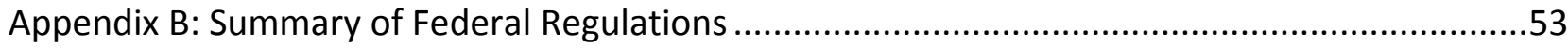


Appendix C: Chief Human Capital Office Actions to Address New Regulations ...........................55

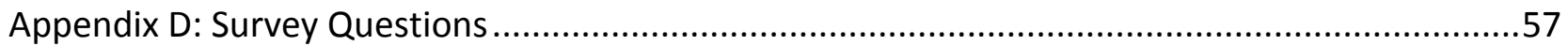

Appendix E: Survey Questions to NIST-Comparable Organizations ..........................................61

Appendix F: The Leadership Competency "Stair Step" ...........................................................62

Appendix G: Leadership Development Programs for First-Line Supervisors in Selected Federal

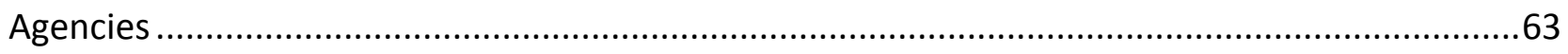

Appendix H: NIST Individual Development Plan Form (DN-13) ..............................................64

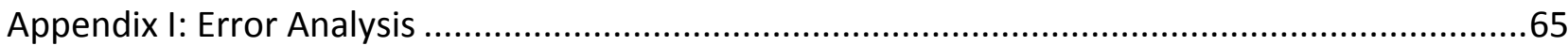

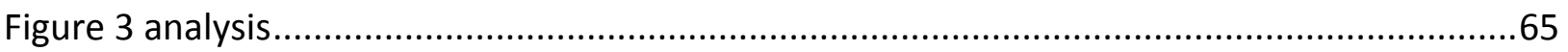

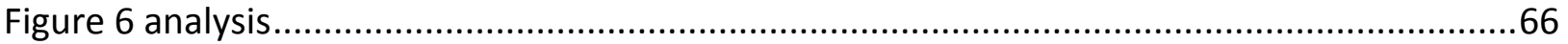

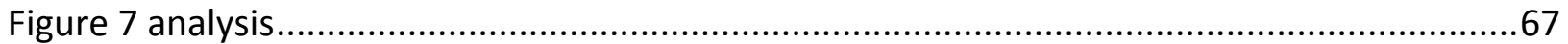

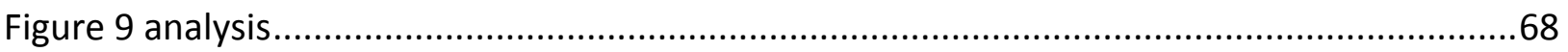

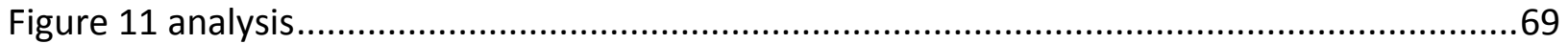

Appendix J: Survey of Leadership and Managerial Development Skills at NIST (1998) ................71 


\section{Executive Summary}

As a result of new Office of Personnel Management (OPM) regulations, the Chief Human Capital Office, through its Leadership and Employee Development (LED) Group, charged the Building the Next Generation (BTNG) Class 7 Special Study Group (SSG) with developing a continuous learning program for experienced supervisors and managers at NIST.

In the first of the two phases of the project, the SSG: briefed the NIST Leadership Board on our project; conducted face-to-face interviews with NIST executives and their designates; conducted an on-line survey with NIST executives, managers, and supervisors; and followed up with additional face-to-face interviews with respondents, where requested.

In the second phase of the project, we extended our data gathering to NIST-comparable organizations. Questions were asked as to whether they require refresher training for their managers/supervisors, the topics that were included, and how the training was delivered. The survey was sent out via emails and followed up where appropriate with personal contact. A number of federal agencies, private sector companies, and counterpart National Metrology Institutes (NMI) were contacted and asked to complete the survey. In order to complete the second phase of the project, the group also surveyed training providers currently used by NIST and those identified by the external organizations surveyed. These, along with resources identified during the various NIST interviews, provide a base from which to build a training program.

Our primary observation was that NIST is not alone in lacking mandatory refresher training for managers and supervisors; most of the outside organizations that we also surveyed do not have such training, or like us, are just starting to plan such a program. What we did find, however, is that some of the organizations we surveyed have a wide variety of possible training areas and delivery methods available to their managers and supervisors, most of which are currently taken by choice.

In terms of training topics three clear themes emerged:

\section{People skills are paramount for great leadership.}

These skills include often-mentioned topics such as communication (oral and written; up, down, and lateral), conflict management, change management, and team building.

Knowledge of NIST operational functions and organizational development skills are vital. Operational functions include acquisitions/contracts, employee relations/resources, finance/budget, and workforce management. Organizational development skills include strategic long-term planning, understanding NIST's role in the political environment, and understanding NIST's history and mission, particularly with respect to US industry and peer NMIs.

\section{Handling of uncommon, high-impact events is required.}

Examples of high-impact events include: media interviews, presentations to visiting Congressional staff or visiting dignitaries, responding to administrative policy changes, or describing the NIST mission to a technical organization. "Just-in-time" training that could be delivered as necessary to NIST staff immediately prior to their participation in a high-impact event can address this need.

As to training delivery methods, on the basis of the responses, no one method of delivery would have an exact fit to all situations, suggesting that a variety of delivery methods for the refresher 
training should be made available. In terms of the NIST surveys, there was a preference given to inhouse training and seminars/lectures. However, there was support for other types of delivery, so these should not be overlooked in structuring a robust, diverse refresher training program that can appeal to and be useful to managers and supervisors. NIST and its employees would benefit from having a private internal social network site that would foster teamwork and communication NISTwide.

Based on the information that the Special Study Group has gathered, we make the following recommendations:

1. There should be choices built into the mandatory refresher training for managers and supervisors. We suggest a tiered approach. The first tier (Tier I) consists of training that emphasizes people skills that all of the surveyed managers agree are important. Tier I training also covers NIST operational functions and organizational aspects. The Tier II training includes just-in-time training to prepare managers for an imminent event, the outcome of which has the potential to impact NIST in a significant way. The Tier III training includes more courses and areas of study directly relating to the needs of individual managers. Tier III training courses may be taken as "electives," but still count towards the mandatory refresher training.

2. The Operating Units (OUs) within each Directorate should have a common Tier I training curriculum. Tier II and Tier III training schedules and requirements could be left to the discretion of the individual OUs. This would give OUs a degree of independence and the ability to tailor training to their own needs while ensuring that all NIST managers have a common basic skill set. It would also allow managers from different OUs to train together to gain exposure to people from other areas of NIST, as was suggested in the OU Director interviews. We encourage the NIST Director's office to assist and encourage the OUs within each of these three areas to devise a common Tier I program while allowing them the freedom to add what Tier II and Tier III training they desire, even if they decide that this amount should be zero.

3. The Leadership and Employee Development Group should coordinate the refresher training.

4. No one method of delivery would have an exact fit to all situations, so providing a variety of delivery methods for the refresher training is suggested.

5. To plan what type of refresher training is most appropriate for each manager/supervisor, we recommend that an Individual Development Plan (IDP) be considered.

6. NIST Office of Workforce Management (OWM) should annually review the training requirements and curricula and make any modifications or additions that they deem necessary. 


\section{Special Study Group Assignment}

The Chief Human Capital Office (CHCO), through its Leadership and Employee Development (LED) Group, charged the Building the Next Generation (BTNG) Class 7 (See Appendix A) with developing a continuous learning program for experienced supervisors and managers at NIST.

A subset of NIST's current BTNG7 class volunteered to serve as a Special Study Group (SSG). The purpose of a SSG is to study a NIST-wide, high-level issue and to recommend a course of action for senior leadership. The BTNG7 SSG has been specifically tasked by the Chief Human Capital Officer, with support from LED, with recommending to CHCO how NIST should address the new Office of Personnel Management (OPM) Federal regulations (See Appendix B) that mandate refresher training for supervisors and managers at least every three years. The current NIST training program was designed prior to the new regulations and needs to be updated to comply with them.

In an effort to provide NIST leaders with current leadership best practices and satisfy the new federal training regulations, the BTNG7 SSG has organized its activities into two phases to accomplish its goals. In the first phase the group will perform an assessment of the training needs at NIST and recommend a suite of options that address those needs. In the second phase resources will be identified that can fulfill the requirements.

NIST and the Department of Commerce (DOC) provide some mandatory general training on an annual basis, such as, Ethics, IT Security, and Safety Training. At NIST, new managers are required to take a mandatory training session entitled "Managerial Survival Skills," within the first year of their managerial appointment.

NIST and DOC currently have a wide range of training offerings for leaders, but there is no mandate or time frequency requirement for continuous learning. These current activities are described later in this report.

NIST has an opportunity to respond proactively and effectively to these new requirements that have been mandated by OPM and DOC (See Appendix C). 
Providing NIST Supervisors with a Continuous Learning Program 


\section{Project Chronology}

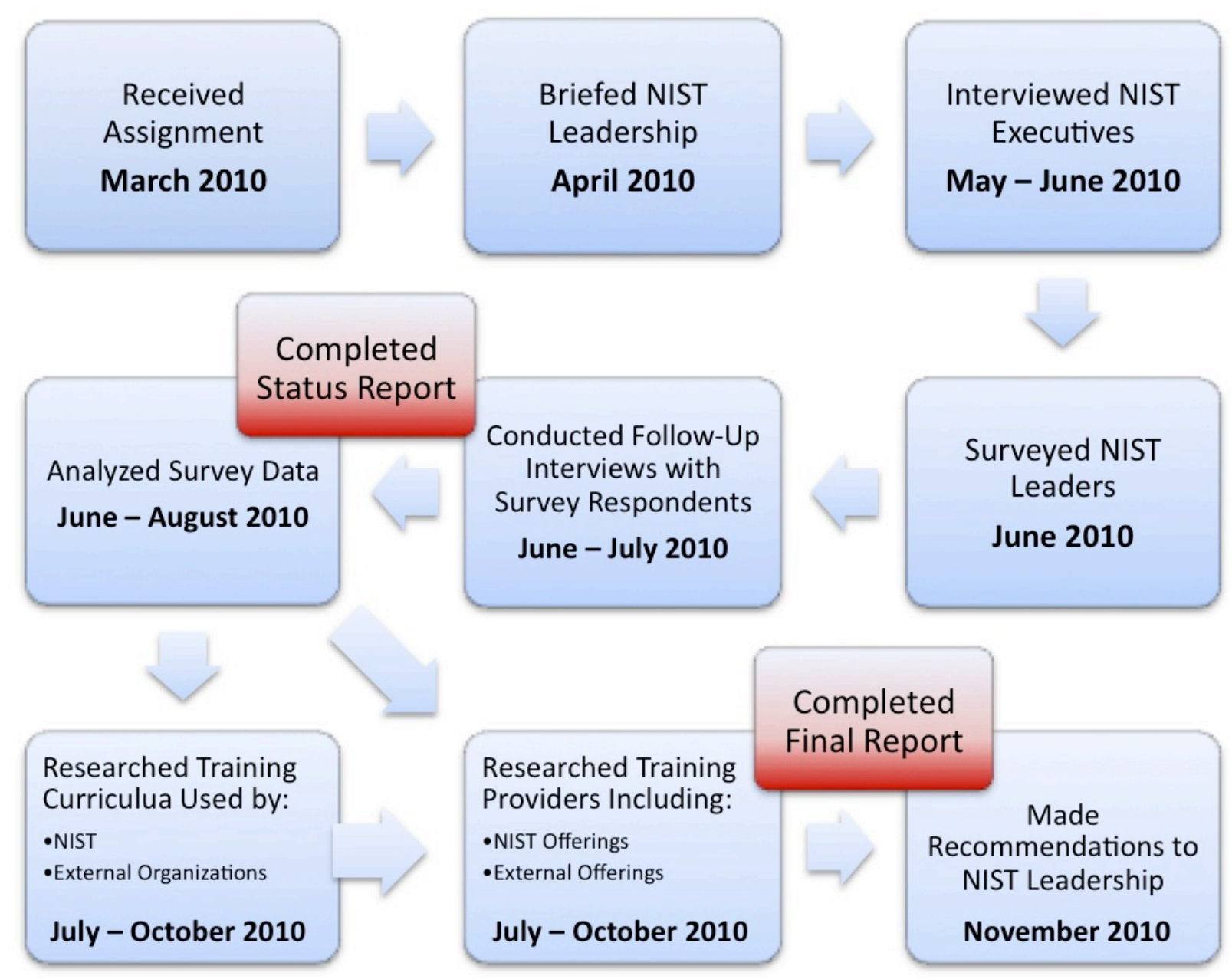


Providing NIST Supervisors with a Continuous Learning Program 


\section{Internal Data Gathering}

In the first phase of the project, the SSG briefed the NIST Leadership Board on our project; conducted face-to-face interviews with NIST Executives and their designates; conducted an on-line survey with NIST Executives, Managers, and Supervisors, and followed up with additional face-toface interviews with respondents, where requested.

\subsection{NIST Executive Interviews}

Following the introduction of the BTNG 7 Special Study Group Project at the OU Directors' Lunch on April 26, 2010 and at the Management Council meeting on May 3, 2010, most of the OU Directors offered to assist the group. Specifically, this would be done by allowing SSG members to conduct individual interviews with them to gain insights into their needs, and to get suggestions for training from the unique viewpoints of each Operating Unit. The SSG gained a wealth of information through these interviews, which is summarized below.

The goal of the first stage of our project was to gather information on training needs and current practice and, on the basis of that, to suggest a continuous learning program for experienced (nonSES) managers. We received much useful information towards this goal.

There were three questions that provided the starting point for the discussions:

1. What management/leadership training is your OU currently doing?

2. What do you need? How much time/effort is appropriate for this type of training?

3. How do you manage succession? How do you prepare people for succession?

The discussions went in different directions, depending on the emphasis of the individual OU Director. The interviewees made many excellent suggestions during the interviews; their comments gave us a good picture of the unique views of each OU, with their different structures, missions, and sizes. Two SSG members typically conducted the interviews, and each interview lasted approximately 45 to 60 minutes.

\subsubsection{Current Training}

Responding to the question on what their OU is currently doing for management/leadership training, almost all of the interviewees mentioned that they support the LED programs, especially NLP and BTNG. We learned that there were a variety of additional ways that OUs are currently carrying out management/leadership training. These include the following:

1. Coaching/Mentoring

2. Presentation skills course, suggested as mandatory

3. Encouraging outside training/education

- University degree program reimbursement

- OPM Eastern Management Development Center

- Federal Executive Institute (FEI) - Leadership for a Democratic Society course

- Partnership with Johns Hopkins University for Graduate Certificate Programs 
- California Institute of Technology

- Brookings Institute

4. Opportunities for staff rotation/detail assignments, including NIST Program Office or outside NIST

5. "On-the-job" training or "Acting" manager status

6. NIST People Council

7. Encouraging external committee leadership roles

8. OU-Sponsored and/or organized training

9. Library of books on management and leadership

10. Baldrige National Quality Program (BNQP) Quest Conference

11. Technology Innovation Program (TIP) - specific training, dependent on individual's position and management role

12. Manufacturing Extension Partnership (MEP)

- On the job - team/project leaders

- In-House Developed Webinars (TS)

- NIST/LED library resources on leadership

- MEP University

- MEP Emerging Leader Programs for Center Staff

- Share Best Practices among Centers

13. Baldrige Performance Excellence Program (BPEP)

- Assessment of a case study using the Baldrige Categories (modified version of the examiner training)

- Attendance at the annual Quest for Excellence Conference

Both MEP and BNQP noted that they have team leaders, who are not formal supervisors, but still act in a leadership capacity. BNQP uses teams that are groups of eight to nine people that are mostly self-managed to accomplish their work; team leaders are assigned a one- or two-year term. In this way more people develop leadership and management skills and are also more sensitive to the issues associated with a team environment after their "tenure."

\subsubsection{Training Needs}

There were many different responses to the question on what management and leadership skills need to be strengthened or developed at NIST. There were quite a few interviewees who believe that interpersonal skills need to be emphasized. Most often mentioned were effective communication (both oral and written), conflict management, dealing with difficult people, change management, customer service skills, and team building. Some interviewees termed these "soft skills." A need for providing effective training in these types of skills came up in 13 out of 18 interviews.

In addition, several of the interviewees mentioned the need for training in NIST history, NIST culture, or the NIST mission as applied to all its laboratories and programs, not just the sub-section where the manager is working. A more specific suggestion was to provide training on NIST's unique mission and history, to develop an attitude of leadership as stewardship for the organization, and not as competition against other parts of the organization. A number of the interviewees recommended training outside one's normal working environment, not only to network, but to develop an awareness of other NIST operating units, their particular missions, and staff requirements. 
Not coming up often in the interviews, but significant nevertheless, was the suggestion for training on how to effectively manage projects and creative problem-solving, and also a desire for more emphasis on strategic sourcing and planning.

Another idea that emerged was to provide updates on NIST "protocols," the nuts and bolts of what a manager needs to deal with, as DOC and USG guidance on important topics such as procurement acquisitions, contracts, and personnel issues changes with time.

An unusual suggestion came for the need for training in "hot" management topics, almost impromptu, but pertinent areas for training, covering e.g., changing regulations in Human Resources, or in Procurement. A variation on this was a suggestion for "just-in-time" training. The suggestion was to have a catalog of inexpensive recorded video presentations, such as "training on press relations before an important press event."

An idea that came up a few times in different guises was the need to make management jobs more appealing in general (although this is not strictly a training need). There is a need to reduce the amount of administrative burden on managers, and give more tools and support so they can actually "manage."

Related to needs, and also connected to "how to deliver training," was the idea of having managers use Individual Development Plans whether related to the performance plan or not. This was emphasized by several of the interviewees, and was related to providing more structure to the required training.

\subsubsection{Delivery of Training}

There were diverse, and sometimes quite strong, thoughts from the OU Directors on how to deliver the training. There seemed to be a consensus that there needs to be a variety of training opportunities available. Not only do people learn differently, but there are different training needs for different OUs and there is not "one size that will fit all." For example, a manager working in a laboratory may have different needs than one working in one of the extramural programs.

Some of the suggestions included:

1. An annual one-week off-site training course for managers, e.g., at Federal Executive Institute (FEI) or a similar location, to allow participants to concentrate on training.

2. Just-in-time-delivery courses (e.g., sets of videos for different scenarios a manager may encounter).

3. Training should be conducted across OUs to allow interaction between employees from different areas of expertise.

4. That there be no absolute time requirement; instead, define the objectives of training, and allow sufficient time to meet those objectives.

5. Development of training around individual development plans and/or an assessment tool such as $360^{\circ}$ assessments.

6. On-line training using internal and external resources.

7. Increased use of participatory learning versus static courses.

8. As there is much training already required, management/leadership training should be targeted and useful.

9. Mandatory customer service training when a manager works in this area. 


\subsubsection{Interviewees}

A list of the interviewees is shown below: ${ }^{1}$

OU Director or Designate Interviewed

Shyam Sunder
Harry Hertz
Michael Culpepper
Robert Celotta, Lloyd Whitman,
Willie May
Kent Rochford
James St. Pierre
Howard Harary
Roger Kilmer
Richard Cavanagh
Robert Dimeo, Michael Moore
Howard Hochman
Stephen Kunze
Susannah Schiller
Kevin Kimball
William Ott
Lorel Wisnewski
Belinda Collins

EL (formerly BFRL)

BPEP (formerly BNQP)

OWM (formerly $\mathrm{CHCO}$ )

CNST

MML (formerly CSTL)

EL (formerly EEEL)

ITL

EL (formerly MEL)

MEP

MML (formerly MSEL)

NCNR

OFPM (formerly CFMO)

OFRM (formerly CFO)

OISM (formerly OCIO)

OD

PML (formerly PL)

TIP

(formerly TS)

${ }^{1}$ At the time of this report's printing, NIST had completed an Agency-Wide Reorganization. The Operating Unit name identified in parentheses was the name of the Operating Unit at the time the interview was conducted. 


\subsection{NIST Leadership Survey}

Using information gathered from the interviews with NIST executives, we developed an electronic survey consisting of nine questions. The survey was intentionally brief to maximize the response rate (See Appendix D).

During the period of June 7 to June 14, 2010, the group surveyed 373 supervisors, managers, and executives. Of those 373, 167 replied (a $46 \%$ response rate) with 10 respondents requesting followup face-to-face interviews.

\subsubsection{Summary of the Respondents}

The respondents spanned the full range of responsibility and experience, with 20 being executives (e.g., OU Directors), 34 being managers (e.g., Division Chiefs) and 113 being supervisors (e.g., Group and Team Leaders). Figure 1 shows the breakdown of the NIST leaders who responded to the survey based upon their current leadership position and their time as a leader.

Experience as a supervisor varied from less than 5 years to over 30 years, although the majority of respondents had fewer than five years of experience in their position. There is an interesting contrast between the leadership tenure distributions of the supervisors and those of the managers and executives. About half of the respondents from each of the latter groups had from 11 to 20 years of experience; people with 0 to 5 years experience accounted for less than $10 \%$ of managers and $20 \%$ of executives (see Figure 1). As expected, the managers and executives who responded tend to be the more experienced "veterans," while the typical responding supervisors are relatively new to managing other people.

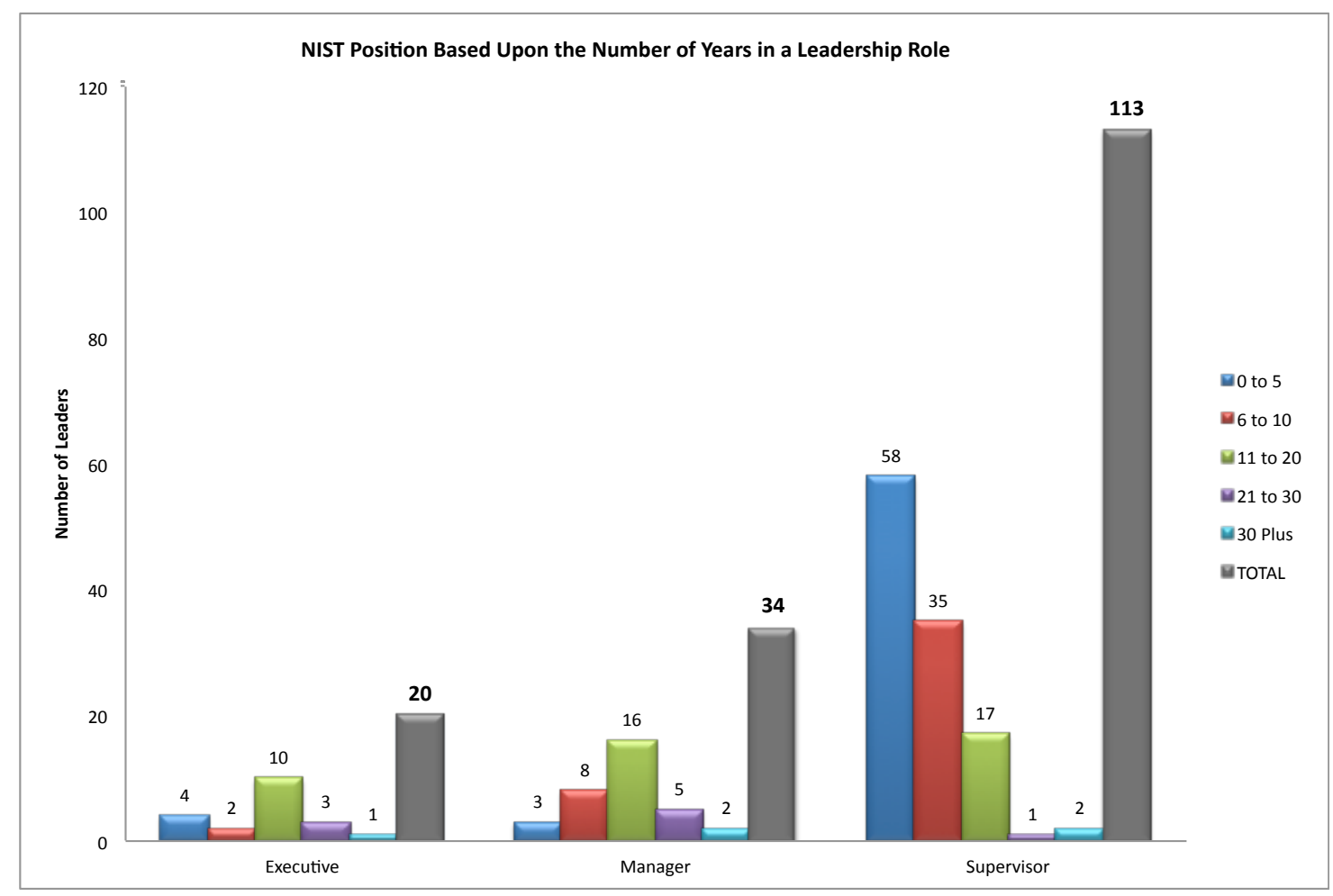

Figure 1: NIST Leaders by Position and Leadership Tenure 


\subsubsection{Results and Findings}

The figures presented here show values as calculated directly from the survey data. Where possible error analysis has been performed and the analysis, along with survey results with confidence intervals are given in Appendix I.

Figure 2 is based upon the same data shown in Figure 1, but presents the data versus time in a supervisory role. This perspective provides a clear view of the leadership levels of those leaders with minimal time in experience compared to those leaders with significant time in experience. As is shown in Figure 1, Figure 2 clearly demonstrates that a majority of the new leaders are supervisors as compared to executives and managers. The distribution changes with increasing experience, so that the proportions of each group become more equal.

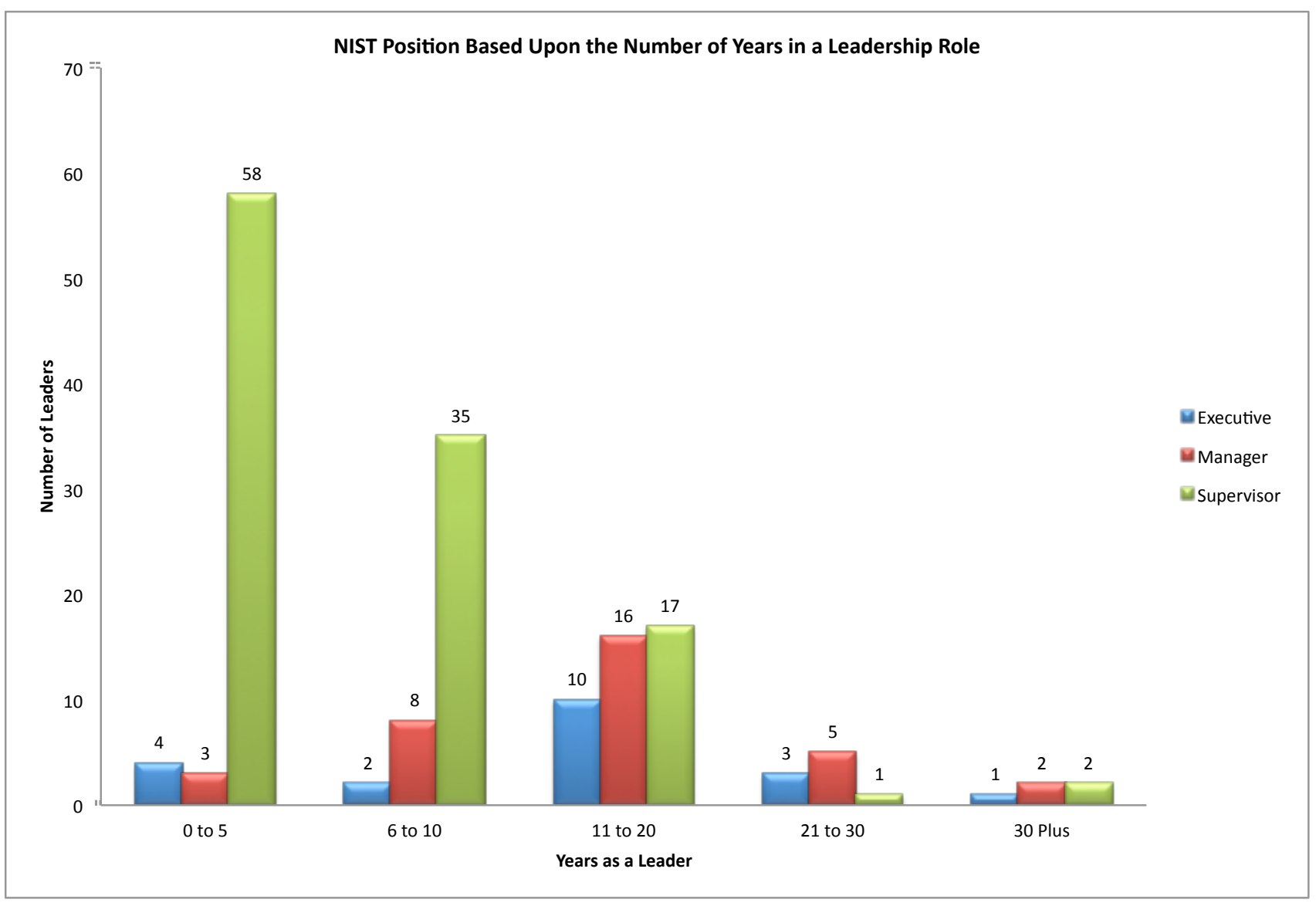

Figure 2: Graph Detailing NIST Leaders Based Upon the Number of Years in a Supervisory Role 
The next series of figures address the responses to the third survey question:

NIST provides leadership and management training that meets the needs of my position
a) Strongly Agree
b) Agree
c) Neutral
d) Disagree
e) Strongly Disagree

Figure 3 presents the overall responses to this third survey question regarding the leaders' perceptions of how NIST provides the appropriate leadership and management training. It is evident that a majority of respondents $(>64 \%)$ are in agreement, at minimum, that NIST is meeting their needs in this training area. What is most noteworthy about this data is that $\sim 14 \%$ of the respondents disagreed or strongly disagreed that NIST was meeting their needs.

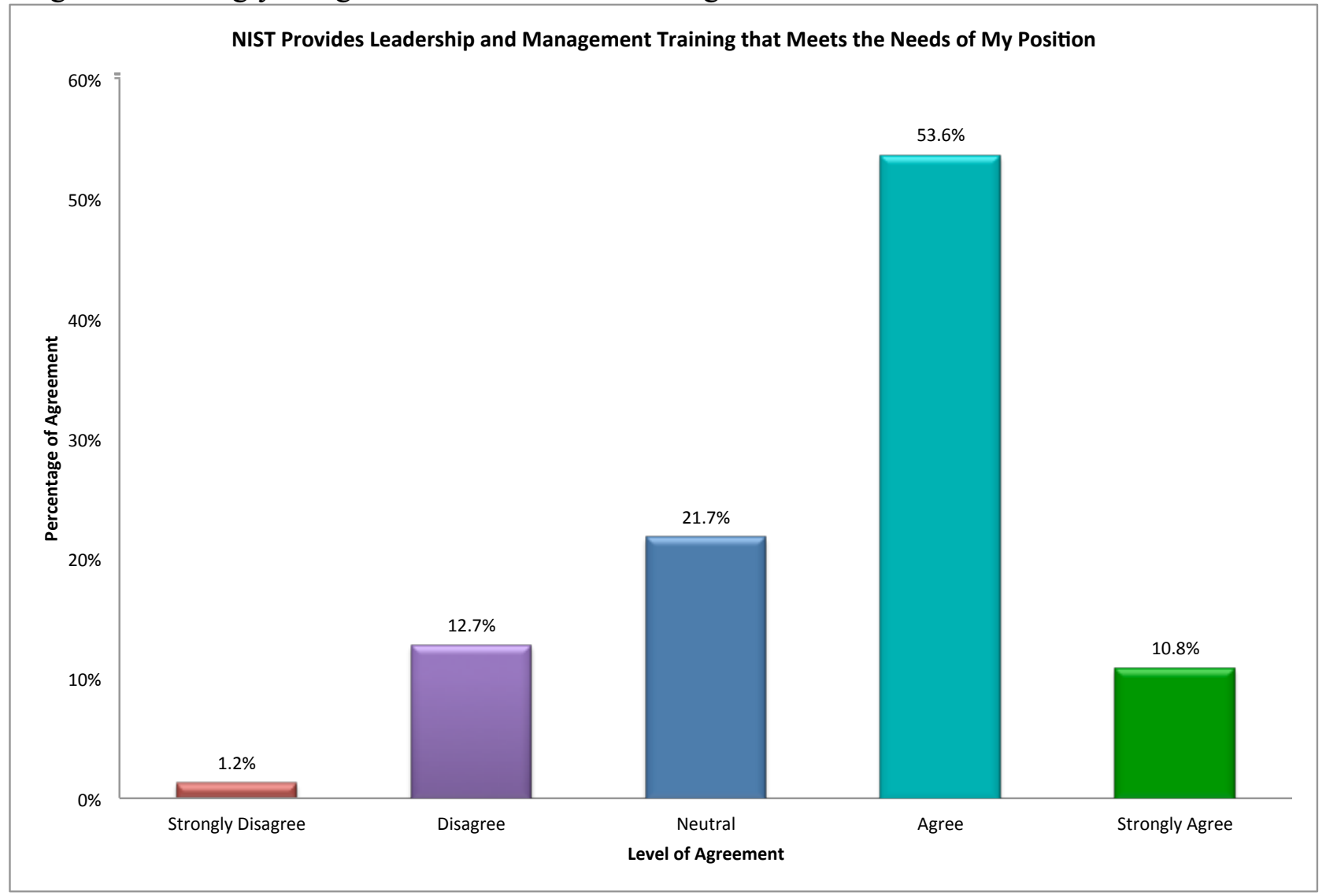

Figure 3: Overall Responses to the Third Survey Question 
Figure 4 takes a deeper look at the data captured from the third survey question by breaking it out from a leadership perspective. This figure features three bars from $0 \%$ to $100 \%$ and details the percentages of each leadership group with respect to their level of agreement. For example, $0 \%$ of executives strongly disagreed with the statement that NIST was meeting their training needs as stated in question 3,16\% of executives disagreed, $37 \%$ of executives were neutral in response, 47 $\%$ of executives agreed, and $0 \%$ of executives strongly agree. The manager and supervisor bars can be understood in a similar manner. Some interesting notes regarding this part of the data analysis are:

- $0 \%$ of executives strongly agree that NIST is meeting their leadership and management training needs and nearly $16 \%$ of executives disagreed that NIST was meeting their leadership and management training needs.

- $2 \%$ of supervisors strongly disagreed that NIST is meeting their leadership and management training needs. This is surprising given that this group is composed of some of the most inexperienced personnel who are required to take specific managerial training classes. Of course, these managerial training classes are fresh in these supervisor's minds and could have been insufficient to answer their incoming leadership questions.

- More supervisors than managers and executives agreed or strongly agreed that NIST was meeting their leadership and management training needs. One way to explain this is that most supervisors are new leaders who have attended mandated training while managers and executives are typically experienced leaders who are not required to attend refresher training (as of the time of this study). Another way this could be explained is that since supervisors usually have less leadership experience than executives and managers, they are unaware of all of the necessary leadership skills they should possess in order to be effective.

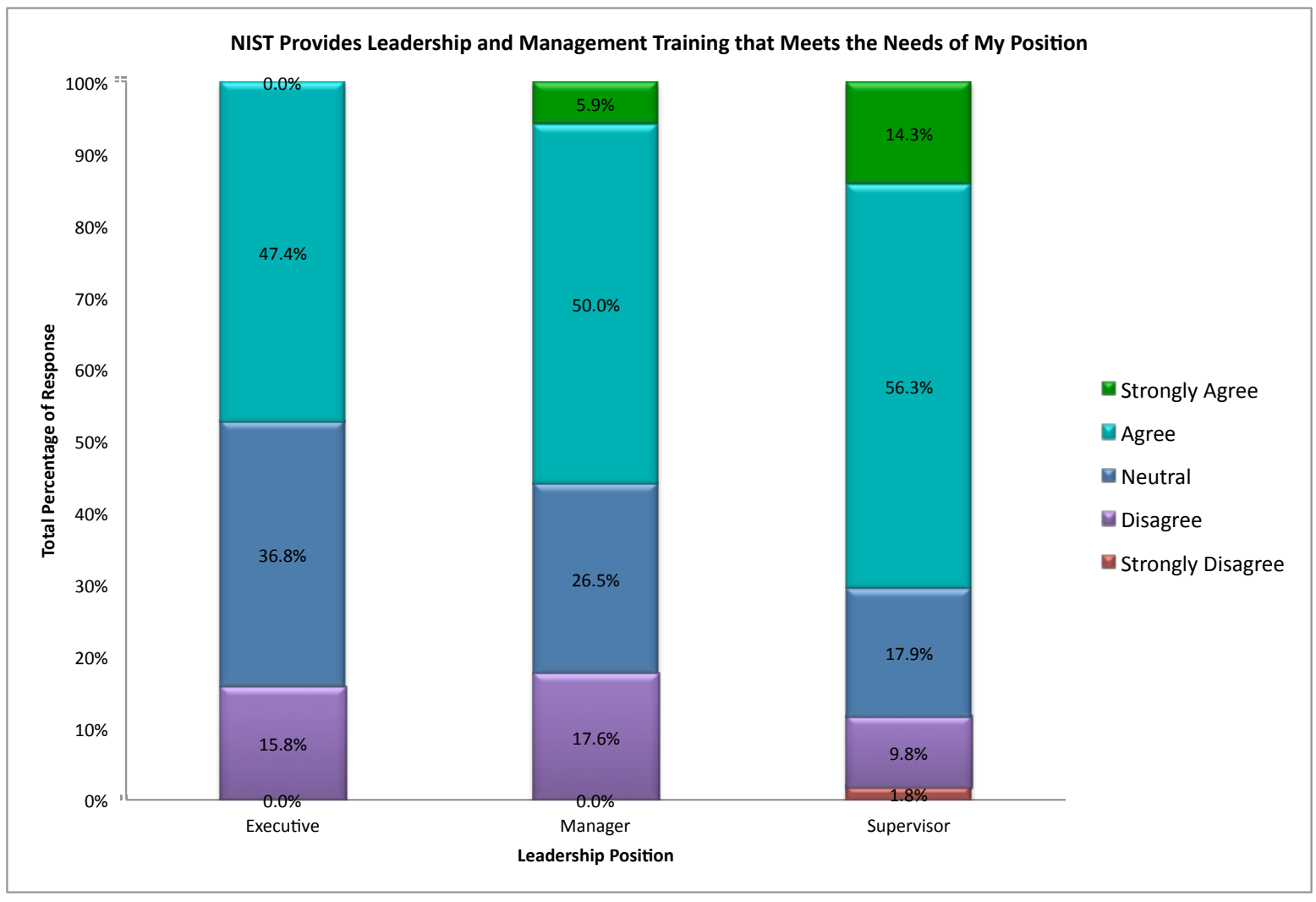

Figure 4: Responses to the Third Survey Question Based Upon Leadership Position 
Figure 5 takes the data collected from survey question three and now examines it from the perspective of a leader's time in experience from which some trends emerge.

- All of the respondents that strongly agree that NIST is meeting their training needs have less than 20 years experience as supervisors.

- None of the leaders who have more than 20 years of experience either strongly agree or strongly disagree that NIST is meeting their training needs.

- Over $72 \%$ of those leaders with less than 5 years experience either agree or strongly agree that NIST is meeting their training needs. Note this percentage is the greatest as compared to other experience ranges.

- As a leader's experience increases, their agreement (or strong agreement) that NIST is meeting their training needs decreases, from $72 \%$ with 0 to 5 years experience, to $40 \%$ with $30+$ years experience.

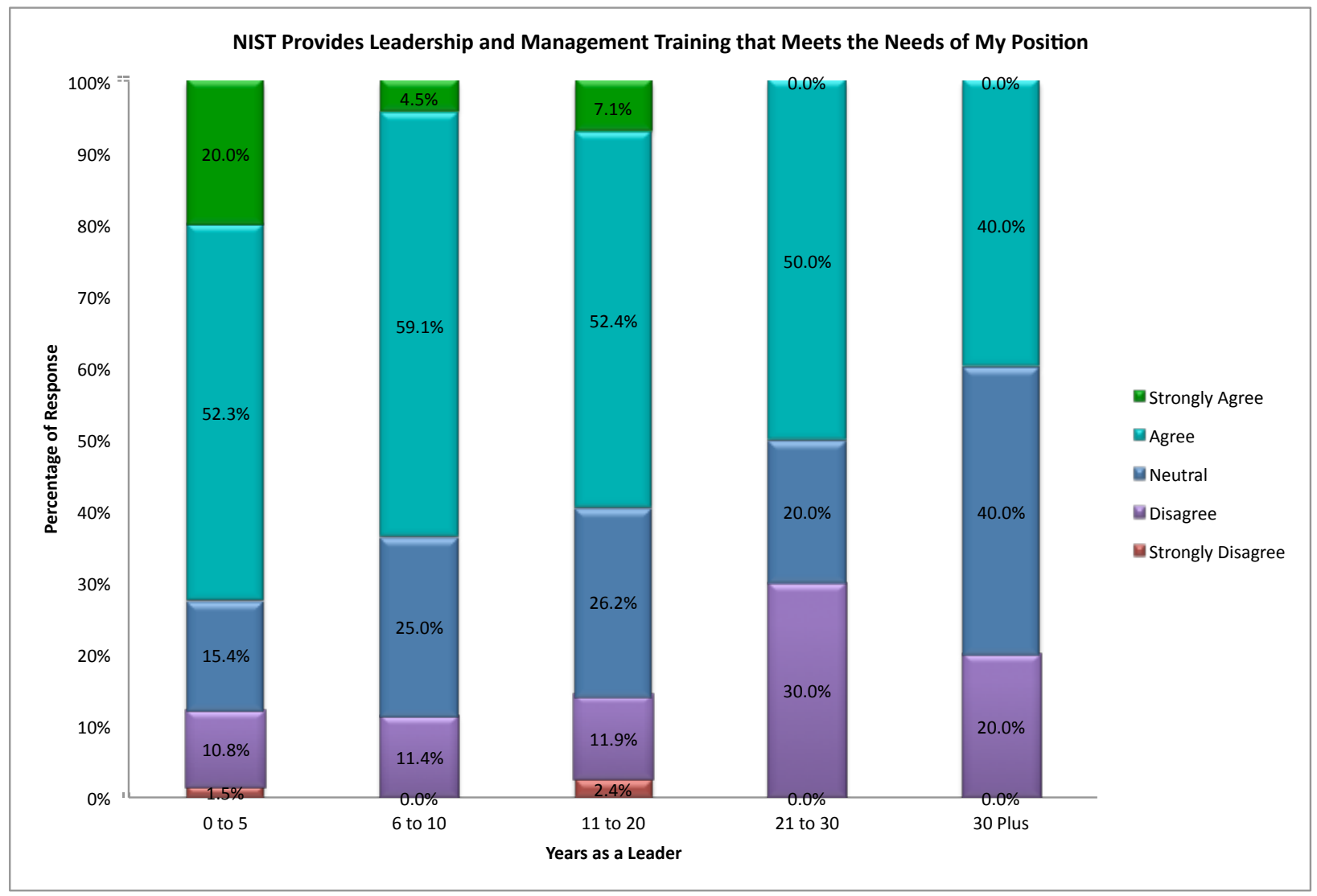

Figure 5: Responses to the Third Survey Question Based Upon Time as Leader 
The fourth question of the survey focuses on the core competencies that leaders feel they should possess in interacting with their direct reports and their peers (other managers):

Please select UP TO FIVE (5) NIST Leadership Core Competencies below, that are most important for your effectiveness in working with your direct reports AND those most important for your effectiveness in working with other managers at NIST.

a) Communication

b) Conflict Management

c) Delegation/Empowerment

d) Flexibility/Adaptability

e) Integrity/Honesty

f) Leading Change

g) Motivating Others

h) Organizational Skills

i) Problem Solving

j) Service Motivation

k) Strategic Development/Thinking

Figure 6 presents the overall data captured from the responses to this fourth survey questions. Some interesting points of notes are:

- Communication and Integrity/Honesty were viewed as important core competencies for interacting with both other managers and direct reports.

- Leading Change and Problem Solving are viewed as equivalent (critically-speaking) competencies to possess for interacting with both other managers and direct reports yet they are not viewed as important as Communication and Integrity/Honesty.

- Conflict Management was viewed as more important to possess when dealing with direct reports as compared to other managers. This makes sense considering that leaders are more often required to resolve conflicts occurring among their direct reports and are less likely to experience conflict among their peers.

- Delegation/Empowerment and Motivating Others are more important when interacting with direct reports as compared to other managers. This also makes sense since a leader's responsibilities may include tasking their direct reports. Leaders are unlikely to delegate to or motivate their fellow leaders, especially if they are on an equal playing field. Tasking could be done by the leaders above them or on their own.

- Flexibility/Adaptability is viewed as more important to possess when interacting with other managers as compared to direct reports. One way to explain this difference is that leaders may feel less inclined to be flexible with their direct reports considering they are overseeing their work and assigning them responsibility whereas other managers are on more equal footing so compromise must exist at this level in order to accomplish mutual goals.

- Strategic Development/Thinking is significantly viewed as more important for interacting with other managers as compared to direct reports. This makes sense given that strategic planning activities are more likely to occur with other leaders as compared to direct reports. 


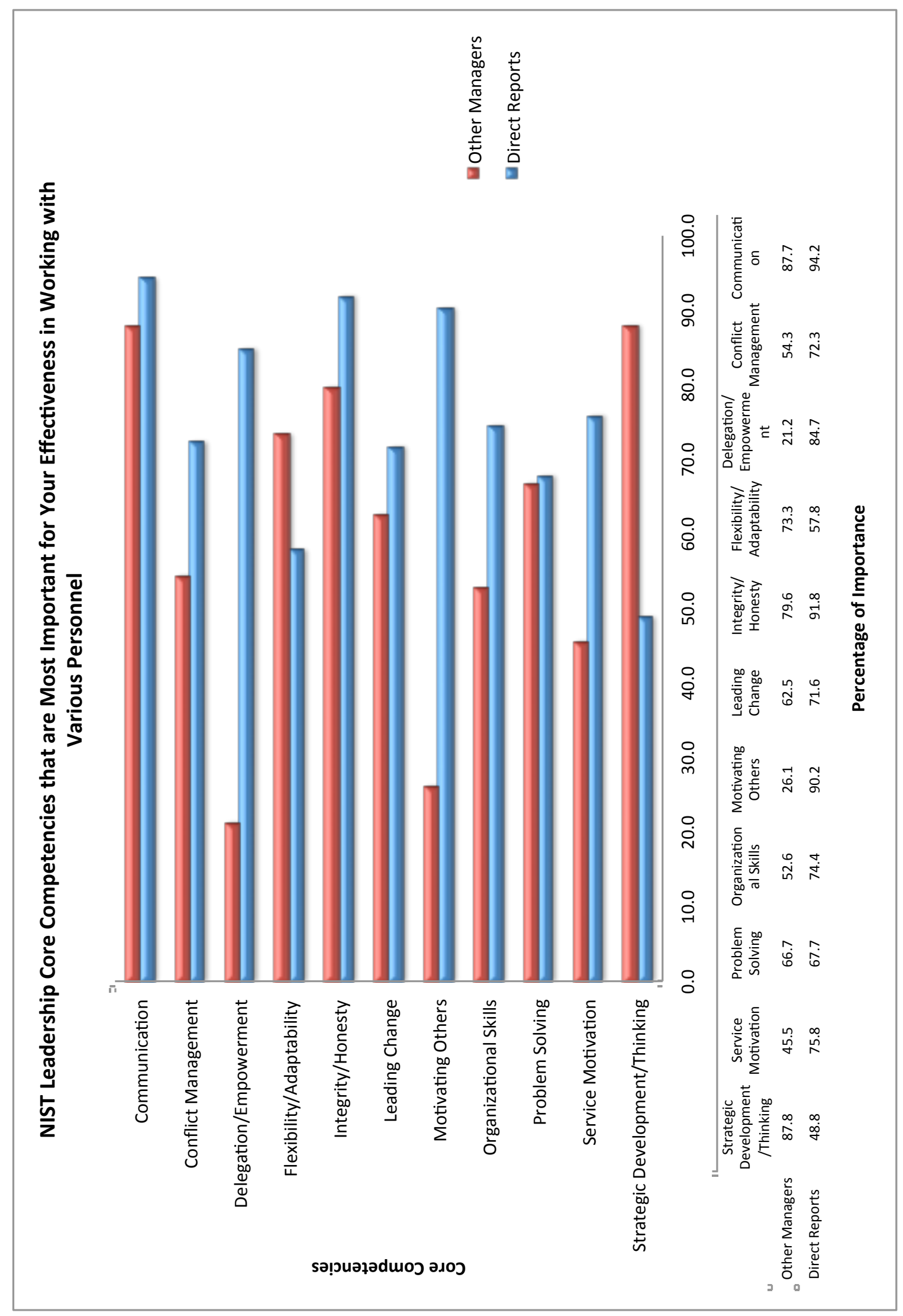

Figure 6: Overall Responses to the Fourth Survey Question 
Figure 7 represents the data captured from the responses to the fifth survey question:

Please select the leadership/management skills that you would like to develop...

a) Building Relationships

b) Change Management

c) Coaching/Mentoring

d) Communication

e) Conflict Management

f) Creating a Safe/Fear-Free Environment

g) Decision Making

h) Delegation/Empowerment

i) Managing Diverse Groups of People

j) Program Management

k) Strategic Planning/Development Thinking

l) Teambuilding

m) Time Management

Figure 7 shows which skills leaders would like to develop and which they would not. Those skills they feel do not need to be developed can be attributed either to the leader thinking they are not important or believing they are already competent in these areas. Specifically:

- Strategic Planning and Developmental Thinking was the skill most leaders stated they would like to develop. This is a logical selection considering that leaders are faced with more strategic development assignments as they continue to climb the leadership ladder.

- Conflict Management, Change Management, Time Management and Teambuilding were all seen as important skills (second to Strategic Planning) that leaders would like to be developed.

- Surprisingly, Creating a Safe/Fear-Free Environment was not viewed as an important skill to develop. Either leaders felt they were already sustaining this type of work environment and thus they did not need any training with respect to this skill, or the other skills were far more important. It is also possible that the definition of this skill was unclear. 


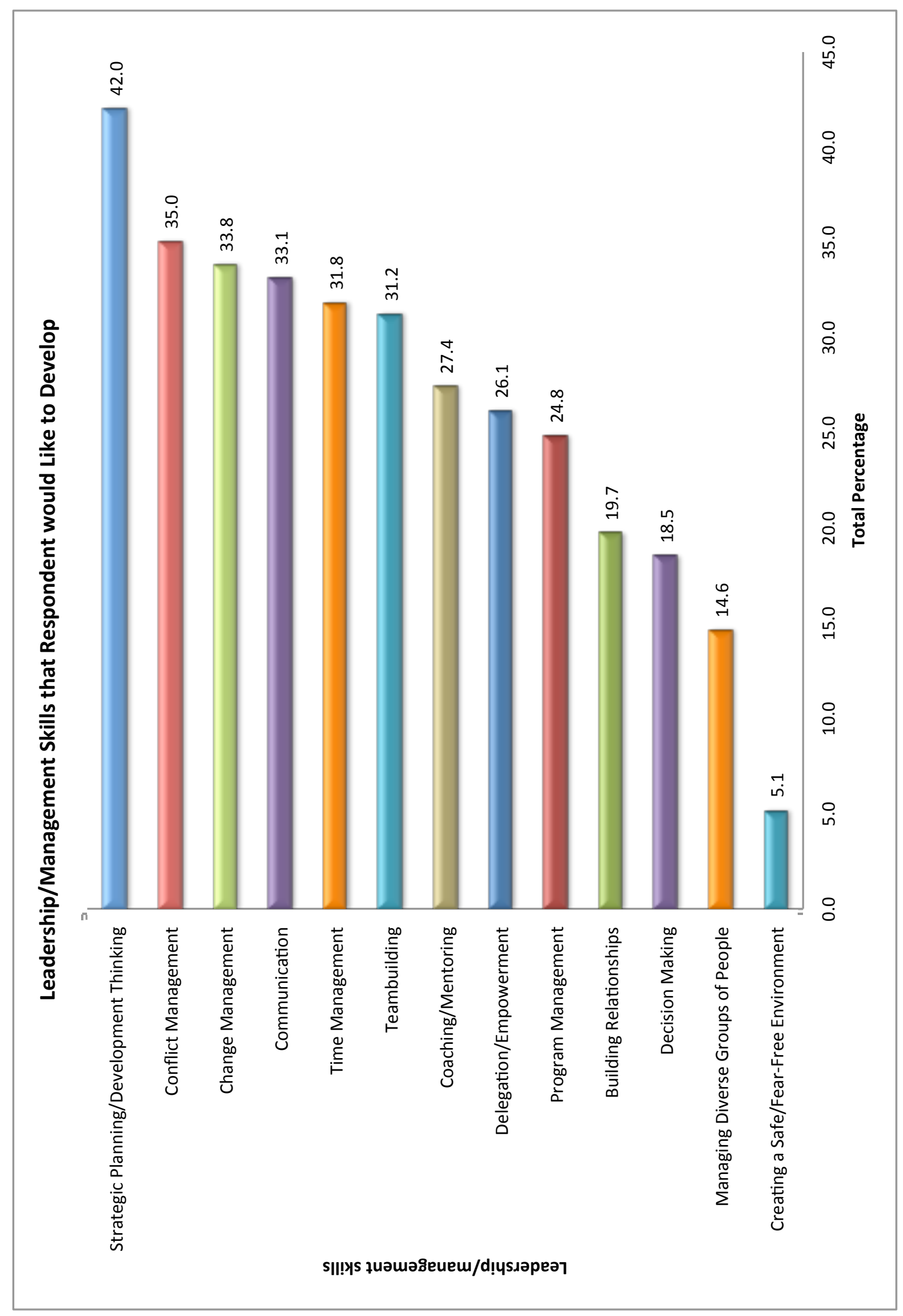

Figure 7: Overall Responses to the Fifth Survey Question 
Figure 8 presents the data from the fifth survey question broken out by leadership position at NIST. Some results that stand out include:

- Strategic Planning/Development Thinking is viewed as the greatest skill that is desired for development across executives, managers, and supervisors.

- Managers and supervisors would like to spend more time developing their time management skills as compared to executives.

- Teambuilding and Conflict Management are seen by executives as the most important (second to Strategic Planning) skills to develop.

- Executives, managers, and supervisors all place low priority in Creating a Safe/Fear-Free Environment.

- Aside from Strategic Planning, Communication is a skill that supervisors would most like to develop.

- Executives do not highly rank Managing Diverse Groups of People as one of the skills they would like to develop. This is quite surprising considering executives lead at broader levels as compared to managers and supervisors. However, this could be countered by the notion that executives tend to have more leadership experience than managers and supervisors and may already feel they have a handle on this skill. 


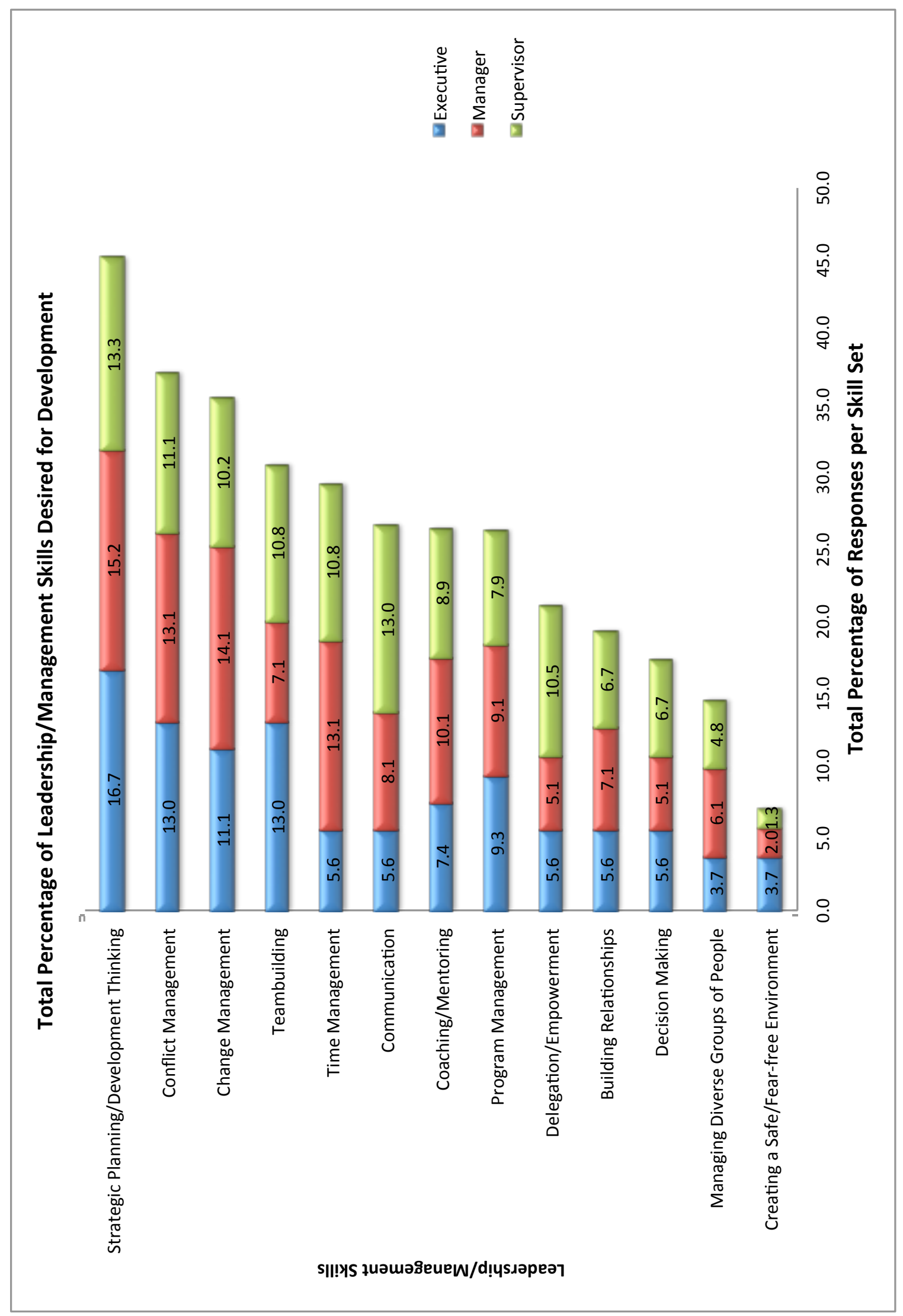

Figure 8: Responses to the Fifth Survey Question based upon Leadership Position 
The sixth survey question is listed below and attempts to ascertain those types of training that are preferred by NIST leaders:

Please select all the types of training you prefer...

a) Classroom (Accredited Institute)

b) Coaching/Mentoring (Internal/External)

c) External Training (Conferences, Industry Visits, Academic)

d) In-House Training (NIST-Sponsored/Organized)

e) Off-Set Workshops/Sessions

f) On-the-Job/Acting Positions

g) Peer Groups (Discussions, Task Groups)

h) Rotational/Detail Assignments

i) Self-Study (Books, Web, Podcasts, CLC)

j) Seminars/Lectures (Internal/External)

Figure 9 presents the training type preferences of the NIST leaders based upon their responses to question six. Some insights that can be seen from the data include:

- NIST leaders have a strong preference for In-House Training. One explanation for this preference is that this option may be viewed as time-efficient and/or cost-effective considering that the participants would not have to travel outside of campus.

- Seminars/Lectures are another strongly preferred training type whether they are conducted internally or externally. A plausible explanation for the preference of internal seminars is that they are usually time-efficient and/or cost effective. However, a similar statement may not be applicable in explaining the preference of external seminars. Unfortunately, the captured survey data did not differentiate between internal vs. external so this preference type cannot be fully and reasonably explained.

- Classroom and External Training were in the next tier of preferred training types. Both of these types are usually not cost-effective considering an attendance/participation fee must be paid and are seldom time-efficient since the attendee must travel to this activity (local or otherwise). One common benefit of these activities is that the off-site offering usually allows the attendee to break away from their NIST responsibilities for the time they are participating allowing them to focus on their training. Also, it can be reasonably stated that most personnel like to attend conferences, visit industrial sites, or participate in academic offerings because it is something of interest to them technically and/or professionally.

- On-the-Job/Acting Positions and Rotational/Detail Assignments were least preferred. One way to explain this is that these positions by definition are temporary so it may be hard to get entirely comfortable considering the individual will have to return to their previous position or go somewhere else. 


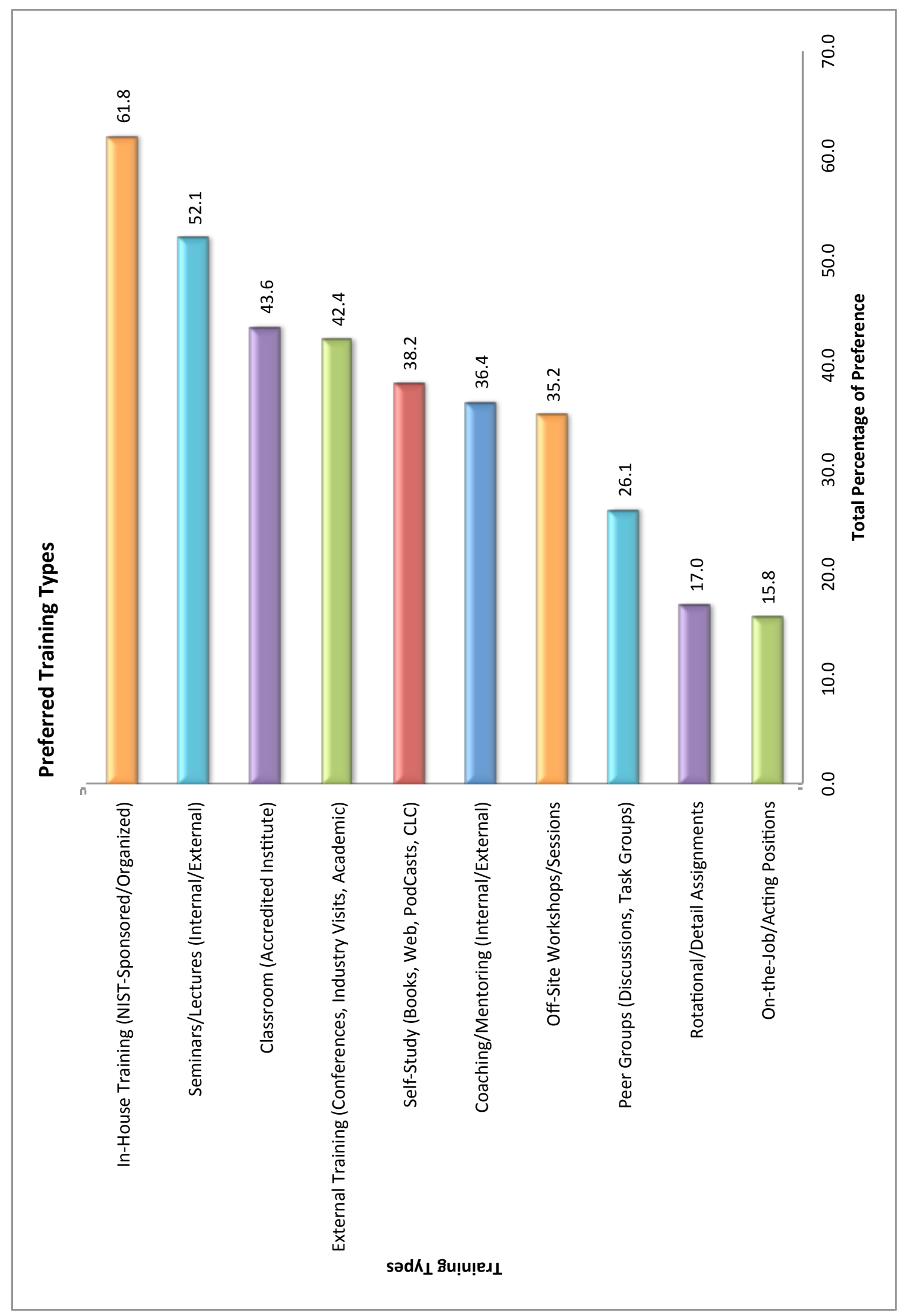

Figure 9: Overall Responses to the Sixth Survey Question 
Figure 10 presents the data from the sixth survey question regarding preferred training types from the perspective of leadership position at NIST. The most interesting insights to be gleaned from the data include:

- Managers and supervisors indicated a greater preference for In-House Training than executives.

- Executives, managers, and supervisors equally (approximation) preferred Seminars/Lectures.

- Executives saw greater value in Rotational/Detail Assignments than managers and supervisors. One plausible explanation is that most of the executives have probably had this type of training experience whereas the supervisors and managers may not have.

- Executives saw more value in External Training than did managers and supervisors. This may also be a function of available expertise within NIST. Few organizations are large enough to have executive level training expertise within. In addition, there are opportunities to see how other organizations work and broaden one's perspective by going outside to FEI or some other executive development program. Further, internal politics and possible embarrassment may make some executives reluctant to go through training with high level peers. 


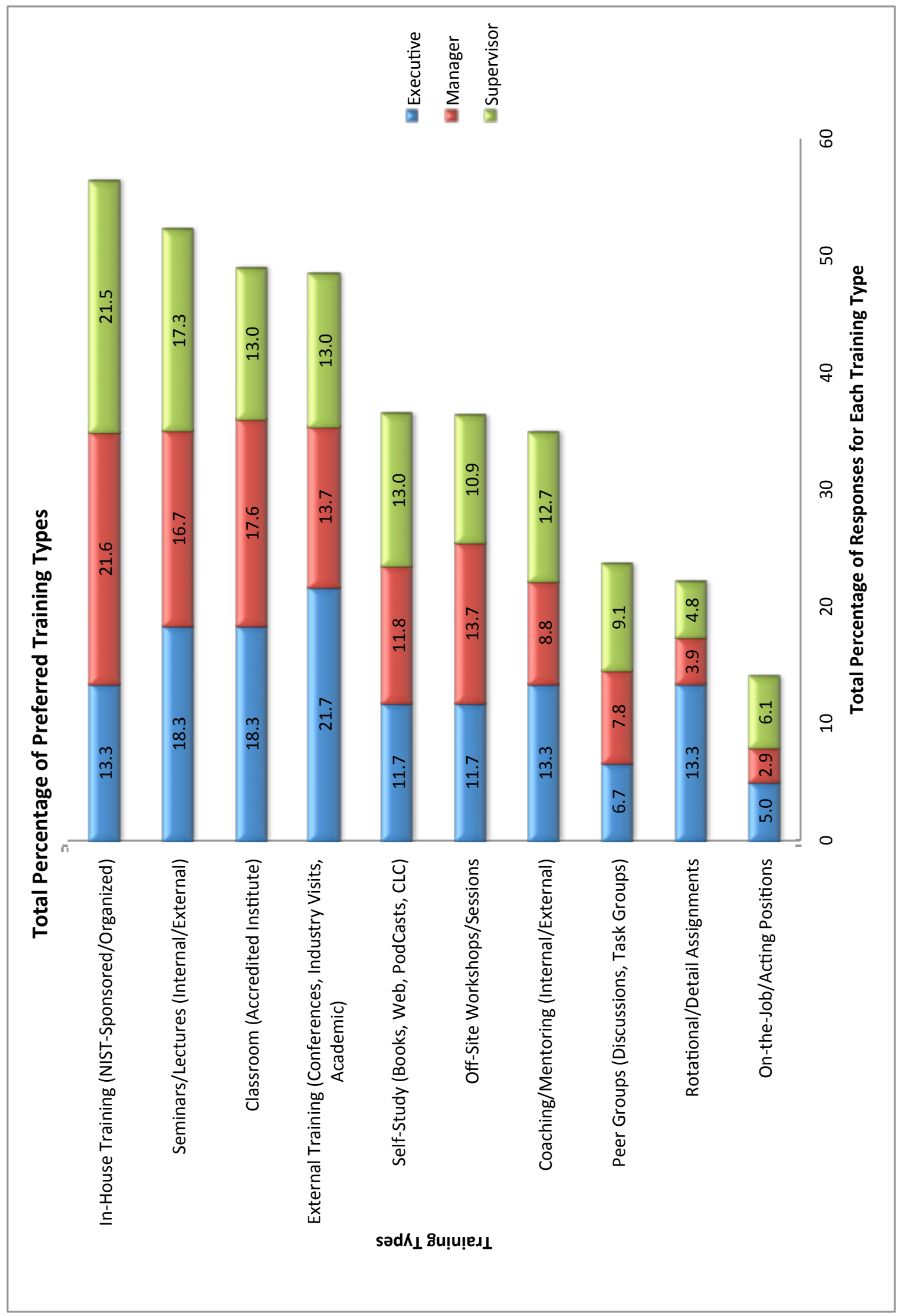

Figure 10: Responses to the Sixth Survey Question Based Upon Leadership Position 
The last survey question discussed in this section asks the respondents which NIST functions to which they would like more exposure. Specifically, they were asked to:

Please select all the NIST functions you would like to learn more about or receive training on...

a) Acquisitions/Contracts

b) Baldrige Program (BNQP)

c) Employee Relations/Resources

d) Facilities

e) Finance/Budget

f) Grants/Agreements

g) Honorary and NIST Awards

h) IT Security/Services

i) Manufacturing Extension Partnership (MEP)

j) NIST Associates Program

k) NIST's History and Mission

l) NIST Role in the Political Environment

m) NIST User Facilities (CNST, NCNR)

n) Promotions

o) Public Affairs and Media Relations

p) Safety, Health, and Environment

q) Standards Services

r) Technical Operating Units/Laboratories

s) Technology Partnerships

t) Technology Innovation Program (TIP)

u) Travel

v) Workforce Management

Figure 11 presents the overall results from this survey question. Note that this data was not broken out further by leadership level or time as a leader because the represented data would lose statistical significance due to the low number of responses.

Some results that stand out include:

- Acquisitions/Contracts, Employee Relations/Resources, Finance/Budget, NIST Role in the Political Environment, and Workforce Management stood out as being the NIST functions that a great of leaders would like to better understand. One plausible explanation is that the number of policies, rules, placement, and/or regulations within these areas are updated so frequently that it is hard for leaders to keep pace.

- Programs and Centers, such as Baldrige, MEP, CNST, NCNR, and TIP were all seen as NIST functions that did not need to be explored further.

- Safety, Health, and Environment was in the "middle of the pack" and did not rise to the top tier. This is probably because these topics are well served already. 


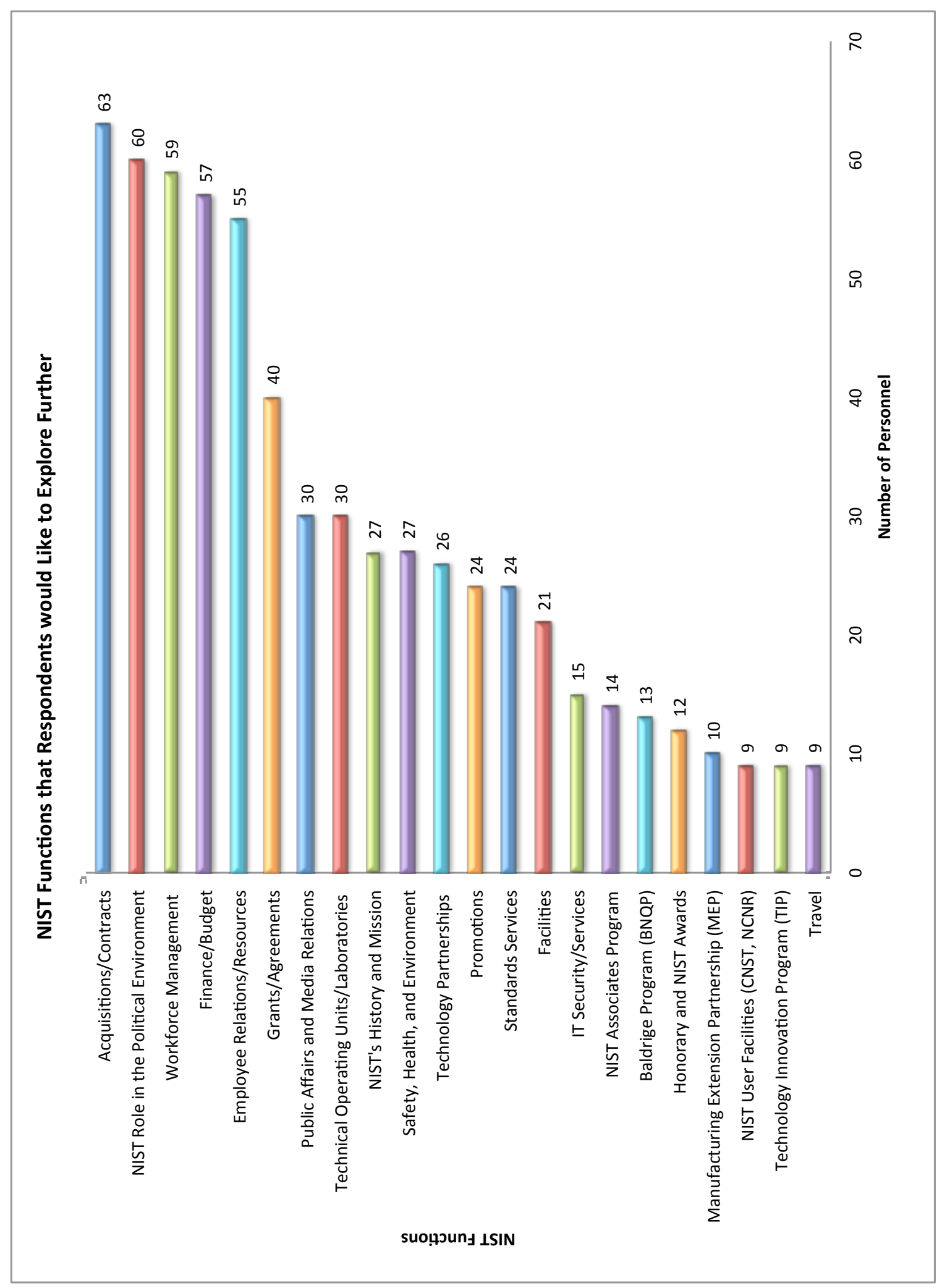

Figure 11: Overall Responses to the Seventh Survey Question 


\subsubsection{Respondent Follow-Up Interviews}

In response to the final request at the end of the SSG survey, a few NIST leaders indicated that they would like to meet directly with representatives from the SSG. There were ten follow up interviews with nine supervisors and one manager from both technical and administrative backgrounds.

The discussions focused on different topics, depending on the individual being interviewed and the training issues that were of greatest interest to them. In general the interviewees were very forthcoming and shared a lot of information with us during the interviews. A summary of those discussions is below.

Again, a majority of the follow-up interviewees emphasized their support for LED programs, and many had direct experience with NLP, in particular. There were several comments by interviewees regarding their positive experiences in the program with people across NIST who were also in the program, allowing them to network and develop connections that they still use today. In addition to the LED program experiences for current management training, several interviewees mentioned the value of a having a diverse management structure, with rotating team leads. It was pointed out that this allows staff to experience some level of leadership in an informal setting, and gives a chance to develop an interest in developing more formal management skills.

Specific training needs that were mentioned included the following:

- Effective communication, especially to support improved customer service

- Conflict management

- Change management

- Finance/budget, especially how to submit initiatives and how to obtain additional funding

- Performance plans

- Strategic planning, especially to counteract NIST's tendency to be reactive rather than proactive

Two of the interviewees mentioned the disconnection between the technical and administrative staff, and the need to bridge the two environments in a positive way.

There were several recommendations for training delivery and other specific suggestions to support managers and supervisors. A common theme during the interviews was the need for NIST to offer diverse tools to provide refresher training to meet the needs of different operating units, including CLC, seminars, discussion groups, self learning, and traditional courses. The interviewees emphasized that the training must be relevant to the OU leaders' needs to obtain buy-in from NIST managers. As a result, it is important to have various options so that the individual would be able to choose what relates to them.

An interesting add-on suggestion to the traditional courses was to follow up a traditional classroomtype course with a discussion group, preferably led by a subject matter expert who could answer questions and allow follow-on discussion of the material after some time has passed since the class (to let the material "sink in"). 
In addition to the more traditional training delivery, there were suggestions provided on "continuous" training, based on the experiences of those who had participated in the NLP. These included:

- Establishing peer groups, discussion groups, or buddy systems (i.e., pairing experienced managers with new managers) with the idea of creating a support system for dealing with common issues from different perspectives

- Expanding the NLP Capstone project using a Share Site that includes sections for a book club, discussions, "leadership-pedia," and best practices.

\subsection{Current NIST and DOC Training Activities}

NIST Leadership and Employee Development and other NIST offices provide various training sessions. Some of these sessions are required annual training while for others, employees volunteer to participate or are nominated by their supervisors.

The current available NIST Leadership Development Training Opportunities at NIST are as follows:

\section{Managerial Survival Skills}

All supervisors/managers new to NIST or new to the Leadership Role are required to attend this week-long training. The workshop is conducted by external and internal trainers and covers the following topics to assimilate new managers/supervisors into their roles:

- Leadership Skills for New Supervisors

○ External Training - Mac Bogert, Benchmark Training

- Classification, Staffing, Pay and Leave Administration, Employee Relations, Employee Assistance Program (EAP)

Internal Training - NIST HR staff and EAP staff

- Safety, Acquisitions, Leadership/Employee Development

○ Internal Training - NIST Safety Office, HR/LED, Acquisitions Roadshow given by senior Acquisition Management Division staff

- NIST Budget Process, Legal Do's and Don'ts, Freedom of Information Act, Records/Paperwork Reduction

○ Internal Training - NIST Budget Office, Legal Office, Management and Organization Office

- Civil Rights Program

O Internal Training - NIST Civil Rights and Diversity Office Staff

- Equal Employment Opportunities/Sexual Harassment/Diversity

○ External Training - Mauricio Velásquez, The Diversity Training Group

\section{Division Chief Round Table Discussion}

This continuous learning opportunity is currently in development and will consist of facilitated conversations on topics of practical interest to Division Chiefs. Monthly topics will be selected based on Division Chief input. The target audience is those whose official position is Division Chief. 
The discussions will be held the first Tuesday of each month from 11:30 am - 1 pm EST. Meetings will usually be held in the NIST Heritage Room in Building 101/Gaithersburg. Initially, participation will be on-site in Gaithersburg only. VTC/audio capability will be provided in the near future once meeting logistics are worked out. Boulder Division Chiefs are urged to participate in Gaithersburg if plans and travel schedules permit.

Many NIST-specific, Department of Commerce, and other various on-line courses are available in the Commerce Learning Center (http://learning.doc.gov).

\section{Annual Mandatory Training}

This training include requirements such as IT Security, Annual Ethics Training for Managers, Security Clearance Training, and annual Safety Training based on an employee's job requirements. These sessions are arranged and conducted by the various NIST offices involved.

In addition to the mandated training sessions, NIST Leadership and Employee Development Office offers a New Leader Program (NLP) and a Building the Next Generation Program (BTNG) thourhg which this report originated. Table 1 provides a description and comparison of the two programs.

In addition, through the Department of Commerce, there are other programs:

1. Aspiring Leaders Development Program (ALDP) - designed to provide a series of experiences that will develop leadership competencies.

2. Careers in Motion - improves skills and increase the mobility of employees for potential advancement to higher levels

3. Executive Leadership Development Program (ELDP) - designed for high-potential employees at the GS-13 and GS-14 levels or equivalent whose career plans include moving into upper management positions.

4. Leadership Education and Development (LEAD) Certificate Program - a comprehensive management succession program for developing future managers and agency leadership.

5. Commerce Mentoring Program - offering mentoring informally as well as formally Mentees observe, question, and explore. Mentors demonstrate, explain, and model.

6. Administrative Professional Certificate Program (APCP) Building Bridges - provides the opportunity to assess developmental strengths and needs of administrative and technical support staff at the GS-2 through GS-8 levels or equivalent, provides the opportunity to assess developmental strengths and needs in relation to the outlined program curriculum; and is designed to build a cadre of highly skilled and knowledgeable support staff posed to provide administrative and technical expertise in the accomplishment of the work performed throughout the organization. 


\begin{tabular}{|c|c|c|}
\hline $\begin{array}{l}\text { Program } \\
\text { Feature }\end{array}$ & $\begin{array}{l}\text { Building the Next Generation } \\
\text { (BTNG) }\end{array}$ & New Leader Program (NLP) \\
\hline Purpose & $\begin{array}{l}\text { Develop the skills to support } \\
\text { transition from individual contributor } \\
\text { to leadership role }\end{array}$ & $\begin{array}{l}\text { Provide managers with necessary } \\
\text { support and skills to be effective } \\
\text { NIST leaders }\end{array}$ \\
\hline Target Audience & $\begin{array}{l}\text { NIST employees who have not held a } \\
\text { formal leadership position but would } \\
\text { like to develop skills to lead others }\end{array}$ & $\begin{array}{l}\text { NIST leaders who have been } \\
\text { formally supervising others (e.g., } \\
\text { group leaders) for three years or } \\
\text { less and would benefit from } \\
\text { training in leadership }\end{array}$ \\
\hline Program Length & One year & One year \\
\hline $\begin{array}{l}\text { Competency/ } \\
\text { Preference } \\
\text { Assessments }\end{array}$ & $\begin{array}{l}360^{\circ} \text { leadership competency } \\
\text { assessment (self, boss, peers, } \\
\text { customers if relevant) at start and } \\
\text { end of program; self awareness } \\
\text { assessments throughout year }\end{array}$ & $\begin{array}{l}360^{\circ} \text { leadership competency } \\
\text { assessment also includes direct } \\
\text { reports; also complete other self } \\
\text { assessments throughout year }\end{array}$ \\
\hline $\begin{array}{l}\text { Initial } \\
\text { Leadership } \\
\text { Training Course } \\
\text { (5 days) }\end{array}$ & $\begin{array}{l}\text { Focuses on identifying current } \\
\text { leadership strengths and } \\
\text { improvement areas, understanding } \\
\text { one's impact on others, leadership } \\
\text { theory and practice, group/team } \\
\text { dynamics, conflict resolution, and } \\
\text { communication skills. } \\
\text { Currently conducted in Gaithersburg, } \\
\text { MD }\end{array}$ & $\begin{array}{l}\text { In addition to identifying strengths } \\
\text { and improvement areas: } \\
\text { - } \quad \text { focuses on creating a } \\
\text { flexible leadership style } \\
\text { - } \quad \text { identifying personal styles/ } \\
\text { preferences } \\
\text { - } \quad \text { the benefits of differences } \\
\text { - leveraging groups to solve } \\
\text { problems and accomplish } \\
\text { work } \\
\text { strategic planning. } \\
\text { Currently conducted in } \\
\text { Gettysburg, PA }\end{array}$ \\
\hline
\end{tabular}




\begin{tabular}{|c|c|c|}
\hline $\begin{array}{l}\text { Program } \\
\text { Feature }\end{array}$ & $\begin{array}{l}\text { Building the Next Generation } \\
\text { (BTNG) }\end{array}$ & New Leader Program (NLP) \\
\hline $\begin{array}{c}\text { Core } \\
\text { Components }\end{array}$ & $\begin{array}{l}\text { Monthly 3-hour leadership } \\
\text { seminars; specific topics } \\
\text { tailored to needs of the class } \\
\text { - One-day leadership training } \\
\text { and graduation } \\
\text { - Design and execution of a } \\
\text { leadership development plan } \\
\text { based on } 360^{\circ} \text { assessment, } \\
\text { career interests, and elective } \\
\text { components of BTNG }\end{array}$ & $\begin{array}{l}\text { - Monthly 3-hour cohort } \\
\text { sessions; half the time is } \\
\text { spent discussing a } \\
\text { leadership topic tailored to } \\
\text { needs of class. Second } \\
\text { half is open discussion on } \\
\text { leadership successes, } \\
\text { challenges, tips, etc. } \\
\text { - Leadership coaching } \\
\text { - Capstone project: work } \\
\text { with NLP colleagues to } \\
\text { accomplish task } \\
\text { Two-day leadership } \\
\text { training and graduation } \\
\text { Design and execution of a } \\
\text { leadership development } \\
\text { plan based on } \\
360^{\circ} \text { assessment }\end{array}$ \\
\hline $\begin{array}{c}\text { Elective } \\
\text { Components }\end{array}$ & $\begin{array}{l}\text { Identify at least one learning } \\
\text { opportunity, typically two: } \\
\text { - Special Study group: work } \\
\text { with BTNG colleagues on } \\
\text { important, NIST-wide issue } \\
\text { with executive sponsor } \\
\text { - Mentoring } \\
\text { - Developmental assignment(s) } \\
\text { - "In lieu of" leadership training }\end{array}$ & $\begin{array}{l}\text { Based on leadership } \\
\text { development plan, on-the-job } \\
\text { activities, and other learning } \\
\text { opportunities identified in } \\
\text { development plan; competency- } \\
\text { specific. }\end{array}$ \\
\hline
\end{tabular}

Table 1: NIST New Leader Program (NLP) and Building the Next Generation (BTNG) 
Providing NIST Supervisors with a Continuous Learning Program 


\section{External Data Gathering}

In the second and final phase of the project, we extended our data gathering to NIST-comparable organizations. Questions were asked as to whether they require refresher training for their managers/supervisors, and the topics that this training included (See Appendix E). The survey was sent out via emails and followed up where appropriate with personal contact.

\subsection{Survey of NIST-comparable Organizations}

This survey included government organizations, our counterpart national metrology institutes (NMIs), and some private sector companies. By and large, the private sector companies were not willing to volunteer information on their training methods, presumably because they consider them proprietary. However, we did obtain a number of responses from our counterpart NMIs and other government agencies, and three responses from private sector companies. This information, which is summarized below, is supplemented by information taken from a 2007 report from the Annenberg Leadership Institute $^{2}$ (Appendices F and G).

\subsubsection{Summaries of Organizations Surveyed}

\subsubsection{Counterpart National Metrology Institutes and International Organizations}

Five NMIs and an International Organization responded to the request for information:

- Bundesanstalt für Materialforschung und -prüfung (BAM)

- Korea Research Institute of Standards and Science (KRISS)

- National Research Council Canada (NRC Canada)

- National Metrology Institute - Australia (NMI-Australia)

- Physikalisch-Technische Bundesanstalt (PTB)

- Bureau International des Poids et Mesures (BIPM)

All of the NMIs apart from BIPM (which takes its staff on detail from elsewhere) require some kind of leadership or management training for new managers. None of the NMIs currently require continuous learning or training on leadership or management, though two require needs-based training (which may be leadership development) centered on an individual's performance plan. Of those two, one requires at least 50 hours of training annually. One NMI used to have a comprehensive multi-year training program for managers; however, since most managers have now taken the program it has been suspended.

2 Thompson, D. J. (2007). Training Supervisors to be Leaders - A Missing Element in Efforts to Improve Federal Performance. University of Illinois at Chicago: Annenberg Leadership Institute. 
Five US federal agencies responded to the request for information:

- Internal Revenue Service (IRS)

- National Aeronautics and Space Administration (NASA)

- Naval Research Laboratory (NRL)

- US Marshals Service

- US Patent and Trademark Office (USPTO)

In summary, only one of the federal agencies that responded currently has any mandated continuous learning requirement for manager or supervisors. However, three have well-developed leadership and management training provisions which are either optional or apply to new managers and supervisors.

At NRL, refresher training is required, however there is no exact requirement, and it appears that the topics can be chosen by the supervisor/manager.

USPTO has no mandatory refresher training. However, a large selection of courses are available, drawn from their Supervisory Resource Center (SRC), the CLC, and instructor-led courses.

IRS has an extensive leadership curriculum, from a front-line leader readiness program to their executive curriculum. However, it does not appear to require current managers to take refresher training, as long as they are remaining in the same position.

The US Marshals Service has no formal refresher training requirement for managers/supervisors at this time. As supervisors are promoted to Chiefs, there is mandatory requirement of attendance at Chiefs Development, which is not considered refresher.

NASA has an extensive leader and management development program, with detailed descriptions of competencies required at each level of managerial responsibility.

\subsubsection{Private Sector Companies}

Three private sector companies responded to the request for information:

- Air Products and Chemicals, Inc.

- Lonza

- Johns Hopkins University Applied Physics Laboratory

All of the private sector companies that responded have only a requirement for initial training of supervisors and managers. All three companies offer the possibility of additional management training; however, it is not required training. None require refresher training or continuous learning other than for compliance with agency-mandated training, such as for safety, prevention of sexual harassment, etc. 


\subsubsection{Training Delivery}

\subsubsection{Counterpart National Metrology Institutes (NMIs)}

All of the NMIs used multiple methods of training, including:

- Classroom (Accredited Institute)

- Coaching/Mentoring (Internal/External)

- External Training (Conferences, Industry Visits, Academic Courses),

- In-House Training

- Off-Site Workshops/Sessions

- On-the-Job/Acting Positions

- Peer Groups (Discussions, Task Groups)

- Rotational/Detail Assignments

- Self-Study (Books, Web, PodCasts)

- Seminars/Lectures (Internal/External)

Three of the NMIs do not use rotational/detail assignments; one does not use self-study as a formal part of their training; one noted that they use $360^{\circ}$ assessments to support development of a learning plan; one noted that they do the bulk of their training in-house; and one does not use coaching/mentoring or off-site workshops.

\subsubsection{US Federal Agencies}

As with the NMIs, the federal agencies employ multiple methods to deliver training, whether mandatory or optional.

NRL noted that they deliver a majority of their refresher training on-line. They also use most of the other methods that we listed with the exception of on the job/acting positions, rotational/detail assignments, and peer groups.

USPTO does not appear to utilize peer groups or seminars/lectures, but does use the remainder of the methods in the survey. They note that they have an on-line tool for their refresher training, Supervisory Center, and also employ courses through the Commerce Learning Center, and use voluntary instructor-led courses.

IRS has continual learning and development through on-line courses through a tool called SkillPort. In addition, their preparatory management programs (not to be confused with any refresher courses) include classroom, shadowing, and acting assignments, and often a peer coach.

NASA's Leadership and Management Development Program courses have been developed in-house. They are for the most part five-day courses held at NASA's Management Education Center, Wallops Island, Virginia. The courses included instructional activities, feedback from peers and subordinates, small group activities, lectures, and videotaped discussions. In addition to the formal courses, NASA provides a web-based resource center with a database for developing leadership skills. The database includes both NASA and non-NASA training courses, books and articles, and experiences such as leading a specific type of group. 
Other US Federal Agencies provide on-line training resources, such as the US Department of Agriculture (USDA) Graduate School (http://www.graduateschool.edu), Health and Human Services (HHS) University (http://learning.hss.gov), and the US Office of Personnel Management (OPM) (http://www.leadership.opm.gov). These on-line resources are available for all levels of management and supervisors.

\subsubsection{Private Sector Companies}

In the private sector companies that responded, emphasis was on on-line tools and in-house training. One of the companies additionally employs teleconferences and one has external certification of their in-house program.

\subsubsection{Training Topics}

For most respondents, the training topics mentioned were similar to the example list we provided:

- Building Relationships

- Change Management

- Coaching/Mentoring

- Communication

- Conflict Management

- Creating a Safe/Fear-Free Environment

- Decision Making

- Delegation/Empowerment

- Managing Diverse Groups of People

- Program Management

- Strategic Planning/Development/Thinking

- Teambuilding

- Time Management

\subsubsection{Counterpart National Metrology Institutes (NMIs)}

Of the listed training topics, the least represented in the NMIs were delegation/empowerment, creating a safe environment, and change management. One of the respondents noted that in addition to all the topics listed, that NMI provides training in personnel legal matters (employment rules, performance evaluation, etc.) as well as on internal management procedures.

\subsubsection{US Federal Agencies}

USPTO includes all of the mentioned topics in their optional training.

The US Marshals Service did not specifically mention any topics; they only have a course "Chiefs Development" when supervisors are promoted to Chiefs. 
IRS appears to cover most of the above topics in their varied curricula; however, none is mandatory for current managers staying in position.

In addition to the topics listed above, NRL also offers drug-free workplace training, basic injury compensation training, Lean Six Sigma, and Privacy Act information.

The NASA Leadership and Management Development Program courses have been developed inhouse, and include: Business Education Program; Leading Through Influence; Leadership Alignment for Managers; Practical HR Solutions for Supervisors; and Leading through Effective Communication.

In addition to the five respondents, the table of information given in Appendix $\mathrm{H}$ has one line surveying for "Experienced Supervisors." The only agencies identified as having mandatory continuous learning requirements were Drug Enforcement Agency, Homeland Security, Defense Logistics Agency, National Security Agency and US Department of State. Optional training was listed for Coast Guard (civilian), Federal Aviation Administration, Federal Bureau of Investigation, US Government Accountability Office, Internal Revenue Service, Nuclear Regulatory Commission, and US Marshals Service.

There were numerous interesting quotes from the Annenberg Leadership Institute report even though the topic was on training for new managers. In a 2003 report $^{3}$, the National Academy of Public Administration (NAPA) summarized comments by focus group participants on the "perceived environment and current skill base" of federal managers and supervisors. This research found that first-line supervisors too often:

- Lack communications skills, both written and oral

- Lack team-building skills

- Have general technical knowledge

- Are not chosen for their people skills

- Are not well trained in supervision

- Do not know how to deal with people issues and lack sensitivity

- Lack listening skills

- Receive minimal and dated supervisory training

- Lack the resources and time for development.

The Annenberg report notes that one reason for these apparent problems is the tendency of agencies to select supervisors based on their technical expertise rather than leadership skills. The report also identifies six agencies that do a good job providing leadership/soft skills training to first-line supervisors: Central Intelligence Agency, the National Security Agency, the Internal Revenue Service, the Federal Aviation Administration, the Government Accountability Office, and the Defense Logistics Agency.

${ }^{3}$ National Academy of Public Administration (2003) First Line Supervisors in Federal Service: Selection, Development, and Management. Washington, DC: Government Printing Office. 
The private companies that responded all include the listed topics, with the exception of program management and strategic planning.

\subsection{Survey of Training Providers}

In addition to surveying NIST-comparable organizations, the group surveyed training providers currently used by NIST as well as those identified by the external organizations and companies surveyed. These are examples of the types of training resources available to build a leadership and management refresher training program.

\subsubsection{Summaries of Training Providers Surveyed}

The following is a sampling of information compiled by the Special Study Group . These providers each have experience with training Federal employees; some have experience training NIST employees. This listing is intended to indicate the range of provider options available (and currently being used by NIST) and is not a recommendation of these providers, nor is it a comprehensive list.

\section{OPM - FEI - The Leadership Journey: How Great Leaders are Made}

The US Office of Personnel Management provides a leadership resource for Federal Government known as the Federal Executive Institute (FEI). FEI is a Federal Government organization that is staffed with program directors, seminar leaders, and facilitators from external training professionals. FEI courses are delivered at their Management Development Centers (MDC) located in Virginia, West Virginia, and Colorado. FEI can provide sessions at either the MDCs or on-site.

OPM's FEI provides programs for first line supervisors through the Senior Executive Service (SES). They provide a program called "Core Leadership Curriculum" specifically designed for a leader in the various stages of his/her career; such as, individual leader, team leader, supervisor, manager, and executive. The curriculum offers classes that build on each other throughout the various stages.

Additionally, FEI offers continuing education for federal leaders through a variety of degree and certificate programs, such as, the Leadership Education and Development (LEAD) Certificate, Executive Masters in Public Administration, and individual academic credits.

\section{PAF Consulting - Paula Anderson-Findley}

Paula Anderson-Findley has worked as an executive member of a leading international company, overseen the implementation of company-wide, team-based strategic plans, developed and managed training programs, and taught undergraduate studies in business.

She is the co-author of a book on quality service and executive coaching, "Changing Behavior, Creating New Habits." She received her M.B.A. from the University of Miami, is a certified NeuroLinguistic Programming (NLP) Master Practitioner and Trainer, and is a qualified administrator of the Myers-Briggs Type Indicator. 
She is the facilitator of the NIST BTNG Fundamental Leadership Course which is a week-long offsite introduction for every new BTNG class and she has also contributed to the NIST NLP. Thus, she has a thorough knowledge of the NIST culture and can tailor her instruction to that culture.

\section{Berney Associates - Dr. Liz Berney}

Dr. Berney is President of Berney Associates, a training and organization development firm. Dr. Berney is a consultant, trainer, public speaker, and coach in the areas of: change management, conflict management, interests-based negotiation, customer service, team development, leadership development, stress and time management, organizational learning, managing challenging personalities and the Myers-Briggs Type Indicator.

Dr. Berney's methodology for training sessions are highly interactive -- using skill practices, cases tailored to NIST, self assessments, film clips, small and large group activities, and discussions. She has taught conflict management at NIST for at least 10 years, worked with an internal committee to develop a Mentoring Program, designed and delivered over eight skill-based trainings for the Mentoring Program, worked with senior team on negotiation, conflict and Myers-Briggs, and worked with the Baldrige Program on conflict and teams.

\section{Benchmark Training - John Gorman}

Benchmark focuses on helping government agencies and corporations meet their executive and employee development needs through state-of-the-art training and executive coaching programs. Mr. Gorman specializes in training programs such as: building relationships; change management; coaching/mentoring; communication; conflict management; decision making; delegation/empowerment; managing diverse groups of people; teambuilding; strategic planning/development/thinking; and time management. Mr. Gorman offers a variety of training delivery methods such as: coaching/mentoring (Internal/External); external training (Conferences, Industry Visits, Academic); In-house Training (NIST-Sponsored/Organized); Off-site Workshops/Sessions; Self-study (Books, Web, PodCasts, CLC); Seminars/Lectures (Internal/External); and Business Simulations.

Benchmark Training has taught leadership skills for new supervisors at the Managerial Survival Skills Sessions for new leaders at NIST.

\section{Zeisler Associates, Inc. - A Program for High Potential Managers - Steven Zeisler}

Steven Zeisler is founder and Director of Zeisler Associates, Inc. an international consulting and development firm that helps enterprises innovate. Mr. Zeisler has advised leading Fortune 500 corporations, private firms, public institutions, city councils, and universities throughout the world. Additionally, Mr. Zeisler has successfully served in consulting capacities, executive coaching roles, has facilitated the transformation of senior teams, and conducted a variety of training and development workshops.

Mr. Zeisler's efforts have helped clients to rethink the ways their business systems and organizations operate, and have triggered breakthrough developments in virtually all corporate functions worth hundreds of millions of dollars. Zeisler's consulting expertise includes creativity and innovation, 
organizational climate, entrepreneurship, individual, team and leadership development, change, and customer focus.

Mr. Zeisler is a frequent instructor at NIST.

Fancine Lanar \& Associates, Inc.

Fancine Lanar \& Associates specialize in provide meeting facilitation, conduct leadership and communication training, assist with organizational consulting services, and facilitating teambuilding exercises.Ms. Lanar's team actively involve participants in workshops and retreats, that results in attendees receiving new acquired skills, knowledge, and insights that are later applied in their individual positions.

The group has worked with private industry, government agencies, military units, and with nonprofit groups.

\section{Donald Swenholt \& Associates, Inc.}

Mr. Swenholt delivers seminars for Government and industry nationwide and abroad. He provides facilitation services for meetings and retreats. He provides executive coaching for leaders in the public and private sectors. He also tackles special communications projects for his customers, from creating global web-based training programs to leading team retreats. In addition, Mr. Swenholt serves as a guest instructor at The Uniformed Services University of the Health Sciences and is a frequent instructor at NIST on effective communication.

\section{Management Concepts, Inc.}

Management Concepts, Inc. (MCI) is a private consulting and training firm that focuses on an individual approach to organizational achievement through training courses, custom learning and development, and professional services and publications. MCI has worked with every major agency in the Federal Government.

MCI offers training courses, certificate programs, college and continuing education credits, professional certifications, custom learning and development, and professional consulting services in the following areas:

- Acquisition \& Contracting

- Analytics

- Business Analysis

- Federal Financial Management and Federal Managers Practicum

- Grants \& Assistance

- Leadership

- Management

- Professional Skills

- Project Management. 
MCI is a provider of training and services to NIST. NIST Acquisition Management Division currently contracts and collaborates with MCI to offer individual training courses required for their acquisition staff to be Federal Acquisition Contracting - Civilian (FAC-C) Certified up to Level 3 and associated continuing educations credits for them to maintain their FAC-C certifications. NIST technical staff in operating units across NIST, have also utilized MCI to provide them with the courses and credits necessary to receive and maintain the FAC-C Contracting Officer's Technical Representative (COTR) certifications that are required for them to be appointed COTRs on contracts critical to NIST's mission and core values.

\subsubsection{Training Provider Conclusions}

The provider statements show that, because of NIST's proximity to Washington, D.C. there exists a broad set of training resources focused on the Federal Government from which NIST can draw to implement refresher training. These resources range in size from single-person consulting firms to large entities such as OPM. Some suppliers provide coaching and seminars only, while others offer more extensive programs that allow students to be accredited or receive college credit. Some do purely on-site work, while others facilitate retreats or other off-site training.

The statements show that the training providers profiled are experienced at providing training within the context of the unique environment of a Federal agency. It is also important to note that NIST has access to an "in-house" resource in the form of OPM itself, which may also be useful in devising and implementing a refresher training curriculum.

The Special Study Group finds that instructors with knowledge of the Federal government environment, and of the NIST culture in particular, are critical for effective training. Off-the-shelf training may contain elements that are not appropriate for NIST staff, for example, in the areas of sales or lobbying. Instructors that have not worked with NIST before should be made fully aware of the NIST culture, history, and mission so that they can tailor their coursework to our needs. 


\section{Observations and Recommendations}

The BTNG7 special study group has documented the results of surveys of NIST management and supervisors, interviews with OU Directors, and collected data on existing programs, both at NIST and DOC, at other agencies in the Federal Government, at counterpart national metrology institutes, and private industry. This presented us with a diversity of information upon which to make our recommendations to start to structure a program of manager/supervisor refresher training sufficient to meet the new OPM mandate.

\subsection{Observations}

NIST is not alone in lacking mandatory refresher training for managers and supervisors; most of the outside organizations that we surveyed also do not have such training, or like us, are just starting to plan such a program. What we found, however, is that some of the organizations we surveyed have a wide variety of possible training areas and delivery methods available to their managers and supervisors, most of which are currently taken by choice. We focused on these organizations in developing our recommendations.

Within NIST, there was some variation of views of the NIST Managers and Supervisors who were surveyed, but the survey found that a subset of areas were identified as both being key to job performance and areas that should be emphasized in training. These areas are usually considered to be soft skills or "people skills" such as communication, conflict management, change management, and team building. This need for training/support in development of "people skills" also came out in the interviews with the OU Directors. This view is supported by the recent NAPA report [NAPA, 2003], which notes that federal managers are often not chosen for people skills, but for their technical knowledge. Our interviews showed that there is a perception that this is true at NIST, with technical skills being valued over "soft skills".

There are general topics on NIST operational functions that managers and supervisors would like to have included so that managers have better understanding of the procedures they need to follow to allow their subordinates to do their work effectively, especially since these administrative procedures routinely change. These courses ideally would include information on the following topics: acquisitions/contracts; employee relations/resources; finance/budget; NIST's role in the political environment; and workforce management. Another important topic for training was strategic planning/developmental thinking and NIST's mission and history.

Some of the OU Director interviews revealed a desire for "just-in-time" training that could be delivered to NIST staff immediately prior to their participation in an uncommon but high-impact event. Examples of such an event include: changes to administrative policy; an interview with journalists; making a presentation to visiting Congressional staff; and appearing before a House or Senate committee to give testimony.

Most of the outside organizations that we surveyed indicated that they offer training in similar topic areas as we listed in our surveys, with some interesting additions. Two topics mentioned in one of the private sector organizations' responses, but missing from the topics in our NIST survey responses, was "effective recruitment and interviewing," as well as "entrance-on-duty and training." These are two topics that one might expect would involve only NIST's Office of Workforce Management; however, since existing managers and supervisors will be increasingly called upon to 
assist with recruitment and interviewing, development of these skills would be useful. In addition, since proper orientation and training of new employees is also increasingly stressed (from the orientation point of view, as well as safety aspects), having training on expectation/requirements from managers to new employees would also be useful.

In summary, there needs to be a choice and variety of topics and methods of delivery to meet the mandatory refresher training requirement in order to satisfy individual operating units and individual manager/supervisor needs.

It would make sense to have these courses and/or training sessions in the NIST LED, and be connected, if not directly with a self-assessment or $360^{\circ}$ assessment, at least with an open discussion between manager/supervisor and their direct supervisor on what topic/training would be beneficial.

On training delivery methods, on the basis of the responses, no one method of delivery would be an exact fit to all situations, suggesting that a variety of delivery methods for the refresher should be made available. In terms of the NIST surveys, there was a preference given to in-house training and seminars/lectures. However, there was support for other types of delivery, so these should not be overlooked in structuring a robust, diverse refresher training program that can appeal to and be useful to managers and supervisors.

It should be noted again that DOC already has a number of programs that support leadership development, although not targeting refresher training. Many of the existing leadership education and development courses already contain the topics that existing managers and supervisors have identified as skills to be developed. It would seem possible to use similar delivery sources/vendors/topic leaders for some of the development and refresher topics, so not as to start from scratch. Examples of some of the overlap topics are new pathways/aspiring leaders program with communication; conflict management customer service, problem solving and team building; executive leadership development program, leading change, leading people, building coalitions (team-building), and communications.

NIST has used the New Leaders Program (NLP) to help new managers become acclimated to their new duties and help them to build the skills that they need to lead technical teams. NIST has extended this training to non-supervisors with the Building the Next Generation (BTNG) program. The BTNG program is designed to improve the participants' abilities to work effectively in teams and to assume leadership roles within NIST, either as supervisors or more informally as team leaders. These courses can form the nucleus of a refresher training curriculum.

NIST has a mechanism for managing the training programs of individual supervisors. The use of Individual Development Plans (IDPs) was instituted at NIST after the 1998 report on leader development, but IDPs no longer appear to be in much use. Since this is an existing, albeit little-used resource, it may be valuable to reintroduce it as a tool for coordinating refresher training.

Through our on-line searching, we found three very different approaches to manager training at USPTO, through their on-line tool, Supervisory Center; at NASA's Leadership and Management Development Courses held at the NASA Management Education Center at Wallops Island, Virginia; and at the Manager Excellence Resource Center (MERC), which is a site maintained by the Learning and Development Roundtable (L\&DR). These approaches have been found to be very successful, so both a self-study approach and training off-site should be considered as options for NIST training, although this type of training did not come up as a top preference in the NIST survey. 
NIST may want to consider implementing a social networking site for NIST employees, such as Facebook and Linked In. NASA has implemented an internal social networking site called Spacebook. This internal social network among NASA employees allows new and established staff to get to know the agency's diverse community of scientists, engineers, project managers, and support personnel. Spacebook was driven by a need to improve teamwork, communication, and access to information across NASA's diverse projects and centers. NIST and its employees would benefit from having a similar private internal social network site to foster scientific teamwork, communications, and collaborations. OWM, LED could respond to the OPM mandate specifically by utilizing an internal network to engage with managers and staff on different types of training tools, events, resources, courses, programs, and vendors. The possibilities could be endless if the NIST staff had a means to be connected to one another.

This work is not the first examination of leadership and management needs at NIST. A previous study was performed and a report presented in $1998^{4}$. There are similarities between the 1998 and this report. Both reports identify that there is a requirement and a desire to provide an improved and continuous leadership and management program. As a result of the 1998 report, the Leadership and Employee Development Group (LED) was established. To date, the LED has provided a majority of the leadership training opportunities through the NLP and BTNG programs.

Additional similarities between the reports exist with respect to training needs and methods of training delivery. Both reports find that those surveyed at NIST prefer delivery of training to be in the form of in-house training and management seminars. Additionally, both reports point out specific leadership skills that should be fully developed, in particular strategic planning, communication, and conflict management.

As both reports point out, there is a culture and audience at NIST that values leadership skills and abilities. This should provide a base of managers and supervisors who are ready to accept enhanced training opportunities.

\subsection{Recommendations}

Based on the information that the Special Study Group has gathered, we make the following recommendations:

1. There should be choices built into the mandatory refresher training for managers and supervisors. We suggest a tiered approach as shown in Figure 12, with the level of responsibility for administering delivery shown. The first tier (Tier I) consists of training that emphasizes soft skills (or people skills) that all of the surveyed managers agree are important. Tier I training also covers NIST function such as acquisitions, working with the Office of Workforce Management (OWM), and preparing budgets. The Tier II training includes just-in-time training to prepare managers for an imminent event whose outcome has

${ }^{4}$ Seiler, D., Cookson, A., Fowler, L., Handwerker, C., Kacker, R., LeSage, D., Taylor, M., Farah, O., Graham, J., Lee, R., Aronoff, R., Mendez, J. (McManis Associates, Inc.), "Survey of Leadership and Managerial Development Needs at NIST," Working Group on Needs Assessment and Benchmarking, NIST, Gaithersburg, MD, November 30, 1998. 
the potential to impact NIST in a significant way. This training would not necessarily be associated with the manager's performance plan, but would allow managers the flexibility to do quick skill-building to maximize their effectiveness when dealing with unplanned highprofile events. The Tier III training includes more courses and areas of study directly relating to the needs of individual managers. Tier III training courses may be taken as "electives," but still count towards the mandatory refresher training.

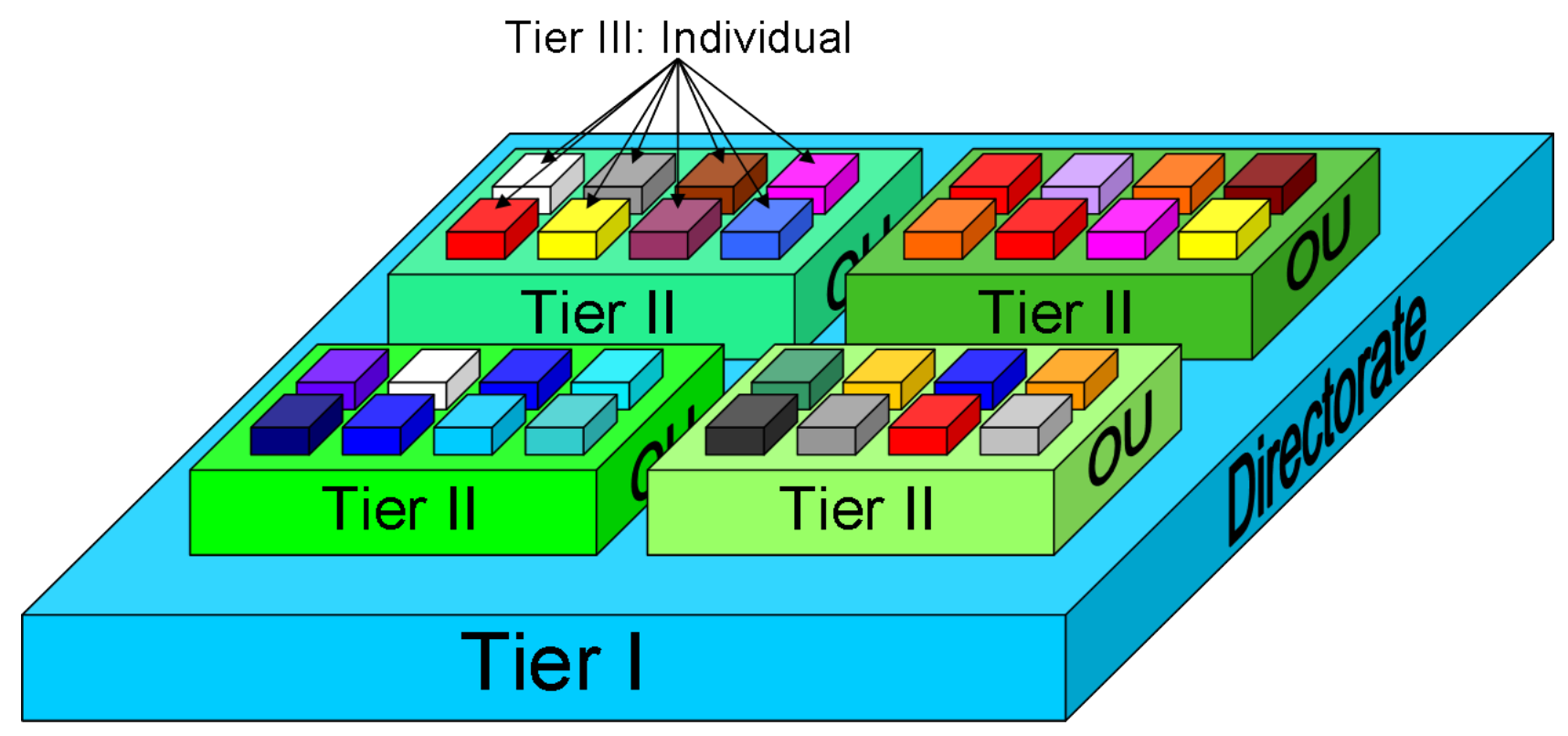

Figure 12 Graphical Representation of the Proposed Tiered Training Structure

2. We have no consensus on the exact amount of refresher training that is needed per year, though the OPM requirement of training every three years needs to be met. Part of the problem is that each OU has different expectations regarding how much training is appropriate. Some OUs already involve their managers in annual refresher training that lasts for up to five days, while others have indicated a preference for far less frequent training. A possible solution would be to have the OUs within each of NIST's three directorates reach a consensus on the frequency and duration of Tier I refresher training within their own directorate. Tier II and Tier III training schedules and requirements could be left to the discretion of the individual OUs. This would give OUs a degree of independence and the ability to tailor training to their own needs while ensuring that all NIST managers who fall into a certain category (laboratory programs, innovation and industry services, or management resources) have a common basic skill set. It would also allow managers from different OUs to train together to gain exposure to people from other areas of NIST, as was suggested in the OU Director interviews. We encourage the NIST Director's office to assist and encourage the OUs within each of these three areas to devise a common Tier I program while allowing them the freedom to add what Tier II and Tier III training they desire, even if they decide that this amount should be zero.

3. The Leadership and Education Development Group should coordinate the refresher training. Many of the existing leadership education and development courses already contain the 
topics that existing managers and supervisors have identified as skills to be developed. Knowing this, it is proposed that NIST use similar delivery sources/vendors/topic leaders to provide some of the development and refresher topics, so not as to start from scratch.

4. On the basis of the responses across our surveys, no one method of delivery would be an exact fit to all situations, so providing a variety of delivery methods for the refresher training is suggested. Since a preference was given in the NIST surveys to in-house training and seminars/lectures, these types of training might be predominant. This again would fit into the model of having LED organize courses/classes, either in-house or bringing in outside vendors to deliver. However, the surveys of outside organizations demonstrate that other methods may also serve well for training in many of the topics.

5. To plan what type of refresher training is most appropriate for each manager/supervisor, we recommend that an Individual Development Plan (IDP) be considered (See Appendix H). The mechanisms for developing and using IDPs already exist but have fallen into disuse. The tools used with the IDP could either be formal, e.g., with a $360^{\circ}$ assessment, more informal, such as the use of the NASA assessment tools, or in open constructive discussions with the manager's direct supervisor. The implementation of this part of the refresher training program should be left to the discretion of the OUs.

6. LED, the NIST Director's Office, the leadership of the directorates, and the OU Directors should periodically review the training requirements and curricula and make any modifications or additions that they deem necessary. These should be periodic reviews that are not tied to actions or lack of action by OPM. 


\section{Appendices}




\section{Appendix A: Charge to the BTNG 7 SSG}

\section{Special Study Group Proposal}

New federal regulations mandate training for new supervisors, managers, and executives, as well as refresher training, every three years. NIST offers Managerial Survival Skills for new supervisors but currently has nothing in place for new managers or executives. Additionally, NIST does not have a structured program of refresher training for experienced supervisors and managers.

The BTNG7 SSG project objective is to propose a continuous learning program for experienced supervisors and managers at NIST. The suggested activities might include:

\section{Phase 1}

- Conduct an assessment to identify the most prevalent training needs using the following:

- Surveys targeting multiple levels of NIST management

- Follow-up face-to-face interviews with managers and supervisors to clarify survey responses

- Research best practices of similar organizations

- Recommend suite of options to meet training requirements based on analysis of the aforementioned data

- $\quad$ To be completed by July 31 st 2010

\section{Phase 2}

- Identify existing learning resources that are capable of meeting the new training requirements

- Contact outstanding organizations to identify additional learning solutions

- Identify external training opportunities

- Propose new in-house learning events

- $\quad$ To be completed by October 31st 2010

The timeframe of the SSG Project will start in February. It is planned that Phase 1 will be completed at the end of July and Phase 2 will be completed by the end of October. 


\section{Appendix B: Summary of Federal Regulations}

Detailed below is the entry in the Federal Register pertaining to training of supervisors, managers, and executives. The parts of the regulations that have led to this project are highlighted in bold text.

Federal Register / Vol. 74, No. 236 / Thursday, December 10, 2009/Rules and Regulations

OFFICE OF PERSONNEL MANAGEMENT

5 CFR Parts 410 and 412

RIN 3206-AK75

AGENCY: Office of Personnel Management.

ACTION: Final rule.

DATES: Effective Date: December 10, 2009.

Training; Supervisory, Management, and Executive Development

SUMMARY: The Office of Personnel Management (OPM) is amending its regulations to implement certain training and development requirements contained in the Federal Workforce Flexibility Act of 2004 (Pub. L. 108-411) and to make other revisions in OPM regulations. The Act makes several significant changes in the law governing the training and development of Federal employees, supervisors, managers, and executives. The first change requires each agency to: evaluate, on a regular basis, its training programs and plans with respect to the accomplishment of its specific performance plans and strategic goals, and modify its training plans and programs as needed to accomplish the agency's performance plans and strategic goals. Public Law 108-411 requires agencies to consult with OPM to establish comprehensive management succession programs designed to provide training to employees to develop managers for the agency. It also requires agencies, in consultation with OPM, to establish programs to provide training to managers regarding actions, options, and strategies a manager may use in relating to employees with unacceptable performance, mentoring employees, improving employee performance and productivity, and conducting employee performance appraisals.

Continuum of Leadership Development

Sec. 412.101 Coverage.

This part applies to all incumbents of, and candidates for, supervisory, managerial, and executive positions in the General Schedule, the Senior Executive Service (SES), or equivalent pay systems also covered by part 410 of this chapter.

Sec. 412.102 Purpose.

(a) This part implements for supervisors, managers, and executives the provisions of 5 U.S.C. chapter 41, related to training, and 5 U.S.C. 3396, related to the criteria for programs of systematic development of candidates for the SES and the continuing development of SES members.

(b) This part identifies a continuum of leadership development, starting with supervisory positions and proceeding through management and executive positions Government-wide. For this reason, this part provides requirements by which agencies: 
(1) Develop the competencies needed by supervisors, managers, and executives;

(2) Provide learning through continuing development and training in the context of succession planning; and

(3) Foster a broad agency and Government-wide perspective to prepare individuals for advancement, thus supplying the agency and the Government with an adequate number of well-prepared and qualified candidates to fill leadership positions.

Sec. 412.201 Management succession.

The head of each agency, in consultation with OPM, must develop a comprehensive management succession program, based on the agency's workforce succession plans, to fill agency supervisory and managerial positions. These programs must be supported by employee training and development programs. The focus of the program should be to develop managers as well as strengthen organizational capability, and to ensure an adequate number of well-prepared and qualified candidates for leadership positions. These programs must:

(a) Implement developmental training consistent with agency succession management plans;

(b) Provide continuing learning experiences throughout an employee's career, such as details, mentoring, coaching, learning groups, and projects. These experiences should provide broad knowledge and practical experience linked to OPM's Federal leadership competencies, as well as agency-identified, mission-related competencies, and should be consistent with the agency's succession management plan; and

(c) Include program evaluations pursuant to 5 CFR 410.202.

Sec. 412.202 Systematic training and development of supervisors, managers, and executives.

All agencies must provide for the development of individuals in supervisory, managerial and executive positions, as well as individuals whom the agency identifies as potential candidates for those positions, based on the agencies' succession plans. Agencies also must issue written policies to ensure they:

(a) Design and implement leadership development programs integrated with the employee development plans, programs, and strategies required by 5 CFR 410.201, and that foster a broad agency and Government-wide perspective;

(b) Provide training within one year of an employee's initial appointment to a supervisory position and follow up periodically, but at least once every three years, by providing each supervisor and manager additional training on the use of appropriate actions, options, and strategies to:

(1) Mentor employees;

(2) Improve employee performance and productivity;

(3) Conduct employee performance appraisals in accordance with agency appraisal systems; and

(4) Identify and assist employees with unacceptable performance.

(c) Provide training when individuals make critical career transitions, for instance from nonsupervisory to manager or from manager to executive. This training should be consistent with assessments of the agency's and the individual's needs. 


\section{Appendix C: Chief Human Capital Office Actions to Address New Regulations}

The text below is that of the memorandum sent on 4/26/10 by the Chief Human Capital Officer, Michael Culpepper, to the NIST Leadership Board relating to the OPM regulations.

Colleagues:

This email is informational only.

At the end of last year, the Office of Personnel Management (OPM) issued new regulations related to management and executive training/development. The Department of Commerce (DOC) is finalizing the departmental policy, so we are initiating work on developing, or in some cases revising, relevant NIST guidance and leadership programs to support this new mandate.

The new policy requires:

- A comprehensive succession program to fill supervisory and managerial positions, strengthen organizational capability, and ensure an adequate pipeline of well-qualified candidates for leadership positions.

- Mandatory leadership training at critical career transitions, including initial appointment to:

- A supervisory position within DOC

$\circ$ A manager position (i.e., division chief)

○ An executive position (i.e., Senior Executive Service)

- Mandatory ongoing leadership training at least every three years for supervisors and managers.

- Continuing executive (i.e., SES) development, which includes an Executive Development Plan to be updated and reviewed annually by an Executive Review Board.

Here are two (of several) activities currently underway to address these new requirements. First, the Department is piloting an Executive Development Program to meet the needs of the SES population. This program is expected to include opportunities for remote, just-in-time learning. I, and several other DOC Executives, are involved in an initial pilot to actually use and critique a number of online Learning programs.

Second, I have taken advantage of a great feature of the Building the Next Generation Program, the Special Study Group, to task a talented cross section of aspiring leaders to study leadership excellence at NIST and to recommend NIST's policy for leadership refresher training for NIST supervisors and managers. The team of eight BTNG7 members are likely to be in touch with you for your experience and suggestions. The group's findings are due to me in early August, with training/learning recommendations due in early November.

This topic will be discussed at the next OU Director's Lunch, this Wednesday, April 28. The Special Study Group and members of my Leadership \& Employee Development staff will be asking you to participate in shaping NIST's new leadership training policies and programs. We are provided with an outstanding opportunity to build the leadership capacity of NIST, through enhancing the skills of our current leaders, accelerating time to effectiveness by better supporting key leader career 
transitions, and through strengthening our pipeline of technical and administrative leaders for the future.

Thank you for your support. I look forward to a discussion during the upcoming OU Director's Lunch, and fielding whatever questions you may have.

Best Regards,

Mike [Culpepper] 


\section{Appendix D: Survey Questions}

Copy of the on-line survey of NIST Executives, Managers, and Supervisors

\section{Survey Introduction:}

This survey you have been asked to participate in is being sponsored and organized by the Building the Next Generation (BTNG), Class 7 Special Study Group (SSG). The purpose of a SSG is to study a NIST-wide, high-level issue and to recommend a course of action for senior leadership, over a six-month period. The BTNG7 SSG has been specifically tasked by the Chief Human Capital Officer (CHCO), with support from LED, with recommending to CHCO how NIST should address the new OPM Federal regulations that mandate refresher training for supervisors and managers at least every three years. The current NIST training program was designed prior to the new regulations and needs to be updated to comply with them.

\section{Key Points of our Task:}

Objective: To propose a continuous learning program for experienced supervisors and managers Background: New Federal regulations (Executive Order 11348 and 5USC4103) mandate training for all new supervisors, managers, and executives, as well as refresher training every three years.

The Special Study Group (SSG) of this year's Building the Next Generation (BTNG) class will develop training recommendations for supervisors and managers.

Questions to be addressed: What is the impact of the new regulations on NIST? What training plan gives the greatest benefit to NIST? What is the best way to handle succession planning at NIST? How do other Federal labs and NMIs handle management training?

Project Customer: Michael Culpepper, NIST Chief Human Capital Officer

Timeline: Needs assessment completed by 7/1/10; Training recommendation completed by $10 / 1 / 10$

NIST has an opportunity to respond proactively and effectively to these new requirements which are mandated by OPM and DOC. The BTNG7 SSG appreciates the support and cooperation from personnel at all levels to maximize NIST's chances for success in enhancing its leadership training program. Any information you provide is anonymous and will not be distributed outside of the SSG. If you wish to be contacted by the SSG for further discussion, please let us know.

Thank you for your assistance. 
Survey Questions

1. Are you a:

$\sqsubset$ Executive (OU Director, OU Deputy Director, Director of Chief Office)

- Manager (Division Chief)

- Supervisor (Group Leader, Team Leader)

2. How long have you been in a supervisory position?

$\sqsubset 0-5$ years $\sqsubset 6-10$ years $\sqsubset 11-20$ years $\sqsubset 21-30$ years $\sqsubset>30$ years

3. NIST provides leadership and management training that meets the needs of my position

$\sqsubset$ Strongly Agree

$\sqsubset$ Agree

$\sqsubset$ Neutral

- Disagree

$\sqsubset$ Strongly Disagree

4. Please select UP TO FIVE (5) NIST Leadership Core Competencies, below, that are most important for your effectiveness in working with your direct reports and those most important for your effectiveness in working with other managers at NIST. The list of the core competencies and definitions can be found at: http://www-i.nist.gov/led/PDFs/web_nist_core_leadership_competencies.pdf

Direct Reports Competencies Other Managers at NIST

$\begin{array}{llc}\sqsubset & \text { Communication } & \square \\ \square & \text { Conflict Management } & \square \\ \square & \text { Delegation/Empowerment } & \square \\ \square & \text { Flexibility/Adaptability } & \square \\ \square & \text { Integrity/Honesty } & \square \\ \square & \text { Leading Change } & \square \\ \square & \text { Motivating Others } & \square \\ \square & \text { Organizational Skills } & \square \\ \square & \text { Problem Solving } & \square \\ \square & \text { Service Motivation } & \square \\ \square & \text { Strategic Development/Thinking } & \square\end{array}$


5. Please select the leadership/management skills that you would like to develop.

$\sqsubset$ Building Relationships

ᄃ Change Management

$\sqsubset$ Coaching/Mentoring

$\sqsubset$ Communication

- Conflict Management

- Creating a Safe/Fear-Free Environment

$\sqsubset$ Decision Making

$\sqsubset$ Delegation/Empowerment

$\sqsubset$ Managing Diverse Groups of People

ᄃ Program Management

$\sqsubset$ Strategic Planning/Development/Thinking

$\sqsubset$ Teambuilding

$\sqsubset$ Time Management

$\sqsubset$ Other

6. Please select all the types of training you prefer.

$\sqsubset$ Classroom (Accredited Institute)

$\sqsubset$ Coaching/Mentoring (Internal/External)

- External Training (Conferences, Industry Visits, Academic)

$\sqsubset$ In-house Training (NIST-Sponsored/Organized)

$\sqsubset$ Off-site Workshops/Sessions

$\sqsubset$ On-the-Job/Acting Positions

- Peer Groups (Discussions, Task Groups)

$\sqsubset$ Rotational/Detail Assignments

- Self-Study (Books, Web, PodCasts, CLC)

$\sqsubset$ Seminars/Lectures (Internal/External)

$\sqsubset$ Other

7. Please select all the NIST functions you would like to learn more about or received training on.

ᄃ Acquisitions/Contracts

- Baldrige Program (BNQP)

$\sqsubset$ Employee Relations/Resources

ᄃ Facilities (Emergency, Administrative, Plant, Engineering/Maintenance/Plant Services)

$\sqsubset$ Finance/Budget

$\sqsubset$ Grants/Agreements

- Honorary and NIST Awards

ᄃ IT Security/Services

- Manufacturing Extension Partnership (MEP)

$\sqsubset$ NIST Associates Program

$\sqsubset$ NIST History and NIST's Mission (Organic and America Competes Act)

$\sqsubset$ NIST Role in the Political Environment (Commerce, Congress, Administration)

- NIST User Facilities (CNST, NCNR)

$\sqsubset$ Promotions 
$\sqsubset$ Public Affairs and Media Relations

$\sqsubset$ Safety, Health, and Environment

- Standards Services (Documentary Standards, Standard Reference Data, Standard Reference Materials, Calibration Services)

$\sqsubset$ Technical Operating Units/Laboratories (Building \& Fire Research, Chemical Science \& Technology, Electronics \& Electrical Engineering, Information Technology, Manufacturing Engineering, Materials Science \& Engineering, Physics Laboratory, and Technology Services)

-Technology Partnerships (Cooperative Research \& Development Agreements, Intellectual Property, Material Transfer, Small Business Innovation Research)

- Technology Innovation Program (TIP)

-Travel

$\sqsubset$ Workforce Management (Management/Organization, Human Resources)

$\sqsubset$ Other/Specific topic within the above categories

8. Please describe an exceptional or standout leadership training experience you have had either inside or outside of NIST.

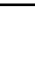

9. If you would like to be contacted by the Building the Next Generation Class 7 Special Study Group, for further information or discussions, please provide us with your name.

Name: 


\section{Appendix E: Survey Questions to NIST-Comparable Organizations}

Questions for Peer Institutions on Their Leadership Development Training Practices

1. Does your organization require periodic (continuous learning) training for supervisors, managers, or executives?

2. Generally speaking, how much training is required? How often must it be taken?

3. How is the training delivered? Some possible methods are:

- Classroom (Accredited Institute)

- Coaching/Mentoring (Internal/External)

- External Training (Conferences, Industry Visits, Academic Courses)

- In-House Training

- Off-Site Workshops/Sessions

- On-the-Job/Acting Positions

- Peer Groups (Discussions, Task Groups)

- Rotational/Detail Assignments

- Self-Study (Books, Web, PodCasts)

- Seminars/Lectures (Internal/External)

- Other

4. What leadership and management topics are covered? Examples include:

- Building Relationships

- Change Management

- Coaching/Mentoring

- Communication

- Conflict Management

- Creating a Safe/Fear-Free Environment

- Decision Making

- Delegation/Empowerment

- Managing Diverse Groups of People

- Program Management

- Strategic Planning/Development/Thinking

- Teambuilding

- Time Management

- Other 


\section{Appendix F: The Leadership Competency "Stair Step"}

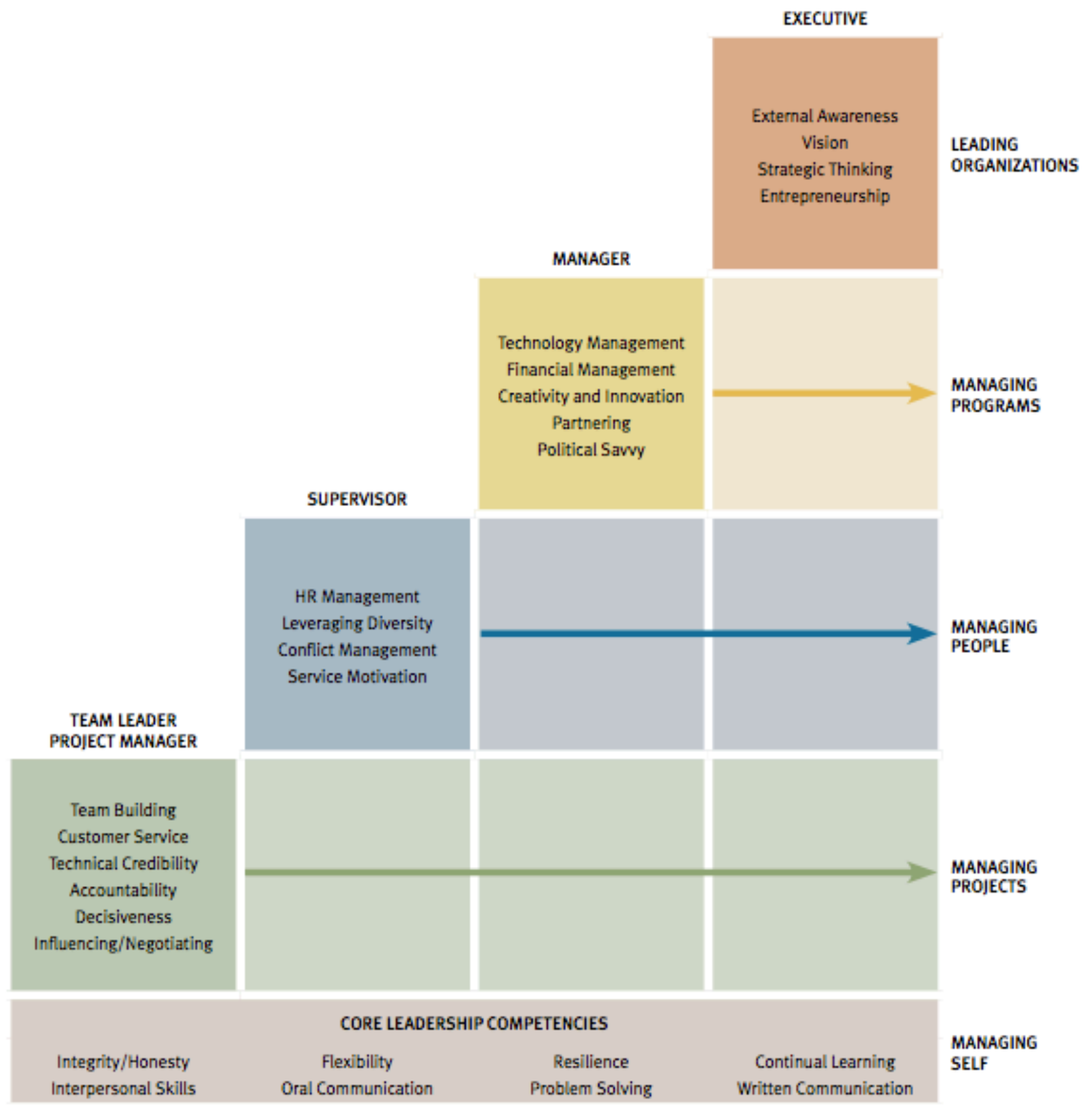

This figure was sourced from the 2007 report "Training Supervisors to be Leaders - A Missing Element in Efforts to Improve Federal Performance." by Dr. J Thompson of the Annenberg Leadership Institute at the University of Illinois at Chicago. 


\section{Appendix G: Leadership Development Programs for First-Line Supervisors in Selected Federal Agencies}

\begin{tabular}{|c|c|c|c|c|c|c|c|c|c|c|c|c|c|c|c|}
\hline \multirow[b]{2}{*}{ Agency } & \multicolumn{3}{|c|}{ target } & \multicolumn{2}{|c|}{ Traising } & \multirow[b]{2}{*}{ 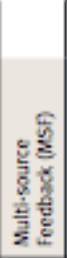 } & \multicolumn{2}{|c|}{$\begin{array}{l}\text { Developmental } \\
\text { Felatisnships }\end{array}$} & \multirow[b]{2}{*}{$\begin{array}{l}\frac{n}{E} \\
\frac{1}{5} \\
\frac{1}{5} \\
\frac{1}{2} \\
\frac{1}{2} \\
\frac{2}{2}\end{array}$} & \multirow[b]{2}{*}{ 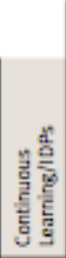 } & \multicolumn{4}{|c|}{ Neans of tvaluation } & \multirow[b]{2}{*}{ 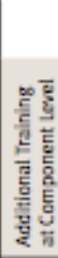 } \\
\hline & 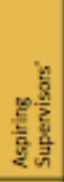 & 产 & 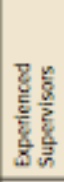 & $\begin{array}{l}\frac{E}{8} \\
\frac{8}{2} \\
\frac{\pi}{2}\end{array}$ & $\frac{\mathscr{E}}{\bar{E}}$ & & $\begin{array}{l}\frac{g}{5} \\
\frac{g}{g}\end{array}$ & $\begin{array}{l}\frac{\omega}{E} \\
\frac{E}{E} \\
\frac{E}{2}\end{array}$ & & & 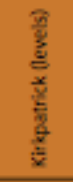 & 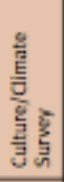 & $\begin{array}{l}\frac{n}{y} \\
\frac{2}{2} \\
\frac{5}{5}\end{array}$ & $\frac{n}{\frac{n}{3}}$ & \\
\hline OA & & 0 & & + & & + & & + & + & + & $1,2,3$ & + & & & + \\
\hline Center for Medicare and Meditaid Servites & & $M$ & & + & & & + & + & & & & & & & \\
\hline Coast Guard (civilian) & & 0 & 0 & + & + & & & + & & & & & & & \\
\hline DEA & & M & $M$ & + & + & & & & & & & & & & \\
\hline Homeland Security & & $M$ & $M$ & + & & & + & & + & & & + & & & + \\
\hline Defense Logistics Agency & & M & $M$ & + & + & + & + & & + & + & & + & + & + & \\
\hline EPA & & M & & + & + & + & + & + & + & + & $1,2,3$ & & & & \\
\hline FAA & & $M$ & & + & + & + & + & & + & + & $1,2,3$ & + & & & + \\
\hline FAA & & & 0 & + & + & + & + & & + & + & $1,2,3$ & + & & & + \\
\hline $\mathrm{FBI}$ & + & & & + & + & & & & + & + & 1,3 & & & & \\
\hline $\mathrm{FBI}$ & & $M$ & & + & + & & & & + & + & 1,3 & & & & \\
\hline $\mathrm{FBI}$ & & & 0 & + & + & & & & + & + & 1,3 & & & & \\
\hline GAO & & $M$ & & + & + & & & & + & + & & & & & \\
\hline GAO & & & 0 & + & + & & & & + & + & & & & & \\
\hline IRS & + & & & + & + & + & & + & + & + & $*$ & & & & \\
\hline IRS & & $M$ & & + & + & & + & & + & & 1,3 & & & & \\
\hline IRS & & & 0 & + & + & & + & & + & & 1,3 & & & & \\
\hline Labor & & $M$ & & + & + & & & & & & & & & & + \\
\hline NIST & & 0 & & + & & & + & & & + & 1 & & & & \\
\hline Nuclear Regulatory Commission & + & & & + & + & + & + & + & + & + & 1 & & & & \\
\hline Nuclear Regulatory Commission & & $M$ & & + & + & + & + & + & + & + & 1 & & & & \\
\hline Nuclear Regulatory Commission & & & 0 & + & + & + & + & + & + & + & 1 & & & & \\
\hline National Security Agency & & $M$ & $M$ & + & + & + & & & & + & 3 & + & + & & + \\
\hline PaGC & & M & & + & & & & & & + & & & & & \\
\hline Bureau of Prisans & & 0 & & + & & + & & + & & & & & & & \\
\hline Social Security Administration & + & & & + & + & + & & + & + & + & 1,3 & & & & \\
\hline Sotial Security Administration & & M & & + & + & & & & & & & & & & + \\
\hline U.S. Department of State & + & & & + & + & + & + & + & + & + & & & & & \\
\hline U.S. Department of State & & M & & + & + & + & + & + & + & + & & & & & \\
\hline U.S. Department of State & & & M & + & + & + & + & + & + & + & & & & & \\
\hline U.S., Marshal's Service & & 0 & 0 & + & & & & & & & & & & & \\
\hline Veterans Benefits Administration & + & & & + & & + & & + & + & + & $1,2,3$ & & & & \\
\hline Veterans Benefits Administration & & M & & + & & + & & & & + & $1,2,3$ & & & & \\
\hline Western Area Power Administration & + & & & + & & + & & + & + & + & & & & & \\
\hline
\end{tabular}

Agencies in which most supervisory training takes plate at the component level: NASA Air force, VhA

M- Mandatory, 0-Optional

* Plus sign (o) indicates that agency offers training for aspiring supervisors; participants must apply to participate.

* The IR5 evaluates its program by tracking the percentage of participants that are promoted.

This figure was sourced from the 2007 report "Training Supervisors to be Leaders - A Missing Element in Efforts to Improve Federal Performance." by Dr. J Thompson of the Annenberg Leadership Institute at the University of Illinois at Chicago. 


\section{Appendix H: NIST Individual Development Plan Form (DN-13)}

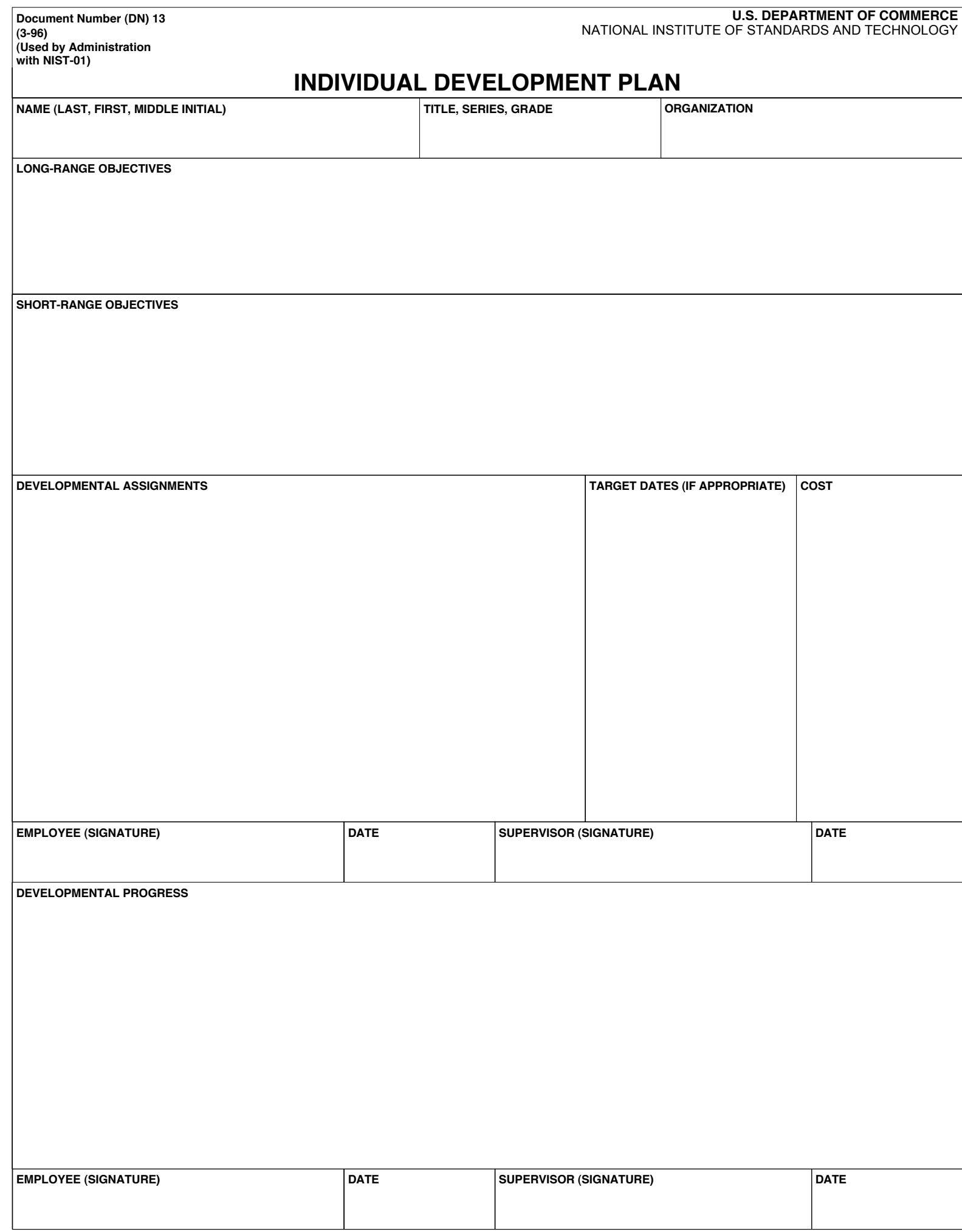

ADMINISTRATION/IPSG ELECTRONIC FORM 


\section{Appendix I: Error Analysis}

The survey produced responses from $n=167$ people out of $N=373$, which gives a sampling fraction of $f=n / N=44.8 \%$. In this appendix, we compute $90 \%$ confidence intervals for the survey results. The survey results included breakdowns into subpopulations based on number of years in a leadership role and leadership position, but while we know how many respondents fit into each of these categories, we do not have information on how many people in the total population of NIST managers are in each category. Thus we restrict our analysis to results involving the total population of respondents.

\section{Figure 3 analysis}

Figure 3 shows the percentage of respondents who responded in one of 5 possible ways indicating their level of agreement with the statement, "NIST provides leadership and management training that meets the needs of my position." $n_{3}=165$ people responded to the question, so the sampling fraction here is $f_{3}=165 / 373=44.2 \%$. The numbers of people who gave the responses Strongly Agree, Agree, Neutral, Disagree, and Strongly Disagree were 18, 89, 36, 20, and 2, respectively. Dividing each by $n_{3}$ gives the percentages shown in the figure, which are listed here in decimal form using 3 significant figures each, although we are taking ratios of exact numbers:

$$
\begin{aligned}
p_{\text {Strongly Agree }} & =0.109 \\
p_{\text {Agree }} & =0.539 \\
p_{\text {Neutral }} & =0.218 \\
p_{\text {Disagree }} & =0.121 \\
p_{\text {Strongly Disagree }} & =0.012 .
\end{aligned}
$$

The sample standard deviation of each estimated proportion is as follows (we use the "Neutral" response to show the form but it is the same for all the others):

$$
s_{\text {Neutral }}^{2}=\frac{n_{3}}{n_{3}-1} p_{\text {Neutral }} q_{\text {Neutral }}
$$

where $q_{\text {Neutral }}=1-p_{\text {Neutral }}$.

$p_{\text {Neutral }}$ is an unbiased estimator of $P_{\text {Neutral, }}$, the actual proportion of the population that would have a "Neutral" response to Question 3. An unbiased estimator of the variance of $p_{\text {Neutral }}$ (which is the mean squared difference of $p_{\text {Neutral }}$ and $\left.P_{\text {Neutral }}\right)$ is:

Using this formula, we get

$$
v\left(p_{\text {Neutral }}\right)=\frac{s_{\text {Neutral }}^{2}}{n_{3}} \frac{N-n_{3}}{N}=\frac{p_{\text {Neutral }} q_{\text {Neutral }}}{n_{3}-1}\left(1-f_{3}\right)
$$

$$
\begin{aligned}
v\left(p_{\text {Strongly Agree }}\right) & =3.30 \times 10^{-4} \\
v\left(p_{\text {Agree }}\right) & =8.45 \times 10^{-4} \\
v\left(p_{\text {Neutral }}\right) & =5.80 \times 10^{-4} \\
v\left(p_{\text {Disagree }}\right) & =3.62 \times 10^{-4} \\
v\left(p_{\text {Strongly Disgree }}\right) & =4.07 \times 10^{-5} .
\end{aligned}
$$

Again using the "Neutral" response as an example and taking the normal approximation, the limits on the confidence interval centered on $p_{\text {Neutral }}$ are 


$$
p_{\text {Neutral }} \pm\left(\frac{1}{2 n_{3}}+t \sqrt{1-f_{3}} \sqrt{\frac{p_{\text {Neutral }} q_{\text {Neutral }}}{n_{3}-1}}\right)
$$

where we choose $t$ based on the desired size of the confidence interval. For a $90 \%$ confidence interval, $t=1.64$. We multiply this constant by the sample standard deviation (i.e., the square root of the sample variance), and add a term as defined in Eq. (3.17) ${ }^{5}$ of which prevents the normal approximation from giving a confidence interval that is too small. Using this expression, the lower and upper $90 \%$ confidence limits are given in the following table.

\begin{tabular}{|l|l|l|l|}
\hline Category & $\begin{array}{l}\text { Estimated } \\
\text { Proportion }\end{array}$ & $\begin{array}{l}\text { Lower 90 \% } \\
\text { confidence limit }\end{array}$ & $\begin{array}{l}\text { Upper 90 \%onfidence limit } \\
\text { confer }\end{array}$ \\
\hline Strongly Agree & 0.109 & 0.076 & 0.142 \\
\hline Agree & 0.539 & 0.489 & 0.590 \\
\hline Neutral & 0.218 & 0.176 & 0.261 \\
\hline Disagree & 0.121 & 0.087 & 0.155 \\
\hline Strongly Disagree & 0.012 & -0.001 (set to 0) & 0.026 \\
\hline
\end{tabular}

\section{Figure 6 analysis}

Table 1: Statistics for Figure 3

Fig. 6 shows the percentage of respondents who identified various NIST leadership core competencies as most important for their effectiveness in working with both other managers and with the people who report directly to the respondents themselves. In this case, we could not determine the number of people who responded to the question, so we set the number to 150 so as not to underestimate the size of the confidence intervals. We get values shown in the following table:

\begin{tabular}{|c||c|c|c||c|c|c|}
\hline $\begin{array}{c}\text { NIST Leadership Core } \\
\text { Competencies }\end{array}$ & $\begin{array}{c}\text { Percentage } \\
\text { (Other } \\
\text { Managers) }\end{array}$ & $\begin{array}{c}\mathbf{9 0 \%} \\
\text { conf } \\
\text { lower } \\
\text { bound }\end{array}$ & $\begin{array}{c}\mathbf{9 0 \%} \\
\text { conf } \\
\text { upper } \\
\text { bound }\end{array}$ & $\begin{array}{c}\text { Percentage } \\
\text { (Direct } \\
\text { Reports) }\end{array}$ & $\begin{array}{c}\mathbf{9 0 \%} \\
\text { conf } \\
\text { lower } \\
\text { bound }\end{array}$ & $\begin{array}{c}\mathbf{9 0 \%} \\
\text { conf } \\
\text { upper } \\
\text { bound }\end{array}$ \\
\hline \hline Communication & 87.7 & 84.0 & 91.4 & 94.2 & 91.4 & 97.0 \\
\hline Conflict Management & 54.3 & 48.8 & 59.8 & 72.3 & 67.3 & 77.3 \\
\hline Delegation/Empowerment & 21.2 & 16.6 & 25.8 & 84.7 & 80.6 & 88.8 \\
\hline Flexibility/Adaptability & 73.3 & 68.4 & 78.2 & 57.8 & 52.3 & 63.3 \\
\hline Integrity/Honesty & 79.6 & 75.1 & 84.1 & 91.8 & 88.6 & 95.0 \\
\hline Leading Change & 62.5 & 57.1 & 67.9 & 71.6 & 66.6 & 76.6 \\
\hline Motivating Others & 26.1 & 21.2 & 31.0 & 90.2 & 86.8 & 93.6 \\
\hline Organizational Skills & 52.6 & 47.1 & 58.1 & 74.4 & 69.5 & 79.3 \\
\hline Problem Solving & 66.7 & 61.5 & 71.9 & 67.7 & 62.5 & 72.9 \\
\hline Service Motivation & 45.5 & 40.0 & 51.0 & 75.8 & 71.0 & 80.6 \\
\hline Strategic & 87.8 & 84.1 & 91.5 & 48.8 & 43.3 & 54.3 \\
\hline Development/Thinking & & & & & \\
\hline
\end{tabular}

Table 2: Statistics for Figure 6

${ }^{5}$ Cochran, William G., Sampling Techniques (second edition), New York: John Wiley \& Sons, 1963. 


\section{Figure 7 analysis}

Fig. 7 reports the percentages of respondents who indicated their interest in developing various leadership or management skills. Since these are expressed as percentages, we can use the previously described techniques to find the $90 \%$ confidence intervals. Since the number of respondents was not given in the Excel sheets, we used a simple routine in Matlab to multiply the set of percentages by candidate values for $n_{7}$ and identify which $n_{7}$ value resulted in a set of products that were all within the rounding error of 0.1 of being integers. In the figure below, we plot the number of products within the rounding error versus $n_{7}$. There is only one value of $n_{7}$ that "works," i.e., it gives 13 out of 13 products that are within the rounding error of integer values, and that is $n_{7}=$ 157.

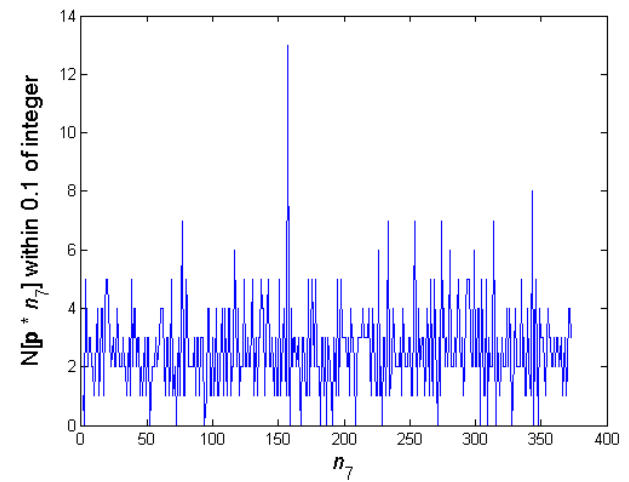

Figure 1: Plot of number of products of ratios and $n_{7}$ values that are within 0.1 of an integer

Proceeding with the analysis, we find that the number of people who selected the various skills, the ratio of question respondents who selected the skills, and the $90 \%$ confidence interval limits are as given in the following table:

\begin{tabular}{|c|c|c|c|c|}
\hline $\begin{array}{l}\text { Leadership/management } \\
\text { skills }\end{array}$ & $\begin{array}{l}\text { Number of } \\
\text { respondents }\end{array}$ & $\begin{array}{l}\text { Percentage of } \\
\text { respondents }\end{array}$ & $\begin{array}{l}\text { Lower bound } \\
\text { for } 90 \% \text { conf } \\
\text { interval }\end{array}$ & $\begin{array}{l}\text { Upper bound } \\
\text { for } 90 \% \text { conf } \\
\text { interval }\end{array}$ \\
\hline Building Relationships & 31 & 19.7 & 15.4 & 24.0 \\
\hline Change Management & 53 & 33.8 & 28.8 & 38.8 \\
\hline Coaching/Mentoring & 43 & 27.4 & 22.6 & 32.2 \\
\hline Communication & 52 & 33.1 & 28.1 & 38.1 \\
\hline Conflict Management & 55 & 35.0 & 29.9 & 40.1 \\
\hline $\begin{array}{l}\text { Creating a Safe/Free-free } \\
\text { Environment }\end{array}$ & 8 & 5.10 & 2.58 & 7.62 \\
\hline Decision Making & 29 & 18.5 & 14.3 & 22.7 \\
\hline Delegation/Empowerment & 41 & 26.1 & 21.4 & 30.8 \\
\hline $\begin{array}{l}\text { Managing Diverse Groups of } \\
\text { People }\end{array}$ & 23 & 14.6 & 10.8 & 18.4 \\
\hline Program Management & 39 & 24.8 & 20.2 & 29.4 \\
\hline $\begin{array}{l}\text { Strategic } \\
\text { Planning/Development } \\
\text { Thinking }\end{array}$ & 66 & 42.0 & 36.7 & 47.3 \\
\hline Teambuilding & 49 & 31.2 & 26.3 & 36.1 \\
\hline Time Management & 50 & 31.8 & 26.8 & 36.8 \\
\hline
\end{tabular}

Table III: Statistics for Figure 7 
Using a similar analysis, we get the $90 \%$ confidence intervals associated with Fig. 9 . The number of respondents for this question was $n_{9}=165$ again. The estimated percentages and confidence interval bounds are in the following table:

\begin{tabular}{|l|r|r|r|r|}
\hline Training Types & \multicolumn{1}{|l|}{$\begin{array}{l}\text { Preference } \\
\text { ratio }\end{array}$} & $\begin{array}{l}\text { Sample } \\
\text { Variance }\end{array}$ & $\begin{array}{l}\text { Lower } \\
\text { Bound }\end{array}$ & $\begin{array}{l}\text { Upper } \\
\text { Bound }\end{array}$ \\
\hline Classroom (Accredited Institute) & 0.436 & $8.361 \mathrm{E}-04$ & 0.386 & 0.486 \\
\hline Coaching/Mentoring (Internal/External) & 0.364 & $7.872 \mathrm{E}-04$ & 0.315 & 0.413 \\
\hline $\begin{array}{l}\text { External Training (Conferences, Industry } \\
\text { Visits, Academic) }\end{array}$ & 0.424 & $8.304 \mathrm{E}-04$ & 0.374 & 0.474 \\
\hline $\begin{array}{l}\text { In-House Training (NIST- } \\
\text { Sponsored/Organized) }\end{array}$ & & & & \\
\hline On-Site Workshops/Sessions & 0.618 & $8.027 \mathrm{E}-04$ & 0.569 & 0.667 \\
\hline On-the-Job/Acting Positions & 0.352 & $7.756 \mathrm{E}-04$ & 0.303 & 0.401 \\
\hline Peer Groups (Discussions, Task Groups) & 0.158 & $4.524 \mathrm{E}-04$ & 0.120 & 0.196 \\
\hline Rotational/Detail Assignments & 0.261 & $6.558 \mathrm{E}-04$ & 0.216 & 0.306 \\
\hline Self-Study (Books, Web, PodCasts, CLC) & 0.170 & $4.798 \mathrm{E}-04$ & 0.131 & 0.209 \\
\hline Seminars/Lectures (Internal/External) & 0.382 & $8.027 \mathrm{E}-04$ & 0.333 & 0.431 \\
\hline
\end{tabular}

Table IV: Statistics for Figure 9 


\section{Figure 11 analysis}

For Fig. 11, the results are reported in terms of the number of people who indicated that they were interested in receiving training on a particular NIST function, out of a menu of options. The easiest way to find the confidence intervals for this data is to convert the response counts to ratios by dividing by the number of respondents, $n_{10}=165$, performing the analysis that we demonstrated for the preceding figures, and then multiplying the resulting bounds by $n_{10}$. If we do this, we get the results in the following table.

\begin{tabular}{|c|c|c|c|}
\hline NIST Function & $\begin{array}{l}\text { Number of } \\
\text { Respondents }\end{array}$ & $\begin{array}{l}90 \% \text { Confidence } \\
\text { Lower Bound }\end{array}$ & $\begin{array}{l}90 \% \text { Confidence } \\
\text { Upper Bound }\end{array}$ \\
\hline Acquisitions/Contracts & 63 & 54.8 & 71.2 \\
\hline Baldrige Program (BNQP) & 13 & 8.25 & 17.7 \\
\hline Employee Relations/Resources & 55 & 47.1 & 62.9 \\
\hline Facilities & 21 & 15.2 & 26.8 \\
\hline Finance/Budget & 57 & 49.0 & 65.0 \\
\hline Grants/Agreements & 40 & 32.7 & 47.3 \\
\hline Honorary and NIST Awards & 12 & 7.40 & 16.6 \\
\hline IT Security/Services & 15 & 9.96 & 20.0 \\
\hline $\begin{array}{l}\text { Manufacturing Extension } \\
\text { Partnership (MEP) }\end{array}$ & 10 & 5.73 & 14.27 \\
\hline NIST Associates Program & 14 & 9.10 & 18.90 \\
\hline NIST's History and Mission & 27 & 20.7 & 33.3 \\
\hline $\begin{array}{l}\text { NIST Role in the Political } \\
\text { Environment }\end{array}$ & 60 & 51.9 & 68.1 \\
\hline $\begin{array}{l}\text { NIST User Facilities (CNST, } \\
\text { NCNR) }\end{array}$ & 9 & 4.92 & 13.1 \\
\hline Promotions & 24 & 17.9 & 30.1 \\
\hline $\begin{array}{l}\text { Public Affairs and Media } \\
\text { Relations }\end{array}$ & 30 & 23.4 & 36.6 \\
\hline $\begin{array}{l}\text { Safety, Health, and } \\
\text { Environment }\end{array}$ & 27 & 20.7 & 33.3 \\
\hline Standards Services & 24 & 17.9 & 30.1 \\
\hline $\begin{array}{l}\text { Technical Operating } \\
\text { Units/Laboratories }\end{array}$ & 30 & 23.4 & 36.6 \\
\hline Technology Partnerships & 26 & 19.7 & 32.3 \\
\hline $\begin{array}{l}\text { Technology Innovation } \\
\text { Program (TIP) }\end{array}$ & 9 & 4.92 & 13.1 \\
\hline Travel & 9 & 4.92 & 13.1 \\
\hline Workforce Management & 59 & 50.9 & 67.1 \\
\hline
\end{tabular}

\section{Table V: Statistics for Figure 11}

An interesting application of these results is that we can multiply the ratio-based estimates and confidence bounds by $N$ and round to the nearest integer, giving us an idea of the total number of NIST managers who may be interested in each of the listed topics. The results appear in the following table. Note that these intervals are not symmetric about the central estimates due to rounding. 


\begin{tabular}{|l|c|c|c|}
\hline NIST Function & Lower Bound & Estimated Number & Upper Bound \\
\hline Acquisitions/Contracts & 124 & 142 & 161 \\
\hline Baldrige Program (BNQP) & 19 & 29 & 40 \\
\hline Employee Relations/Resources & 106 & 124 & 142 \\
\hline Facilities & 34 & 47 & 60 \\
\hline Finance/Budget & 111 & 129 & 147 \\
\hline Grants/Agreements & 74 & 90 & 107 \\
\hline Honorary and NIST Awards & 17 & 27 & 38 \\
\hline IT Security/Services & 23 & 34 & 45 \\
\hline Manufacturing Extension Partnership (MEP) & 13 & 23 & 32 \\
\hline NIST Associates Program & 21 & 32 & 43 \\
\hline NIST's History and Mission & 47 & 61 & 75 \\
\hline NIST Role in the Political Environment & 117 & 136 & 154 \\
\hline NIST User Facilities (CNST, NCNR) & 11 & 20 & 30 \\
\hline Promotions & 41 & 54 & 68 \\
\hline Public Affairs and Media Relations & 53 & 68 & 83 \\
\hline Safety, Health, and Environment & 47 & 61 & 75 \\
\hline Standards Services & 41 & 54 & 68 \\
\hline Technical Operating Units/Laboratories & 53 & 68 & 83 \\
\hline Technology Partnerships & 45 & 59 & 73 \\
\hline Technology Innovation Program (TIP) & 11 & 20 & 30 \\
\hline Travel & 11 & 20 & 30 \\
\hline Workforce Management & 115 & 133 & 152 \\
\hline
\end{tabular}

Table VI: Ranges for the Total Number of Managers Interested in Learning About NIST Functions

We can see that, for example, addressing the need for information on Travel could likely be met by holding a class that would accommodate about 10 to 30 people. As another example, the number of people who are interested in learning about Acquisitions and Contracts is high enough (likely in the neighborhood of 150) that a single class in a lecture room will not suffice; one would need a series of small classes, a session in a large meeting space, or alternative learning venues such as on-line training. 


\section{Appendix J: Survey of Leadership and Managerial Development Skills at NIST (1998)}

This appendix contains a digitized copy of the 1998 report "Survey of Leadership and Managerial Development Skills at NIST" and as such the page numbering that follows is that of the original report. 



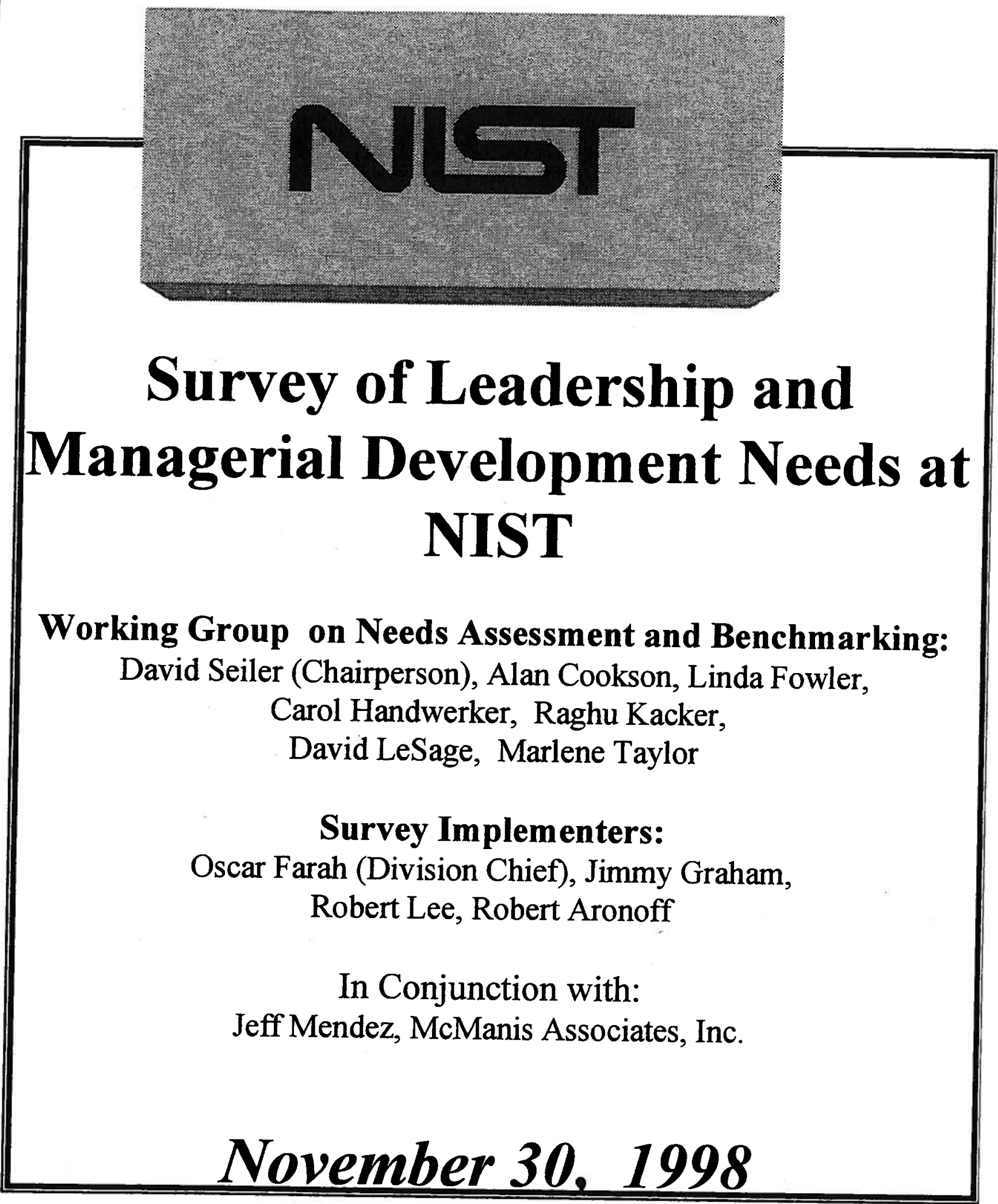




\section{Table of Contents}

\section{EXECUTIVE SUMMARY}

\section{BACKGROUND}

The Respondents

Techniques Used

RESULTS AND FINDINGS

SKILL DEVELOPMENT

Table 1: Senior Management

Table 2: Middle Management

Table 3: Non-management

Chart 1: $\quad$ Skills Identified as Average or Above Average Importance

Chart 2: $\quad$ Skills Identified as Average or Below Average Capabilities

Chart 3:

Chart 4:

Skills Identified as Average or Above Average Desire to Improve

Chart 5:

Senior Management Gap Analysis: Skills Identified for Training

Chart 6: Middle Management Gap Analysis: Skills Identified for Training

LEARNING OPTIONS

Chart 7: Senior Management Who Selected Strongly or Definitely Interested

Chart 8: Middle Management Who Selected Definitely or Strongly Interested

Chart 9: Non-management staff Who Selected Definitely or Strongly Interested

Chart 10:

Learning Options Preferred by all three Groups

\section{OBSERVATIONS AND RECOMMENDATIONS BY MCMANIS ASSOCIATES}

OBSERVATIONS

Developing Leadership Skills

Developing Technical Abilities

RECOMMENDATIONS

APPENDIX A: SURVEY

APPENDIX B: LEARNING OPTIONS

B12

APPENDIX C: UNABRIDGED COMMENTS C31

C1- 


\section{EXECUTIVE SUMMARY}

The Director of NIST has appointed a task group charged to identify and make available an evolving system of leadership and management development and training options suitable for the NIST culture and research environment. To this end, a sub-committee of the task group surveyed about 1,000 employees including senior managers (Division Chiefs and higher), middle managers (Supervisors, Group Leaders, and other Managers), and non-management staff. The results presented here are based on 412 respondents.

The survey provided a list of nineteen skills and asked the survey participants to rate the importance of the skill, their present capability and their degree of motivation to improve the skill. The participants were also asked to rate their interest in ten learning approaches. In addition, the participants were given opportunity to provide written comments.

The written comments express diverse views, but there is consensus on one theme. The theme is that NIST has a critical need for training its managers and non-managers in interpersonal skills, behaviors, and knowledge which make outstanding leaders and managers.

The following skills were rated as highly or vitally important on the average by all three groups (senior managers, middle managers, and non-management staff). The lists of skills provided below are in no particular order:

- Strategic Planning

- Delegating

- Oral Communication

- Written Communication
- Decision Making

- Empowering and Motivating

- Managing Financial Resources

All three groups of respondents (senior managers, middle managers, and nonmanagement staff) rated their current capabilities as low on the average in the following areas:

- Conflict Resolution

- Empowering and Motivating

- Team Building

- Managing Change
- Coaching/Counseling

- Planning for Performance Appraisals

- Dealing with Poor Performers

- Marketing and Promotion

The respondents are well motivated on the average to improve the following skills:

- Strategic Planning

- Delegating

- Oral Communication

- Decision Making

$\bullet$
- Conflict Resolution

- Empowering and Motivating

- Organizational Skills

- Time Management

- Dealing with Poor Performers 
The results above indicate that managers and non-managers alike want to improve their skills in areas that are most important to their jobs, even if they believe that, on the average, their performance in these areas is already good.

Further analyses of the skills specifically for each of the three groups (senior managers, middle managers, and non-managers) are discussed in the report. All groups identified the skill "Empowering and Motivating" as a critical-needs area for training.

The respondents in written comments indicated interest in the following skills that were not included in the survey:

- Customer Service

- Negotiation Training

- Assertiveness

- Listening Skills

- Stress Management

- Diversity Training

- Presentation/Speaking Skills
- Computer Skills/Electronic Communication.

- Priority Setting

- Cost and Time Efficiency

- Across Lab and Interdisciplinary Team Work

All groups expressed definite or strong interest in the following four learning approaches:

- Training developed for (or by) private firms

- Training offered by consultants

- Industry visits

- Leadership and management lecture series

In addition, the non-management staff expressed a strong interest in informal mentoring and coaching.

The results of this survey on leadership and management development will be used to help set priorities for the training opportunities and learning options offered to the NIST staff. Senior managers of NIST should participate in the development and delivery of management and leadership training materials and also mentor and coach the next generation of supervisors and managers. 
Also, the managers/supervisors indicated their years of service in that capacity. The following is a summary of the total managers/supervisor respondents by years of service:

\begin{tabular}{|l|c|}
\hline \multicolumn{1}{|c|}{ Years of Service } & Number of People \\
\hline Less than 5 & 106 \\
\hline $6-10$ & 44 \\
\hline $11-20$ & 72 \\
\hline Over 20 & 26 \\
\hline Total & $\mathbf{2 4 8}$ \\
\hline
\end{tabular}

For the purpose of analysis, the respondents were partitioned into three groups: senior managers, middle managers, and non-management staff.

\section{TECHNIQUES UsED}

The survey, developed by the survey team, contained two major sections. The first section measured the interest of the employees in various learning options. The following ten methods were identified:

- Self Study

- Web Based Training

Formal training programs developed and carried out by other organizations

- Developed for Government Agencies

- Developed for Private Firms

- Offered by Universities, Consultants and Private Firms

Programs developed and carried out by NIST.

- Rotational Assignments

- Industry Visits

- Noon Luncheon Discussions

- Management/Leadership Lecture Series

- Informal Mentoring/Coaching

The respondents rated the learning options on a five-answer interest scale which included: No Interest, Mildly Interested, Interested, Strongly Interested and Would Definitely Participate (see Appendix A). 
The second section of the survey identified the skills which NIST employees felt were most important for their jobs, their capabilities in the particular skill, and their motivation level to improve the skill. The 19 identified skills were:

- Strategic Planning

- Delegating

- Oral Communication

- Written Communication

- Running and Participating In Meetings

- Managing Diverse Groups

- Decision Making

- Conflict Resolution

- Empowering and Motivating

- Team Building
- Managing Change

- Organizational Skills

- Time Management Skills

- Project Management Skills

- Coaching and Counseling

- Planning for Performance Appraisals

- Managing Financial Resources

- Dealing with Poor Performers

- Marketing and Promotion

Respondents rated each skill against three categories: importance - from not important to vitally important; capability - from poor to excellent, and desire to improve the skill - from definitely not interested to definitely yes. Again, a five-answer interest scale was provided for each.

\section{Identification of Common Skills Set}

The mean score for each skill was determined by a value assigned to the five-answer interest scale. Those values were one through five, with five representing the most favorable response option and one representing the least favorable response option. For example, if a respondent rated the skill "Team Building" as "Not Important," the importance category for that skill received a value of one. The mean score for a skill is the average value of all 412 responses. The skills were then ranked according to their mean score. The overall average of the mean score of all the skills was used as a benchmark. For the categories importance and desire to improve the skill, the skills with mean score at or above the overall average were isolated on a three-circle Venn diagram. (A Venn diagram is a graph that employs circles to represent logical relations by the inclusion, exclusion, and intersection of circles.) For the category capability, the skills with mean scores at or below the overall average were isolated. The intersection of the three circles identifies the skills that are common to all three groups. 


\section{Gap Analysis of Skill Sets}

Gap analysis means identifying the skills that correspond to the following three criteria: highly important, low current capability, and highly desired to improve. A gap analysis of skill sets was done separately for each of the three groups: senior mangers, middle managers, and nonmanagement staff. For each of the three groups, the skills were isolated on a three-circle Venn diagram according to the following three criteria: (1) skills with a mean score which fell on or above the overall average in importance, (2) skills with a mean score which fell on or below the overall average in capability, and (3) skills with a mean score which fell on or above the overall average in desire to improve. The gap analysis identified the skills which employees rated vitally important, not highly capable, and definitely motivated to improve. Such skills are depicted as the intersection of all three circles in Charts 4, 5, and 6 in the following pages. 


\section{DATA RESULTS AND FINDINGS}

\section{SKILL DEVELOPMENT}

The following tables provide the mean score for each skill from the survey ordered alphabetically by letter identifier. Two types of skill development emerged: predominant and emergent. The predominant skills are the ones that match all three criteria: average or above average importance and desire to improve and average or below average capability. These skills are also referred to as the "critical-needs" areas for improvement and training. The second emerged as an associated category. That is, those skills that were rated as highly important with either a high desire to improve or a low current capability.

Other skills that were not included in the survey, but were identified by the respondents in their comments ${ }^{1}$ are as follows:

- Customer Service

- Negotiation Training

- Assertiveness

- Listening Skills

- Stress Management

- Diversity Training

- Presentation/Speaking Skills

- Computer Skills/Electronic Communication.

- Priority Setting

- Cost and Time Efficiency

- Across Lab and Interdisciplinary Team Work

These data results and findings were consistent with the written comments provided by the respondents.

The tables of mean scores for each skill and the Venn diagrams displayed in the following pages summarize the survey results.

${ }^{1}$ A detailed summary of all the comments is located in Appendix $\mathbf{C}$ of this report. 
Table 1: $\quad$ Senior Management

\begin{tabular}{|l|l|c|c|c|}
\hline Letter & \multicolumn{1}{|c|}{ Skill } & Importance & Capability & Improve \\
\hline $\mathrm{A}$ & Strategic Planning & 4.5 & 3.7 & 3.8 \\
\hline $\mathrm{B}$ & Delegating & 4.2 & 3.5 & 3.4 \\
\hline $\mathrm{C}$ & Oral Communication & 4.6 & 3.8 & 3.5 \\
\hline $\mathrm{D}$ & Written Communication & 4.4 & 4.2 & 3.0 \\
\hline $\mathrm{E}$ & Running/Participating Meetings & 3.9 & 3.7 & 3.2 \\
\hline $\mathrm{F}$ & Managing Diverse Groups & 4.0 & 3.8 & 3.4 \\
\hline $\mathbf{G}$ & Decision Making & 4.5 & 3.8 & 3.3 \\
\hline $\mathbf{H}$ & Conflict Resolution & 3.8 & 3.3 & 3.6 \\
\hline $\mathrm{I}$ & Empowering and Motivating & 4.2 & 3.6 & 3.6 \\
\hline $\mathrm{J}$ & Team Building & 3.9 & 3.4 & 3.4 \\
\hline $\mathrm{K}$ & Managing Change & 3.9 & 3.5 & 3.6 \\
\hline $\mathrm{L}$ & Organizational Skills & 3.9 & 3.5 & 3.3 \\
\hline $\mathbf{M}$ & Time Management & 3.7 & 3.3 & 3.3 \\
\hline $\mathrm{N}$ & Project Management & 3.4 & 3.6 & 2.6 \\
\hline $\mathbf{O}$ & Coaching/Counseling & 3.5 & 3.5 & 2.9 \\
\hline $\mathbf{P}$ & Planning for Performance Appraisal & 3.5 & 3.3 & 2.6 \\
\hline $\mathbf{Q}$ & Managing Financial Resources & 4.0 & 3.7 & 2.9 \\
\hline $\mathbf{R}$ & Dealing With Poor Performers & 3.9 & 3.2 & 3.5 \\
\hline $\mathbf{S}$ & Marketing and Promotion & 4.0 & 3.2 & 3.6 \\
\hline & Total Mean & 4.0 & 3.6 & 3.3 \\
\hline
\end{tabular}

Senior management's predominant series (average or above average importance and desire to improve and average or below average capability) is:

- Delegating

- Empowering and Motivating

- Marketing and Promotion

Senior management's emergent series (highly important with either a high desire to improve or a low current capability) is:

- Strategic Planning

- Oral Communication

- Managing Diverse Groups

- Decision Making 
Table 2: $\quad$ Middle Management

\begin{tabular}{|l|l|c|c|c|}
\hline Letter & \multicolumn{1}{|c|}{ Skill } & Importance & Capability & Improve \\
\hline A & Strategic Planning & 4.1 & 3.2 & 3.8 \\
\hline B & Delegating & 3.9 & 3.4 & 3.3 \\
\hline C & Oral Communication & 4.3 & 3.6 & 3.5 \\
\hline D & Written Communication & 4.1 & 3.6 & 3.2 \\
\hline E & Running/Participating Meetings & 3.5 & 3.4 & 3.1 \\
\hline F & Managing Diverse Groups & 3.8 & 3.4 & 3.2 \\
\hline G & Decision Making & 4.3 & 3.6 & 3.3 \\
\hline H & Conflict Resolution & 3.7 & 3.1 & 3.5 \\
\hline I & Empowering and Motivating & 3.9 & 3.2 & 3.5 \\
\hline J & Team Building & 3.7 & 3.2 & 3.3 \\
\hline K & Managing Change & 3.7 & 3.3 & 3.4 \\
\hline L & Organizational Skills & 3.8 & 3.4 & 3.3 \\
\hline M & Time Management & 3.9 & 3.2 & 3.3 \\
\hline N & Project Management & 3.8 & 3.5 & 3.2 \\
\hline $\mathbf{O}$ & Coaching/Counseling & 3.3 & 3.3 & 3.1 \\
\hline P & Planning for Performance Appraisal & 3.4 & 3.2 & 3.2 \\
\hline $\mathbf{Q}$ & Managing Financial Resources & 3.8 & 3.5 & 3.1 \\
\hline R & Dealing With Poor Performers & 3.6 & 2.8 & 3.7 \\
\hline S & Marketing and Promotion & 3.4 & 2.9 & 3.3 \\
\hline & Total Mean & 3.8 & 3.3 & 3.3 \\
\hline
\end{tabular}

Middle management's predominant series (average or above average importance and desire to improve and average or below average capability) is:

- Strategic Planning

- Empowering and Motivating

- Time Management

Middle management's emergent series (highly important with either a high desire to improve or a low current capability) is:

- Delegating

- Oral Communication

- Decision Making

- Organizational Skills 
Table 3: Non-management

\begin{tabular}{|l|l|c|c|c|}
\hline Letter & \multicolumn{1}{|c|}{ Skill } & Importance & Capability & Improve \\
\hline A & Strategic Planning & 4.1 & 2.9 & 3.9 \\
\hline B & Delegating & 3.8 & 2.9 & 3.8 \\
\hline C & Oral Communication & 4.6 & 3.5 & 3.9 \\
\hline D & Written Communication & 4.4 & 3.5 & 3.8 \\
\hline E & Running/Participating Meetings & 3.4 & 3.0 & 3.5 \\
\hline F & Managing Diverse Groups & 3.6 & 2.6 & 3.5 \\
\hline G & Decision Making & 4.3 & 3.4 & 3.7 \\
\hline H & Conflict Resolution & 3.8 & 2.8 & 3.8 \\
\hline I & Empowering and Motivating & 3.9 & 3.1 & 3.7 \\
\hline J & Team Building & 3.6 & 3.0 & 3.6 \\
\hline K & Managing Change & 3.6 & 3.1 & 3.5 \\
\hline L & Organizational Skills & 3.9 & 3.4 & 3.7 \\
\hline M & Time Management & 3.8 & 3.2 & 3.7 \\
\hline N & Project Management & 4.0 & 3.1 & 3.8 \\
\hline O & Coaching/Counseling & 3.2 & 3.1 & 3.3 \\
\hline P & Planning for Performance Appraisal & 3.5 & 2.8 & 3.5 \\
\hline $\mathbf{Q}$ & Managing Financial Resources & 3.9 & 3.1 & 3.7 \\
\hline R & Dealing With Poor Performers & 3.6 & 2.4 & 3.8 \\
\hline S & Marketing and Promotion & 3.5 & 2.8 & 3.5 \\
\hline & Total Mean & 3.8 & 3.1 & 3.7 \\
\hline
\end{tabular}

Non-management's predominant series (average or above average importance and desire to improve and average or below average capability) is:

- Strategic Planning

- Delegating

- Conflict Resolution
- Empowering and Motivating

- Project Management

- Managing Financial Resources Non-management's emergent series (highly important with either a high desire to improve or a
low current capability) is:

- Oral Communication

- Written Communication

- Decision Making

- Organizational Skills

- Time Management 


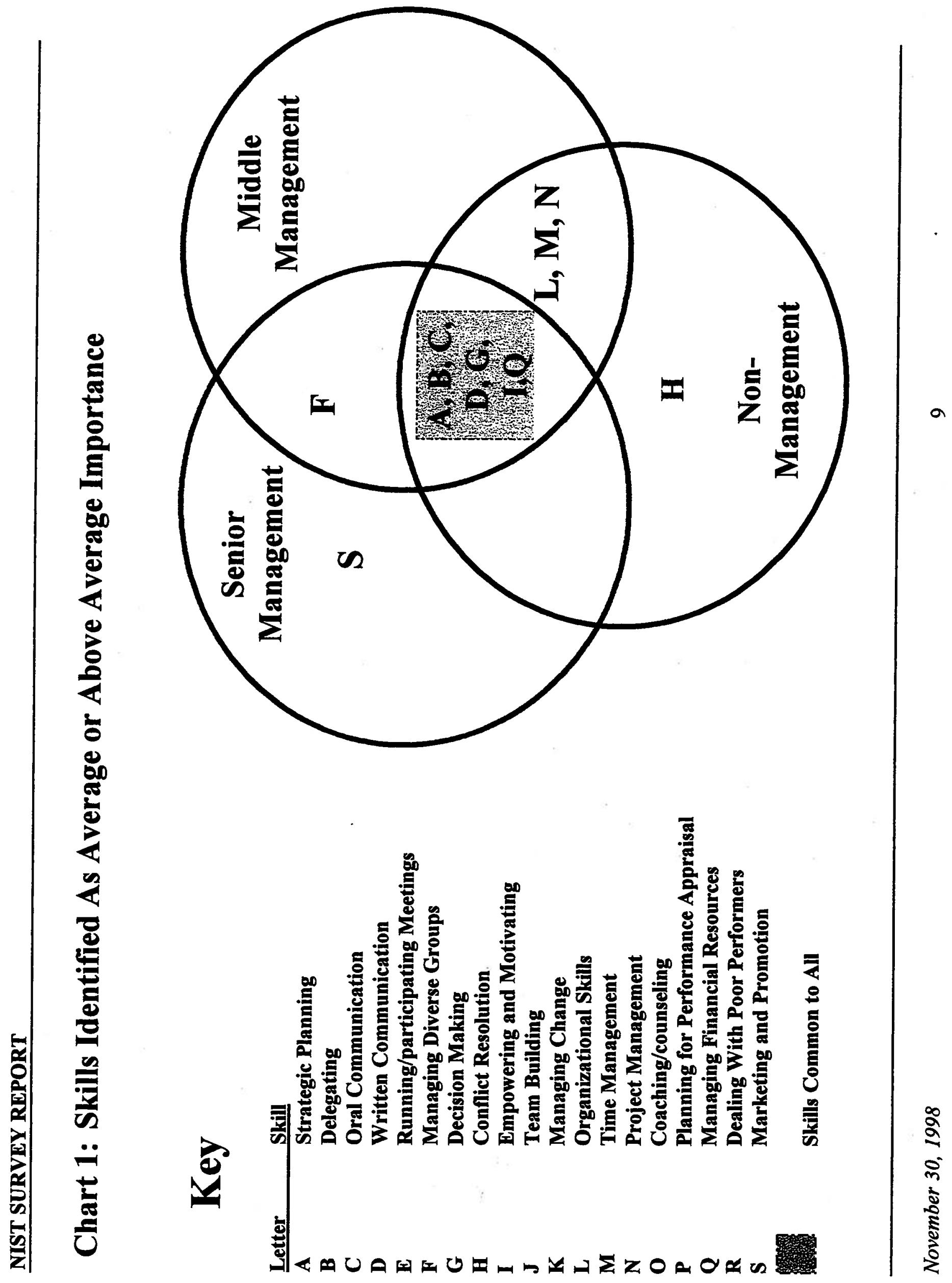




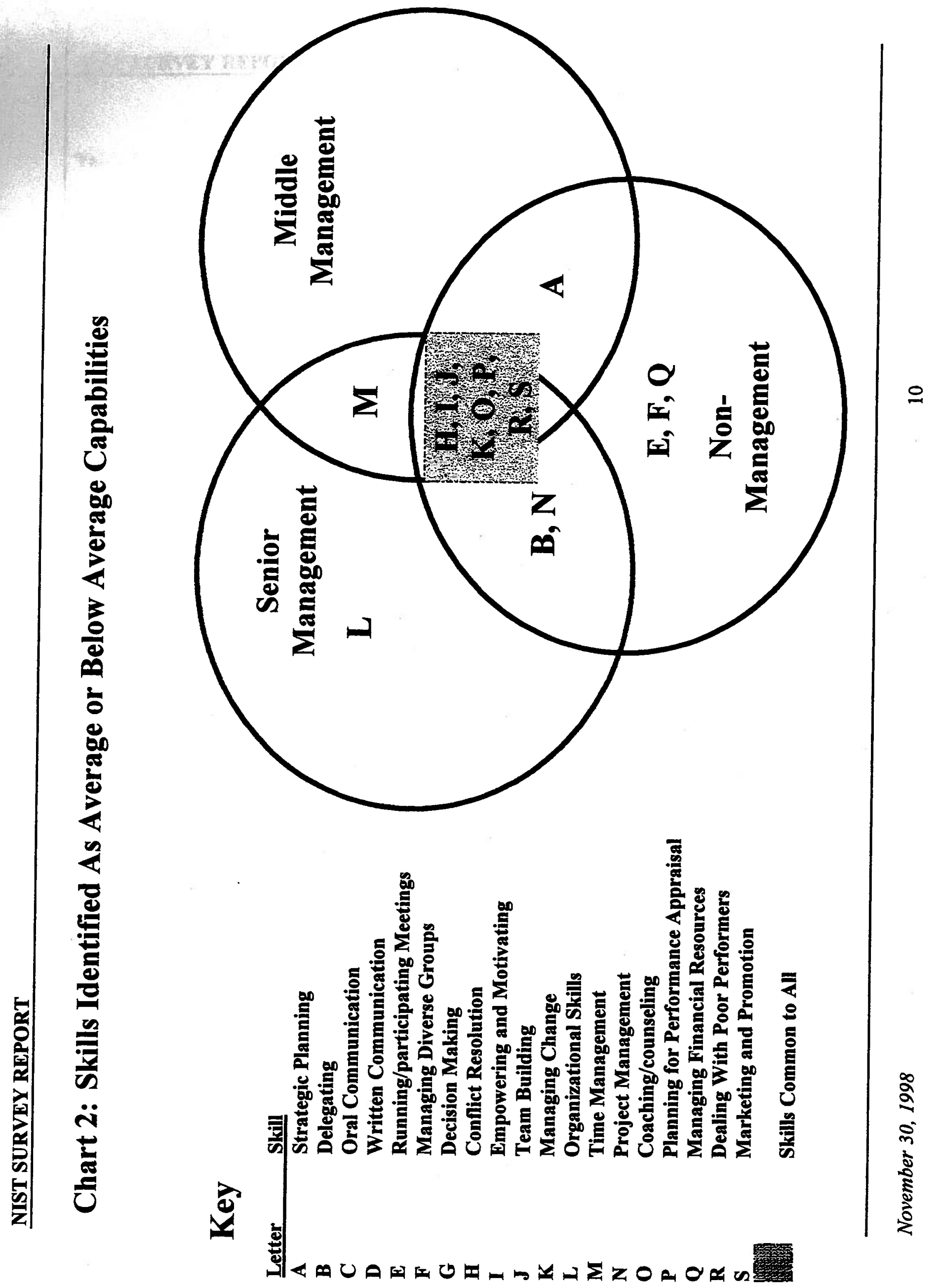




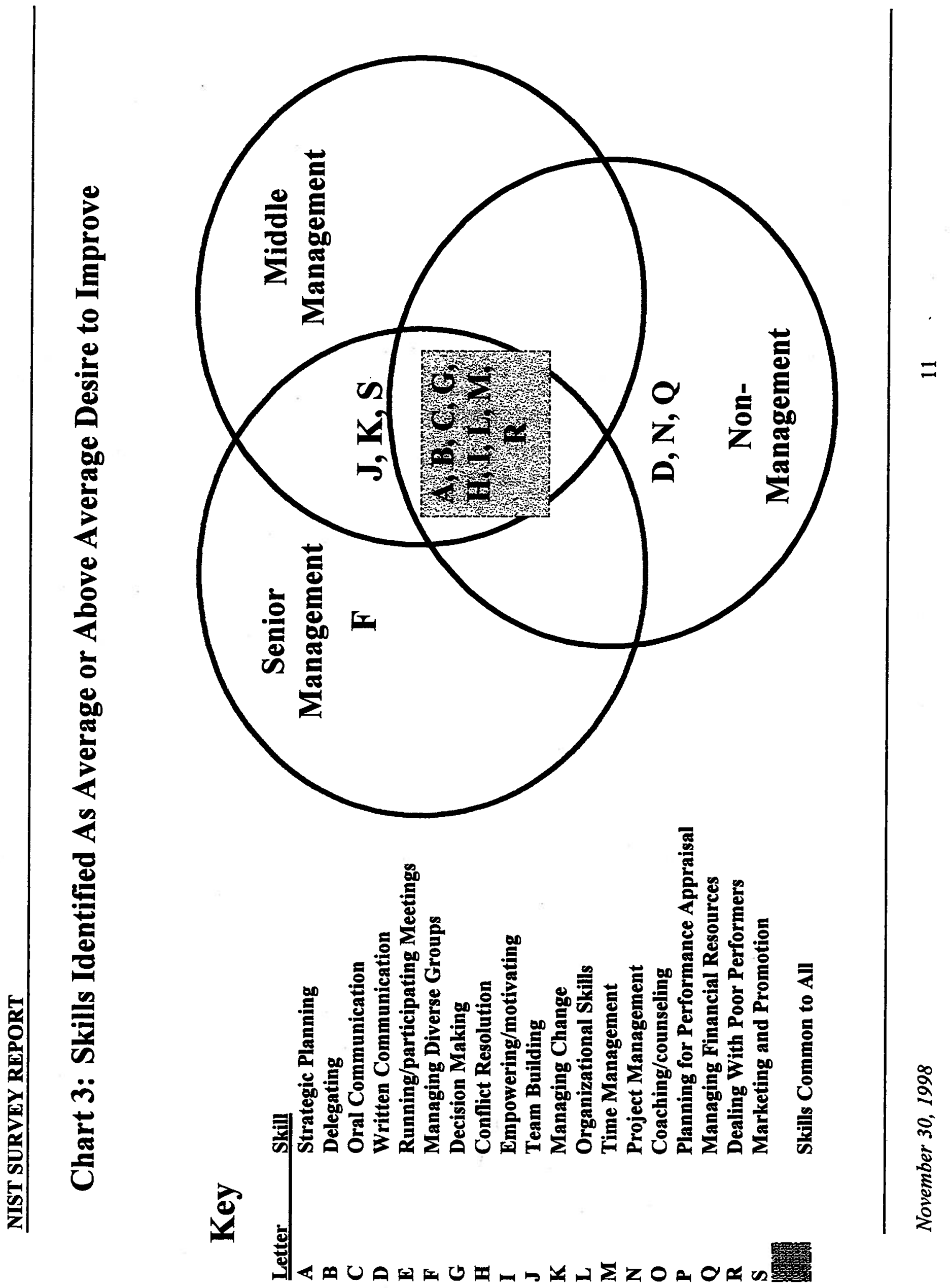




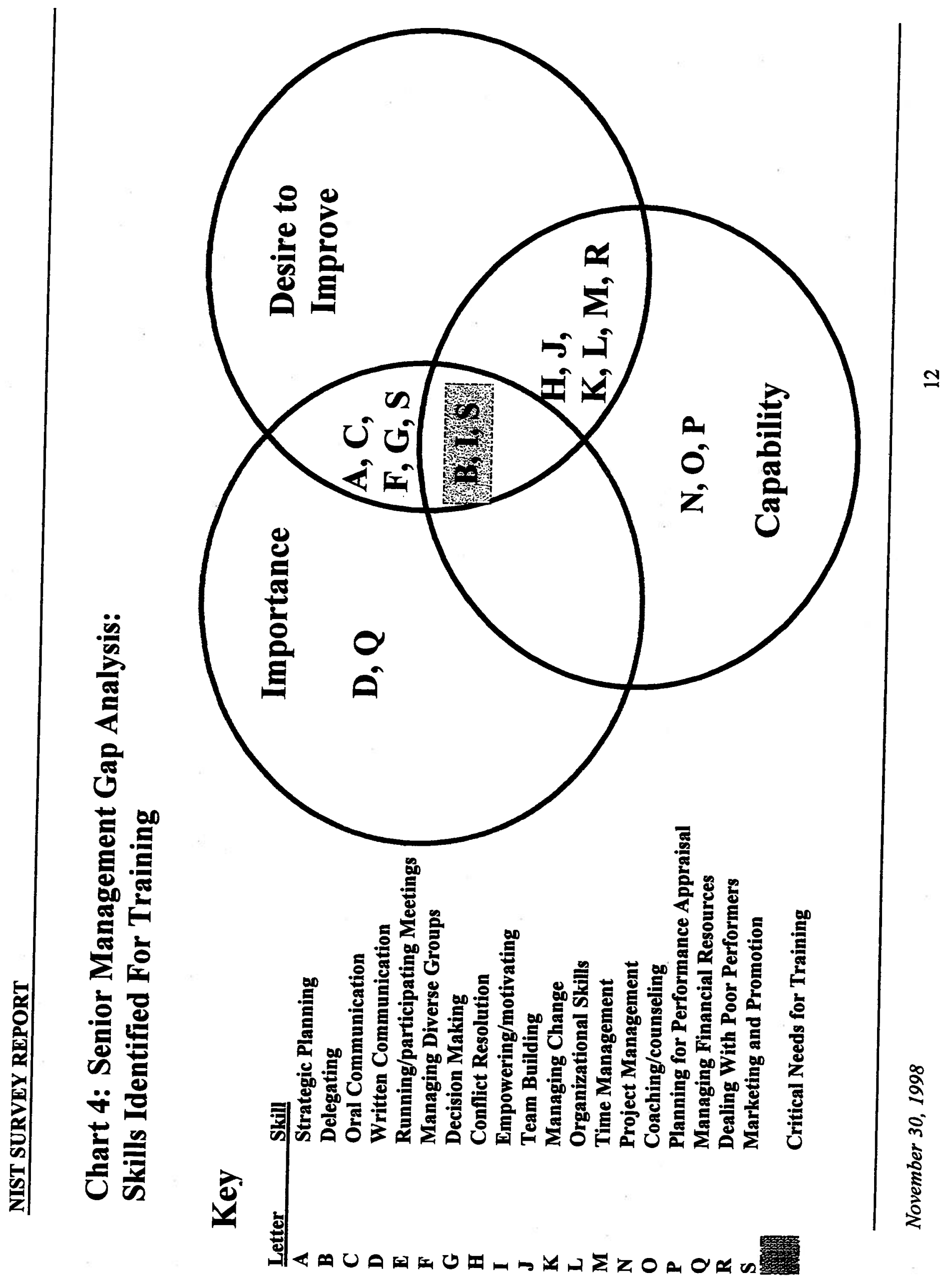



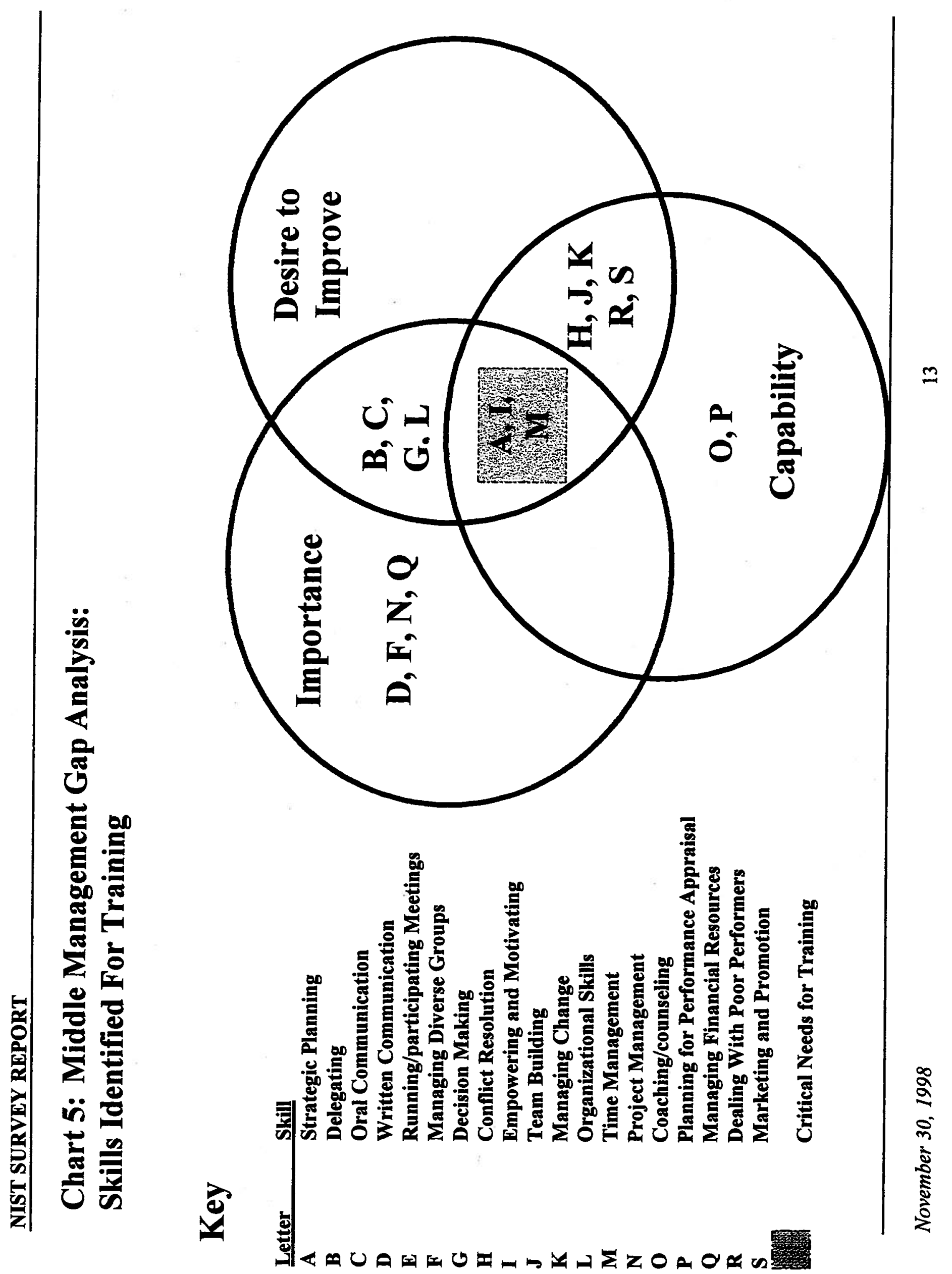


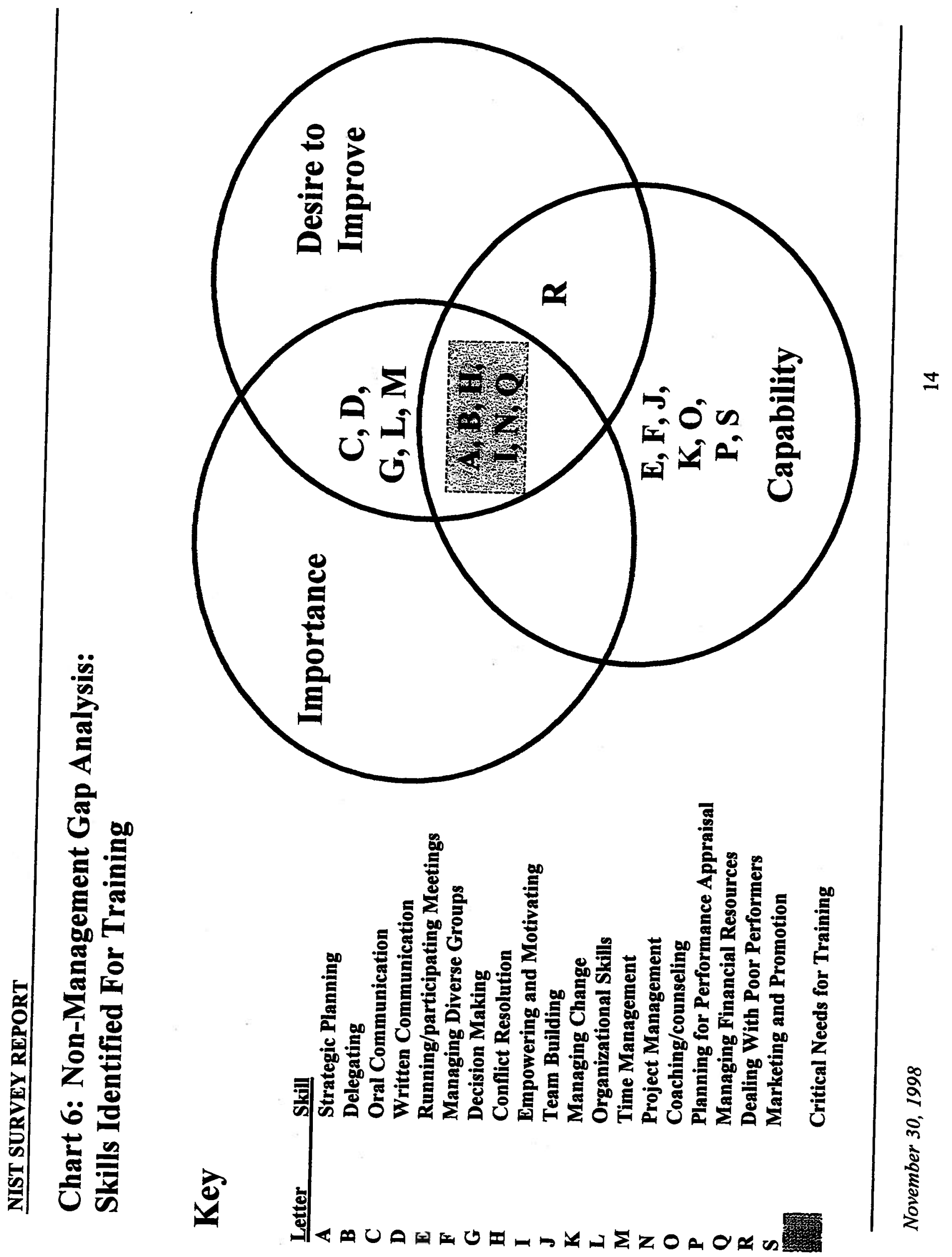




\section{NIST SURVEY REPORT}

\section{LEARNING OPTIONS}

The preferred learning options of the senior managers, middle managers, and non-management staff are shown in the following Charts 7,8 , and 9 respectively.

Chart 7 shows that the senior managers preferred the following five learning options.

- Training developed for private firms

- Training offered by consultants

- Industry Visits
- Luncheon discussions

- Management/Leadership lecture series

\section{Chart 7: Number of Senior Managers Who Selected Strongly or Definitely Interested} $(n=67)$

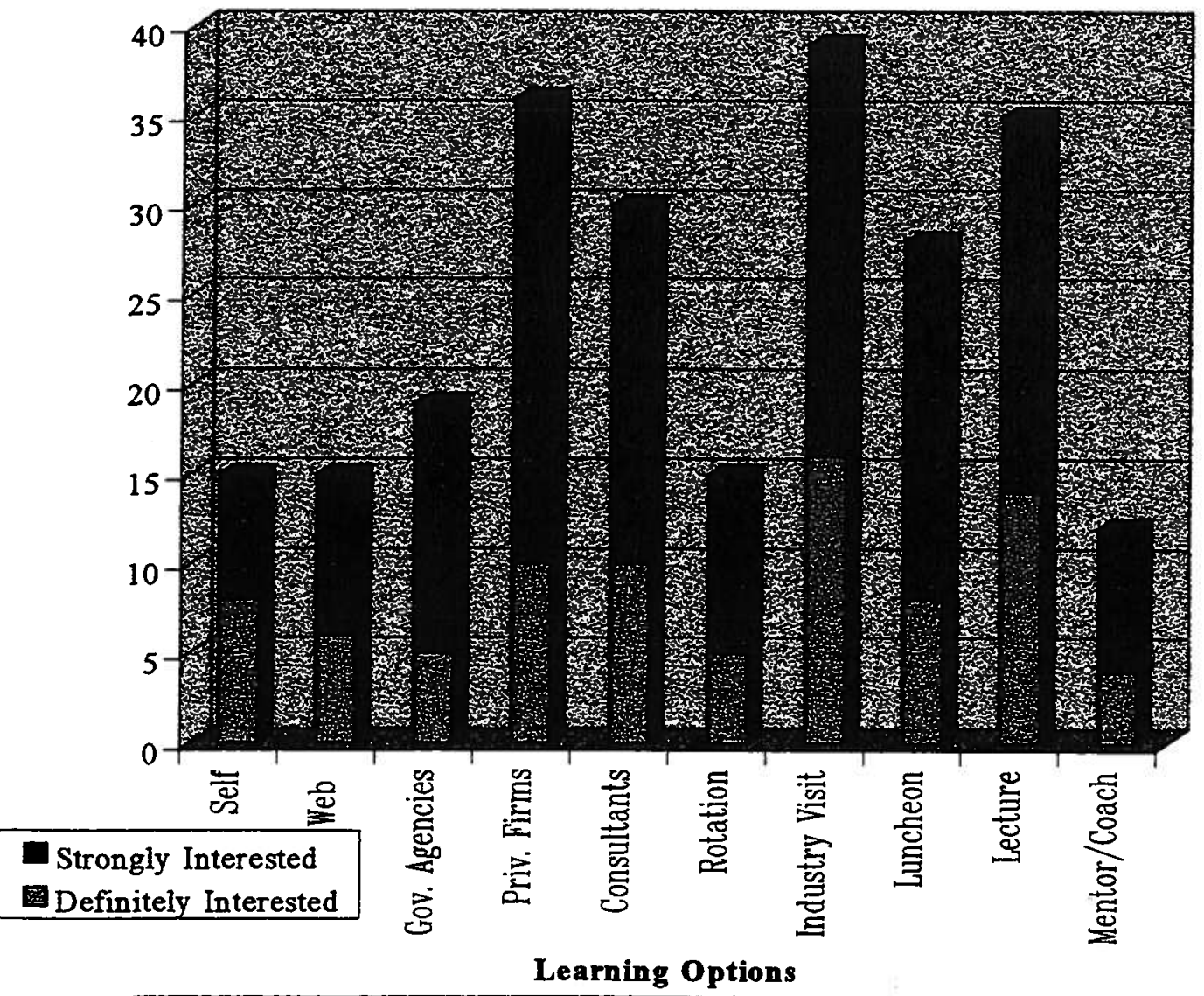

November 30, 1998 
Chart 8 shows that the middle managers preferred the following six learning options.

- Training developed for government agencies

- Training developed for private firms

- Training offered by consultants

- Rotational assignments

- Industry Visits

- Management/Leadership lecture series

Chart 8: Number of Middle Managers Who Selected Definitely or Strongly Interested $(\mathbf{n}=\mathbf{1 8 1})$

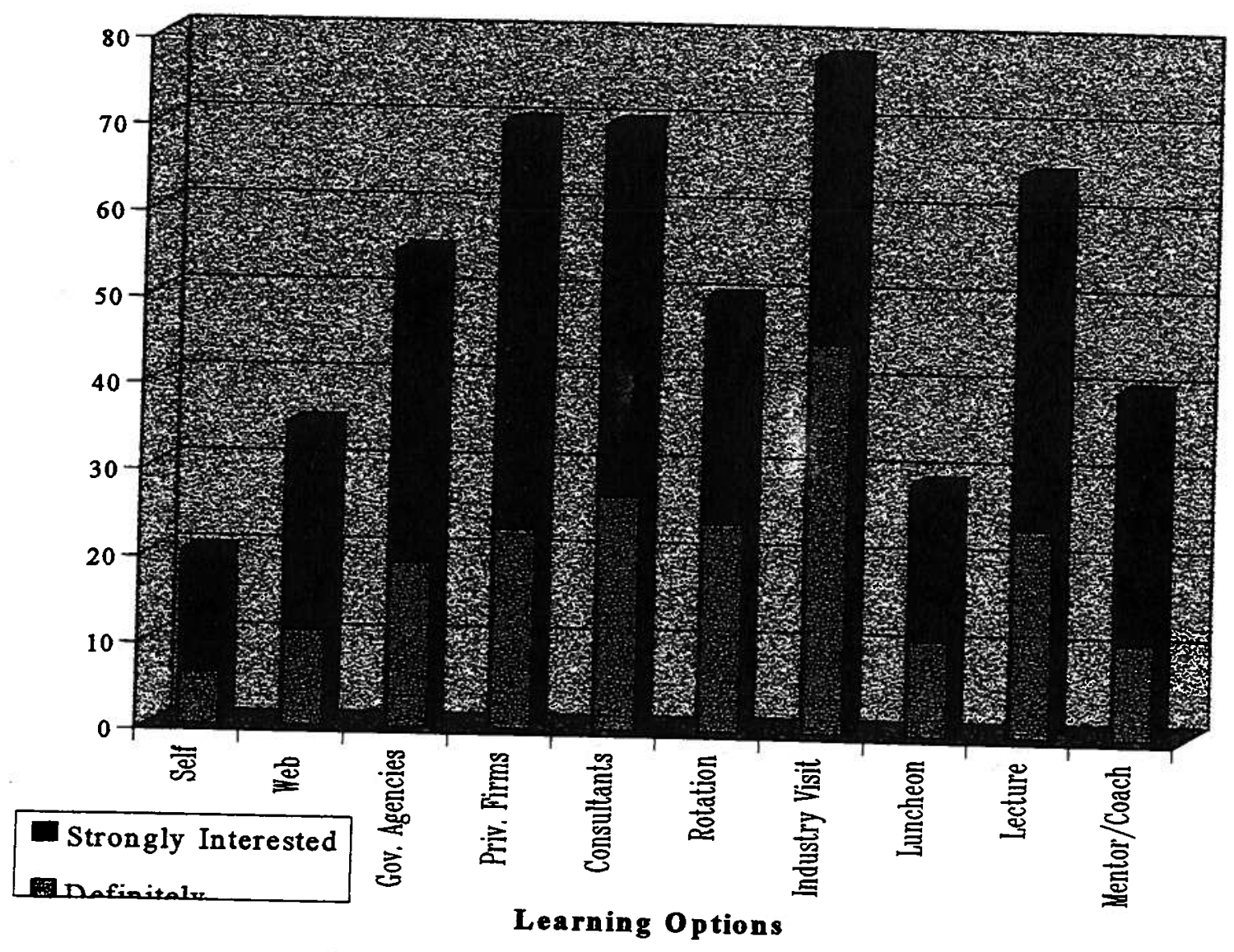

November 30, 1998 
Chart 9 shows that the non-management staff did not favor any particular learning option. But the following eight options may be considered as almost equally preferred.

- Web based training

- Training developed for government agencies

- Training developed for private firms

- Training offered by consultants
- Rotation assignments

- Industry visits

- Management/Leadership Lecture Series

- Mentoring/Coaching

Chart 9: Number of Non-managers/ Staff Who Selected Definitely or Strongly Interested

$$
(n=164)
$$

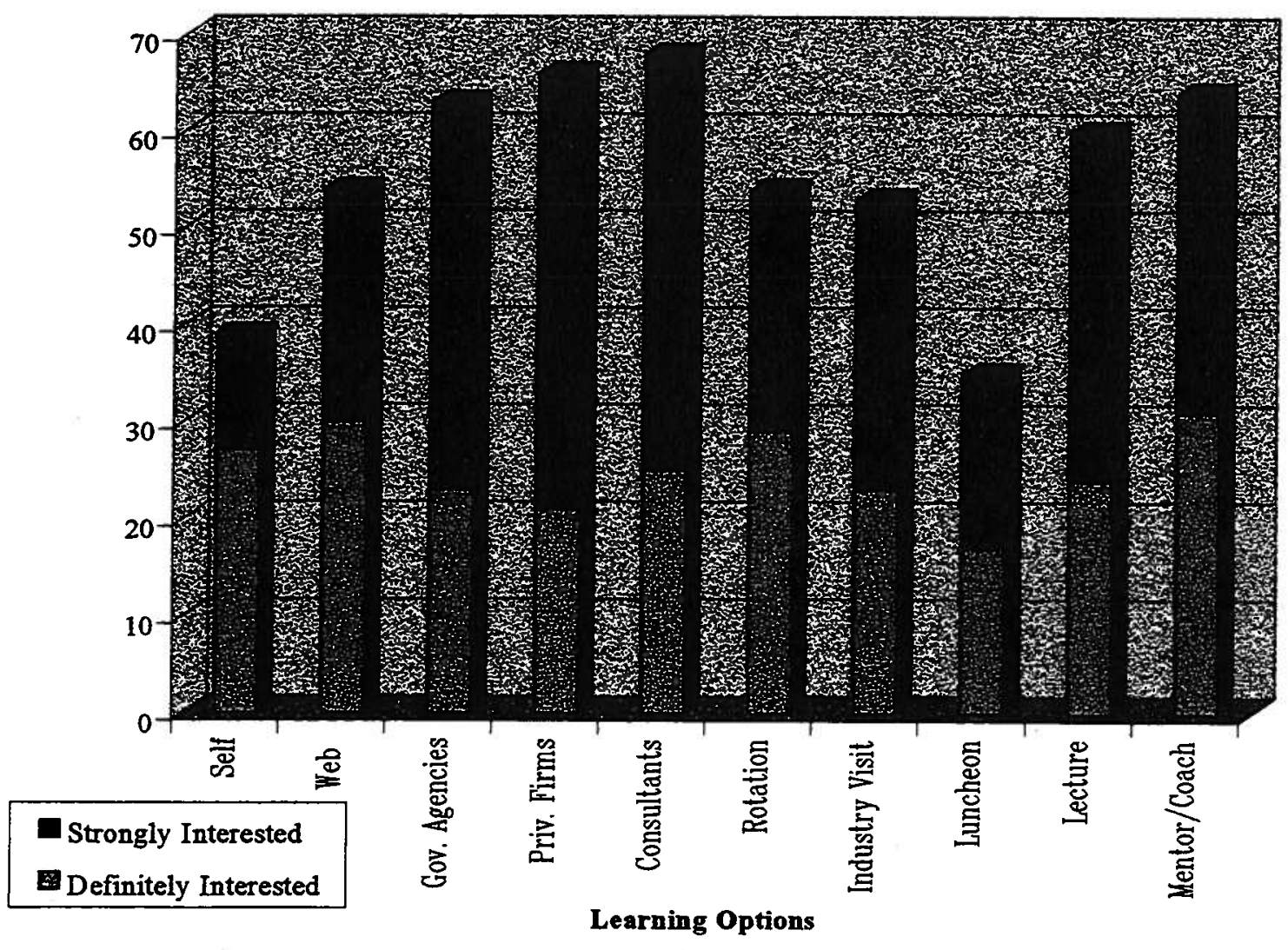


The preferred learning options of the three groups (senior managers, middle managers, and nonmanagement staff) are isolated on a Venn diagram shown in Chart 10. All three groups expressed a definite or strong interest in the following four learning approaches:

- Training developed for (or by) private firms

- Training offered by consultants

- Industry visits

- Leadership and management lecture series

In addition it is interesting to note that the non-management staff expressed a strong interest in informal mentoring and coaching as shown in Chart 9.

A notable find from the charts shown in the Appendix $B$ is that the number of years of service had very little bearing on the preferred learning options. 


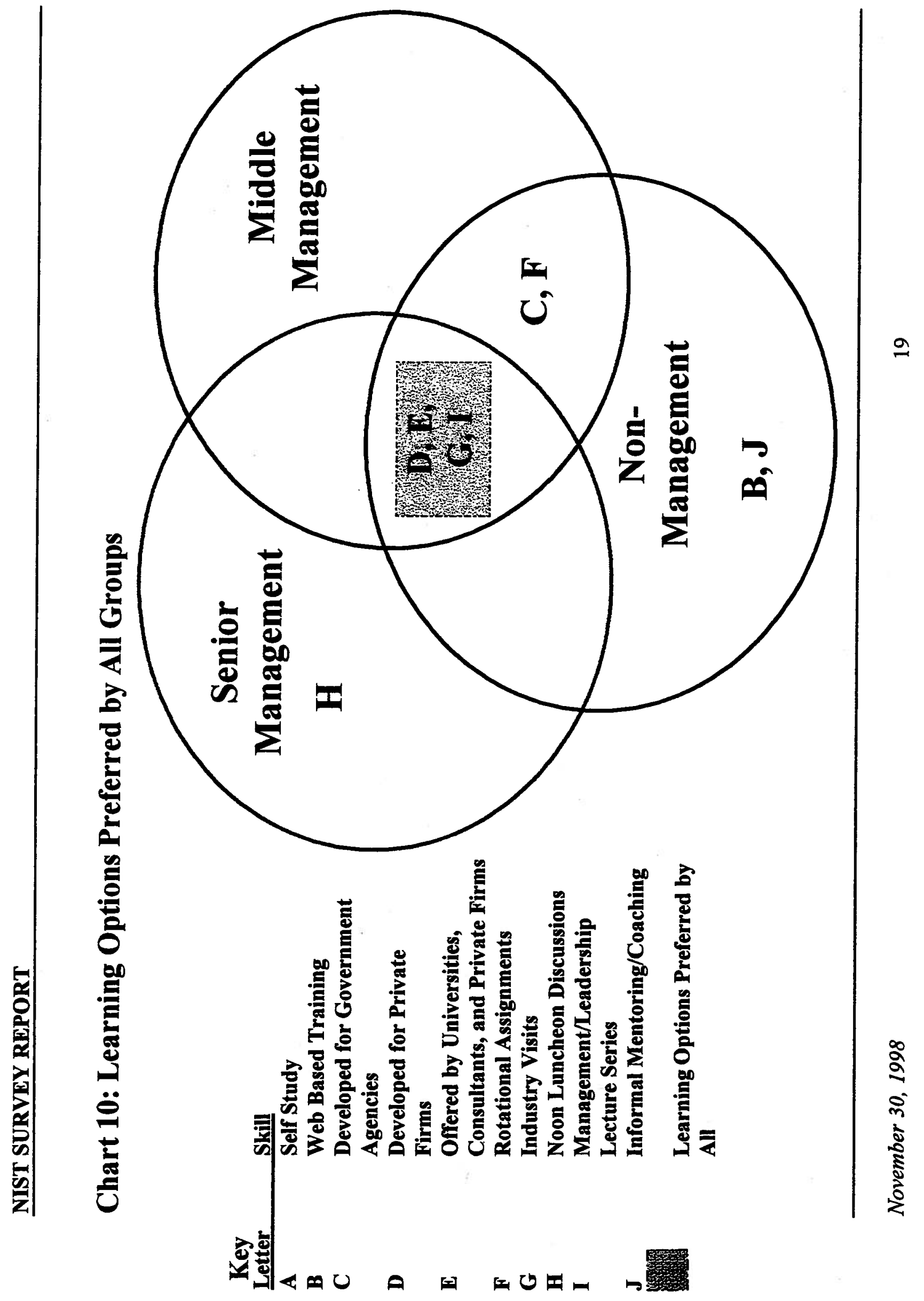




\section{OBSERVATIONS AND RECOMMENDATIONS BY MCMANIS ASSOCIATES}

\section{OBSERVATIONS}

The survey results indicated that all three groups identified the skill "Empowering and Motivating" as a predominant or critical-needs area for training. Likewise, all three groups identified the following skills as areas for training, either at the emergent or predominant level.

- Strategic Planning

- Oral Communication

- Written Communication

- Decision Making

- Delegating

Also, the respondents indicated interest in the following skills that were not included in the survey:

- Customer Service

- Negotiation Training

- Assertiveness

- Listening Skills

- Stress Management

- Diversity Training

- Presentation/Speaking Skills
- Computer Skills/Electronic Communication

- Priority Setting

- Cost and Time Efficiency

- Across Lab and Interdisciplinary Team Work

This would seem to suggest that there are two sets of needs:

- Developing Leadership Skills

- Developing Technical Abilities

Developing Leadership Skills

The present NIST Management Update Series is welcomed by some respondents. This program appears to be effective in providing employees with some of the management ${ }^{2}$ tools to perform

\footnotetext{
${ }^{2}$ Management, as defined by Peter Drucker, is the practice of effective allocation of resources performed by individuals. Management includes the support of the organization's overall mission, vision, fiscal/professional goals, and usually contains an accountability module to measure the performance of their unit against these
} 
their duties. However, the employees would like to include three main adjustments to the program:

- Consistent Scheduling of NIST Management Update Series

- Greater emphasis on industry-type management

- Increase the interpersonal skills development functions, rather than primarily focusing on conveying procedures

Identified skills such as Empowering and Motivating, Decision Making, Oral Communication, Delegating, Assertiveness, and Listening are leadership ${ }^{3}$ tools that enhance the execution of the above-mentioned functions. These tools appeared particularly in senior managers' predominant and emergent series.

\section{Developing Technical Abilities}

While senior managers rated themselves as highly capable in management tools, middle and nonmanagers recognized technical or managerial skills needed to strengthen their job performance. Middle and non-managers selected skills such as Time Management and Organizational skills in their predominant or emergent series. Other identified skills such as Project Management, Managing Financial Resources, Presentation/Speaking Skills, and Computer Skills/Electronic Communication are tools to enhance their management skills set.

\section{RECOMMENDATIONS}

Based upon the numerical results from NIST's Survey of Leadership and Management Needs, as well as supporting comments from the participating respondents, there is an identifiable requirement by both managers and prospective managers for improved leadership development at NIST. Soliciting input from the NIST staff through this survey has demonstrated top management's interest in these issues. However, it should be anticipated that this survey has stimulated expectations from the staff for enhanced attention to leadership development. There are a number of leadership development initiatives that will address the immediate needs of management, establish a culture that values and mentors leadership skills, and immediately begin leveraging the value-added benefits resulting from an increased cadre of trained, skilled leaders.

criteria. Peter Drucker is a leading academician, author, and theorist in the field of management science. His principles are the cornerstone for many management/leadership collegiate textbooks and business practices ${ }^{3}$ Leadership, as defined by Drucker, is the practice of organizational direction provided by individuals. Leadership covers, but is not limited to, the dynamics of visioning, planning, decision making, motivating, organizing, developing, empowering, and directing the activities of others to achieve specific goals. 
Moreover, by incorporating the identified technical-ability needs into training programs, NIST's current and prospective leaders will enhance the future success of NIST.

The following recommendations are proposed.

- Present the findings and recommendations to the Executive Board and the Operations Board and solicit a firm commitment that leadership development for managers at all levels, as well as for prospective managers, will become a hallmark of NIST management.

- Communicate the results of the Survey of Leadership and Management Needs in a well publicized and supported venue for all managers and other interested NIST employees. Discuss the analysis and outline the avenues for initiating improvements to the needs and concerns of NIST.

It is recommended that training for NIST employees be implemented in two phases. The first phase would be "Just-in-Time" training to cover the leadership and technical gaps identified in this survey.

- All employees would equally benefit from leadership development. NIST's success with the Management Update Series demonstrates the result of a dedicated focus and commitment from top management. The success of this series, in conjunction with continued input from managers and employees at all levels, may serve as a model for NIST to resource and develop a corresponding leadership development initiative.

- Identify and align the existing wealth of successful leadership training and development initiatives currently in place that support the advancement of leadership skills at NIST. These initiatives may be both internal and external, formal and informal. Such initiatives include:

- The Management Update Series curriculum should be reviewed, and aspects of team building, diversity training, and basic leadership skills should be integrated within the program. Managers and supervisors should have access to these types of training as soon as possible. Also, employee recommendations to the Series resulting from this survey should be implemented.

- The senior and middle managers should be involved in a planning process to identify battery technical courses needed to be successful in the administrative functions of their positions.

- Identify short-term, low cost initiatives that can begin immediately addressing the needs of managers: 
- Senior and middle managers should receive seminar training on business concepts such as measuring for results, strategic planning, goal setting, and presentation skills to help bridge the current gap in these areas.

- Identify opportunities to leverage external resources for enhancing NIST's leadership development:

- Senior management should benchmark with other industry leaders to check best managerial and technical practices. Specifically, they should target private sector organizations with high employee retention and customer satisfaction.

- All managers should Network with other government, scientific agencies to collaborate on training and development opportunities

The second phase would consist of developing long-term, sustainable training courses in the areas of Leadership Development and Management Skills. This will serve to develop a comprehensive Leadership Development Plan that accounts for the needs of managers and developing employees (survey results), considers the existing internal and external resources available to NIST, and finally, identifies the remaining skills to be addressed by formal training programs and processes. Consideration should be given to formally linking this leadership plan to NIST's Strategic Plan as a demonstration of NIST's executive-level commitment to excellence in leadership. 


\section{APPENDIX A} SURVEY 


\section{MESSAGE FROM THE DIRECTOR INVITING CONTRIBUTION TO THE SURVEY OF MANAGERIAL AND LEADERSHIP DEVELOPMENT NEEDS AT NIST}

Date: Mon, 13 Jul 1998 12:06:20 -0400 (EDT)

Message From Ray Kammer

To all NIST Managers and Selected Staff

We all know that the knowledge, skills and behaviors which are required to excel in research aren't necessarily the same attributes as those needed for an outstanding leader or manager. As an organization, we have always invested generously in the technical education and development of our professional staff but have slighted the development of our leaders and managers. Recently, I established a small cross-cutting task group on Management Development and Training and asked the Task Group to assess the management development resources presently available at NIST and to formulate a strategy for training future technical leaders and managers for NIST.

The Task Group has formulated an electronic questionnaire as part of its Needs Assessment:

$<$ http://www-i.nist.gov/survey/survey.htm. This questionnaire is being sent to all NIST managers and randomly selected staff for input. The survey should take about 15 to 20 minutes to complete. I would appreciate your response by 5:00 pm on Wednesday, July 22,1998 . Your responses will be kept confidential. A summary report will be available in August, 1998.

Your participation in this survey is important to the future of NIST, and is an opportunity for you to improve your professional environment and career development.

Thank you.

Sincerely,

Raymond G. Kammer

Director 
If you experience difficulties submitting your responses, please RELOAD this page.

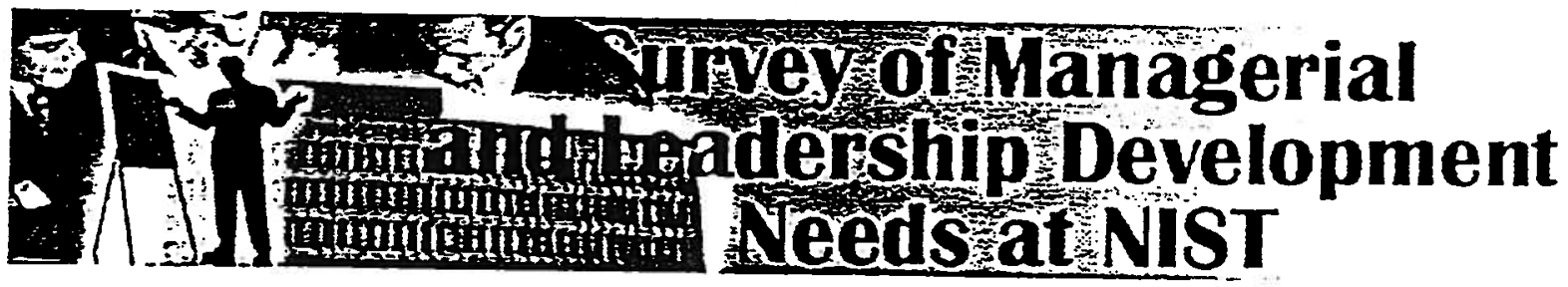

This survey of managerial and leadership development needs at NIST is being sent to all managers, supervisors, and a random selection of NIST staff who are not managers or supervisors. For NIST staff who are not managers or supervisors, please fill out this survey onlv if you are interested in improving your management/leadership skills. Responses will be kept CONFIDENTIAL. The results will be posted on the NIST Internal Web in August 1998.

1. Are you a:

OGroup Leader ODivision Chief

ODirector/Deputy Director of an OU or of an Office ONeither a Manager nor a Supervisor Other Type of Manager/Supervisor

2. If you are neither a manager nor a supervisor, are you a project leader?

OYes ONo

3. If you are a manager/supervisor how many years have you worked as a manager/supervisor at NIST?

$$
O(<5 \text { yrs }) \quad O(6-10 \text { yrs }) \quad O(11-20) \quad O(21-30) \quad O(>30 \text { yrs })
$$

4. Management/Leadership Skills Development Options At NIST

\begin{tabular}{|c|c|c|c|c|c|}
\hline \multicolumn{6}{|c|}{$\begin{array}{l}\text { Click the dot that describes best how you feel about participation in the following } \\
\text { management/leadership training options }\end{array}$} \\
\hline \multicolumn{6}{|c|}{ 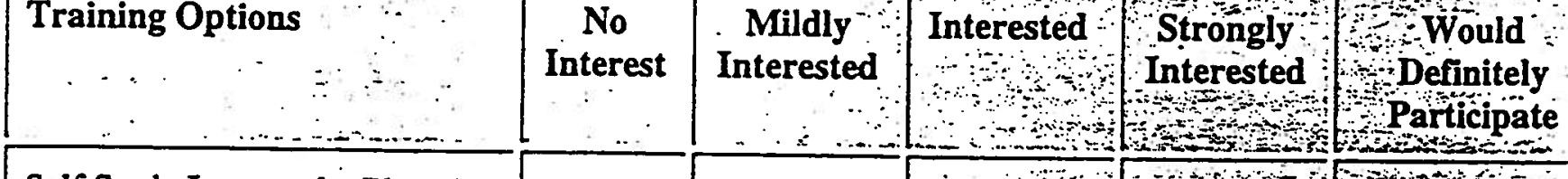 } \\
\hline \\
\hline Web-based Training Programs & $\dot{0}$ & & & & \\
\hline
\end{tabular}

Formal Training Programs Developed and Carried Out by Other Organizations. May Be Offered at NIST or Other Locations.

\begin{tabular}{|c|c|c|c|c|c|}
\hline $\begin{array}{l}\text { Developed for Government } \\
\text { Agencies (DoC, OPM, NASA, } \\
\text { NOAA, etc.) }\end{array}$ & $\begin{array}{l}\because \\
\because 0 \\
\because \\
\ddots\end{array}$ & $\therefore$ & 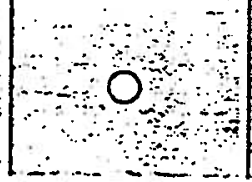 & 40 & 40 \\
\hline
\end{tabular}




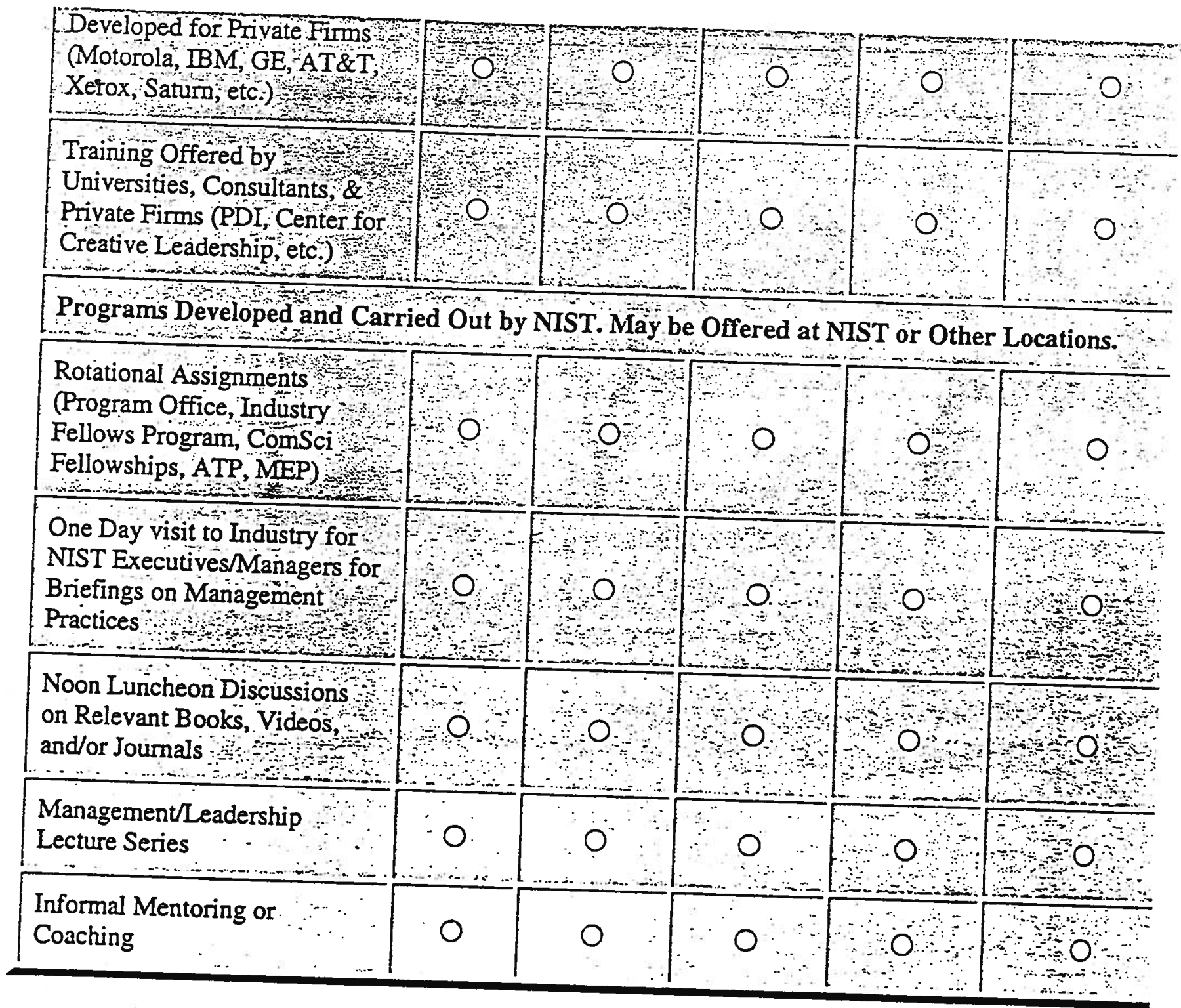

\section{Motorola, IBM, GE, AT\&T \\ Xetox, Saturn, etc.) \\ Training offered by \\ Universities, Consultants, \& \\ Private Firms (PDI, Center for \\ Creative Leadership, etc.) \\ Rotational Assigno... \\ (Program Office, Industry \\ Fellows Program, Comsc \\ Fellowships, ATP, MEP) \\ One Day visit to Industry for \\ NIST Executives/Mañagers for \\ Briefings on Management \\ Practices \\ Noon Luncheon Discussion on Relevant Books, Videos; \\ and/or Journals \\ Management/Leadership \\ Informal Mentoring or \\ Coaching}

NIST. May be Offered at NIST or Other Locations.

5. If you are a manager or a supervisor, please rate the importance of the following skills for your effectiveness in your current job. If you are a currently not a manager or a supervisor, please rank the importance of the skills for your future grouth. Also, please rate your present capability and whether you would take training to improve this skill.

SKILLS

\section{IMPORTANCE RATING}

vitally important

highly important

important

marginally important

not important

\begin{tabular}{l} 
MY PRESENT \\
CAPABILITIES \\
\hdashline \\
\end{tabular}




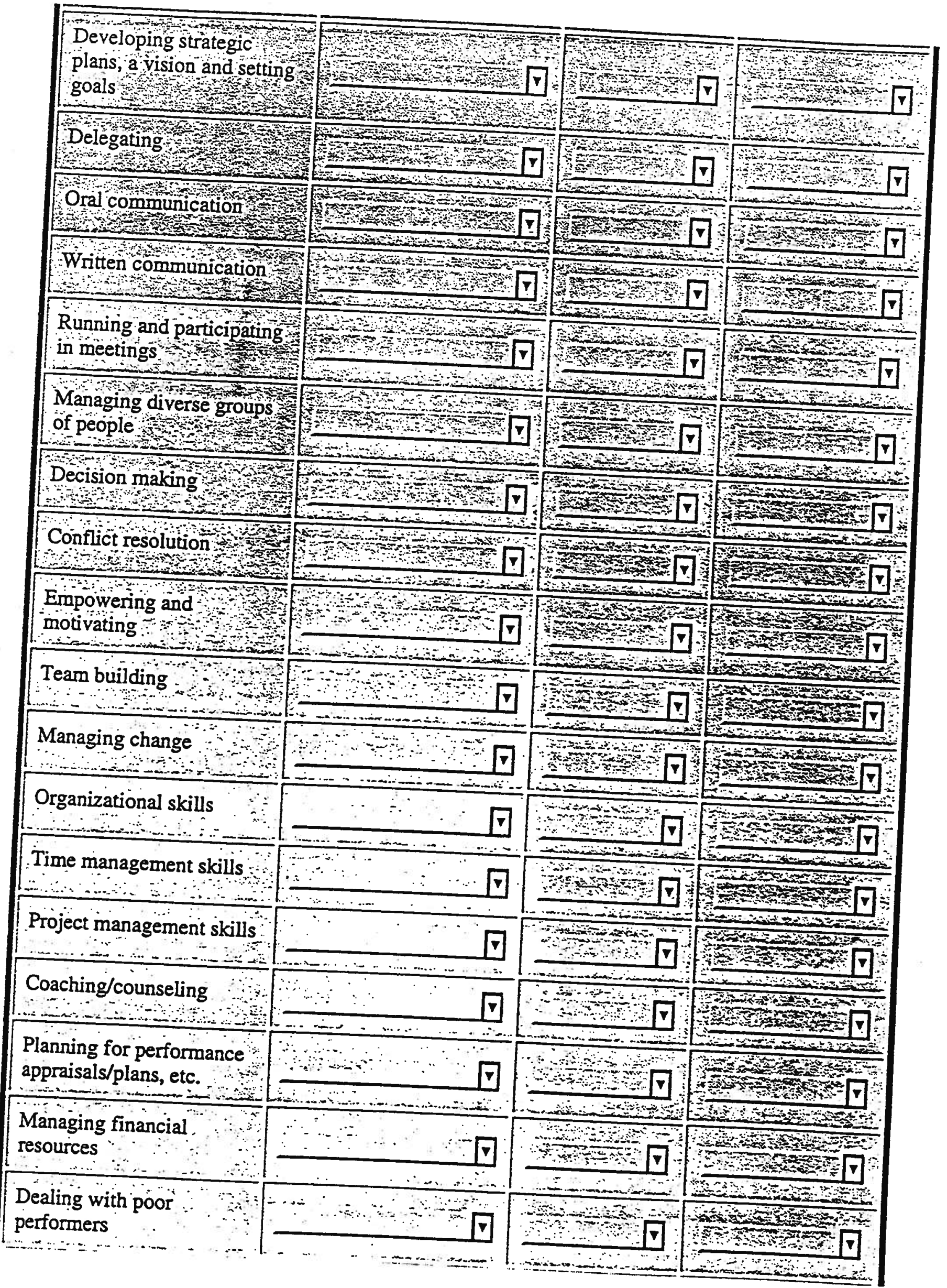




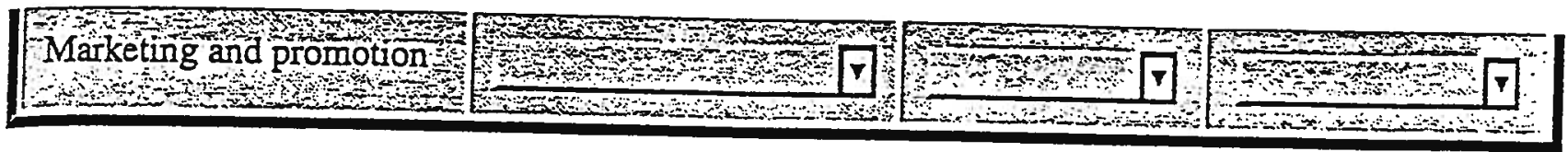

6. Are there any additional items that you feel should be added to Tables 4 \& 5 above?

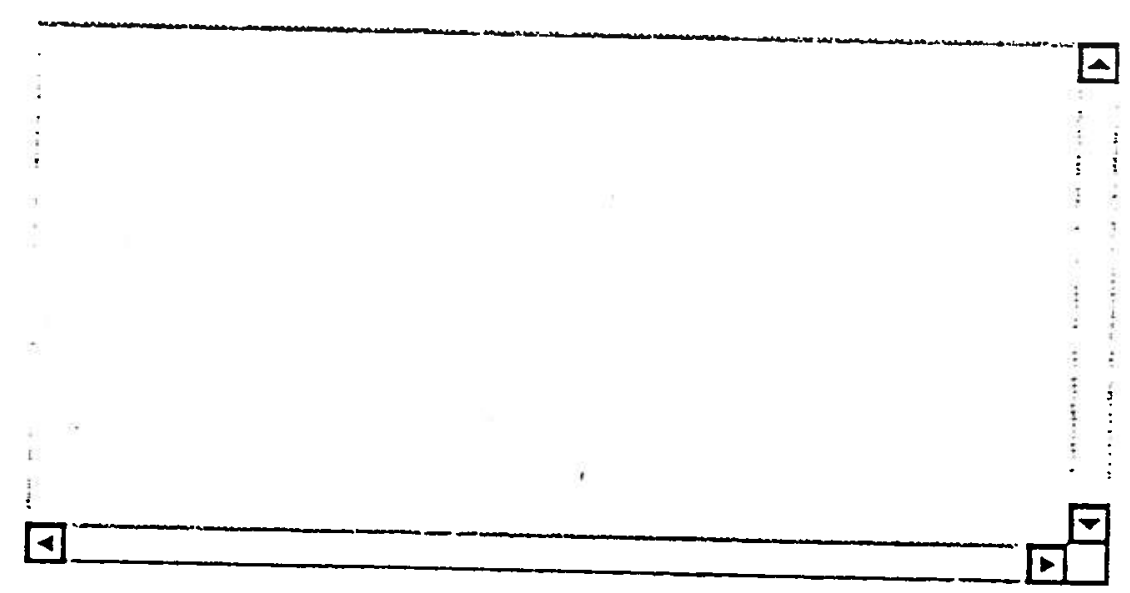

7. Do you have any comments regarding management/leadership development education at NIST?

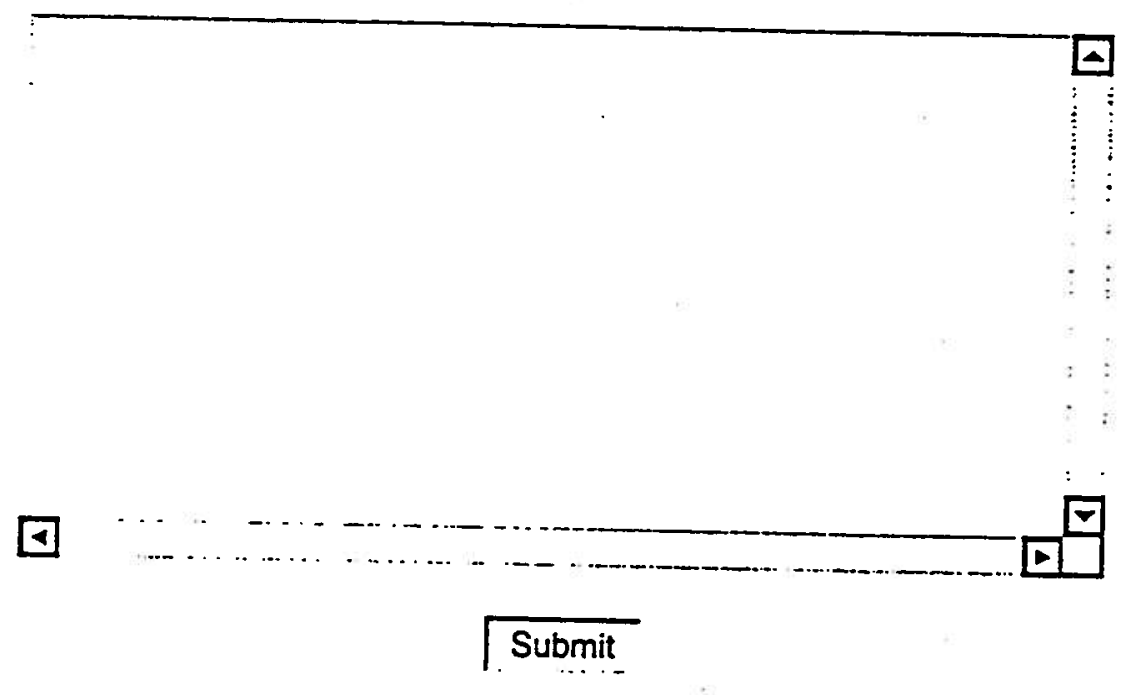




\section{APPENDIX B}

\section{LEARNING OPTIONS}

November 20, 1998 


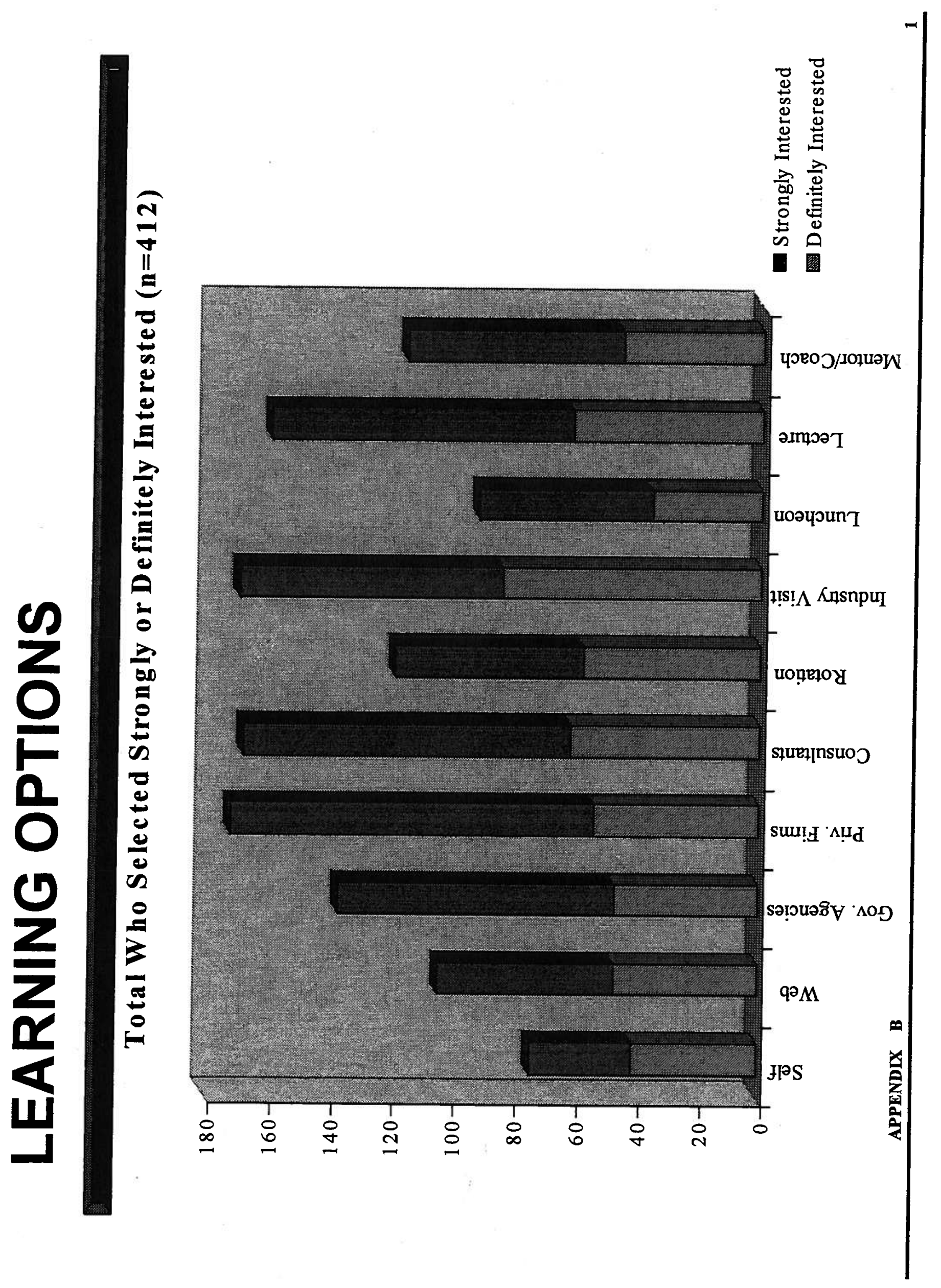




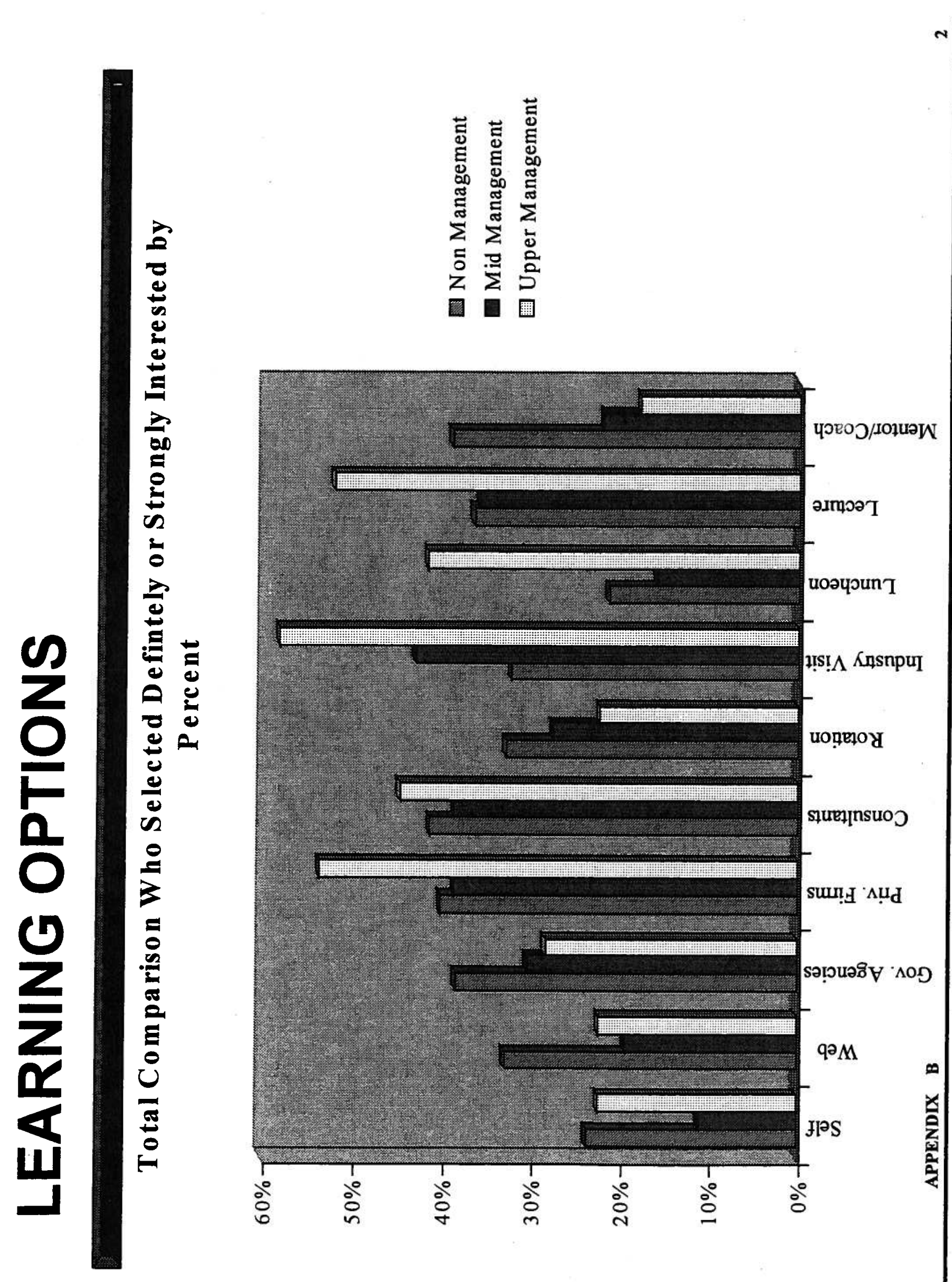




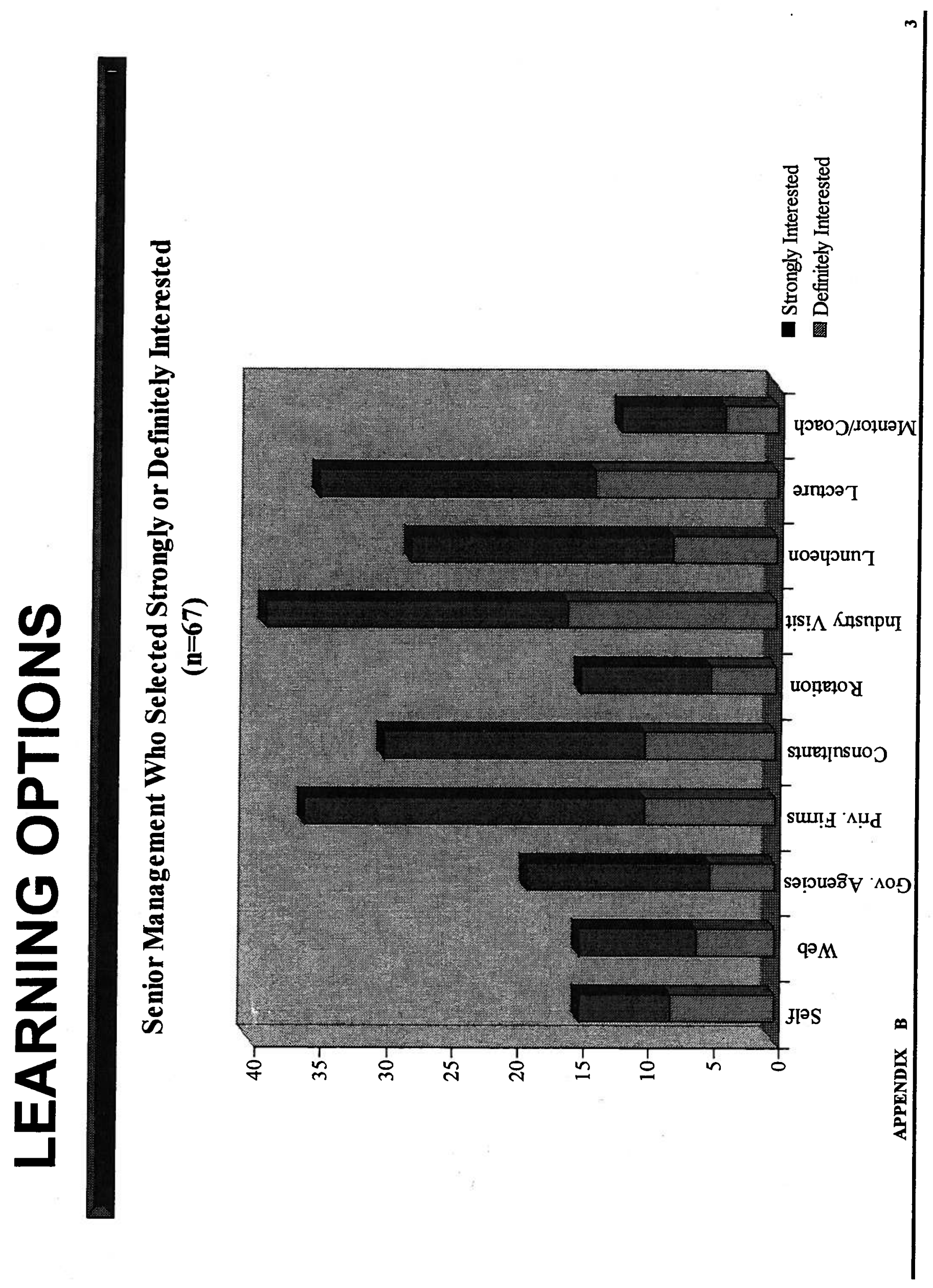




$$
\begin{aligned}
& \sim \sum_{0}^{2} \sum^{2} \\
& \text { ? } \frac{1}{1} \\
& \text { - } b=\wedge \\
& \text { 圆口口国 }
\end{aligned}
$$

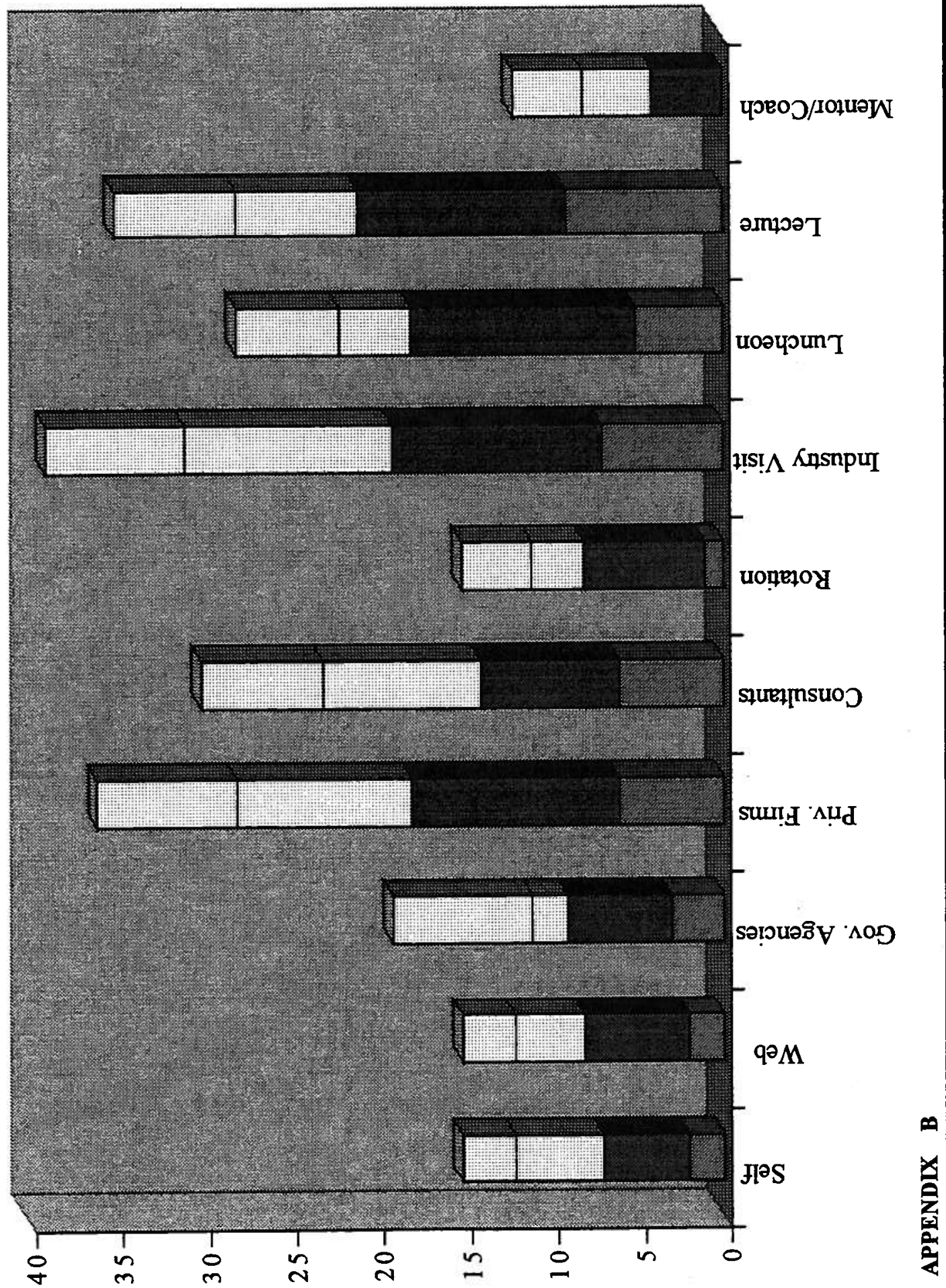




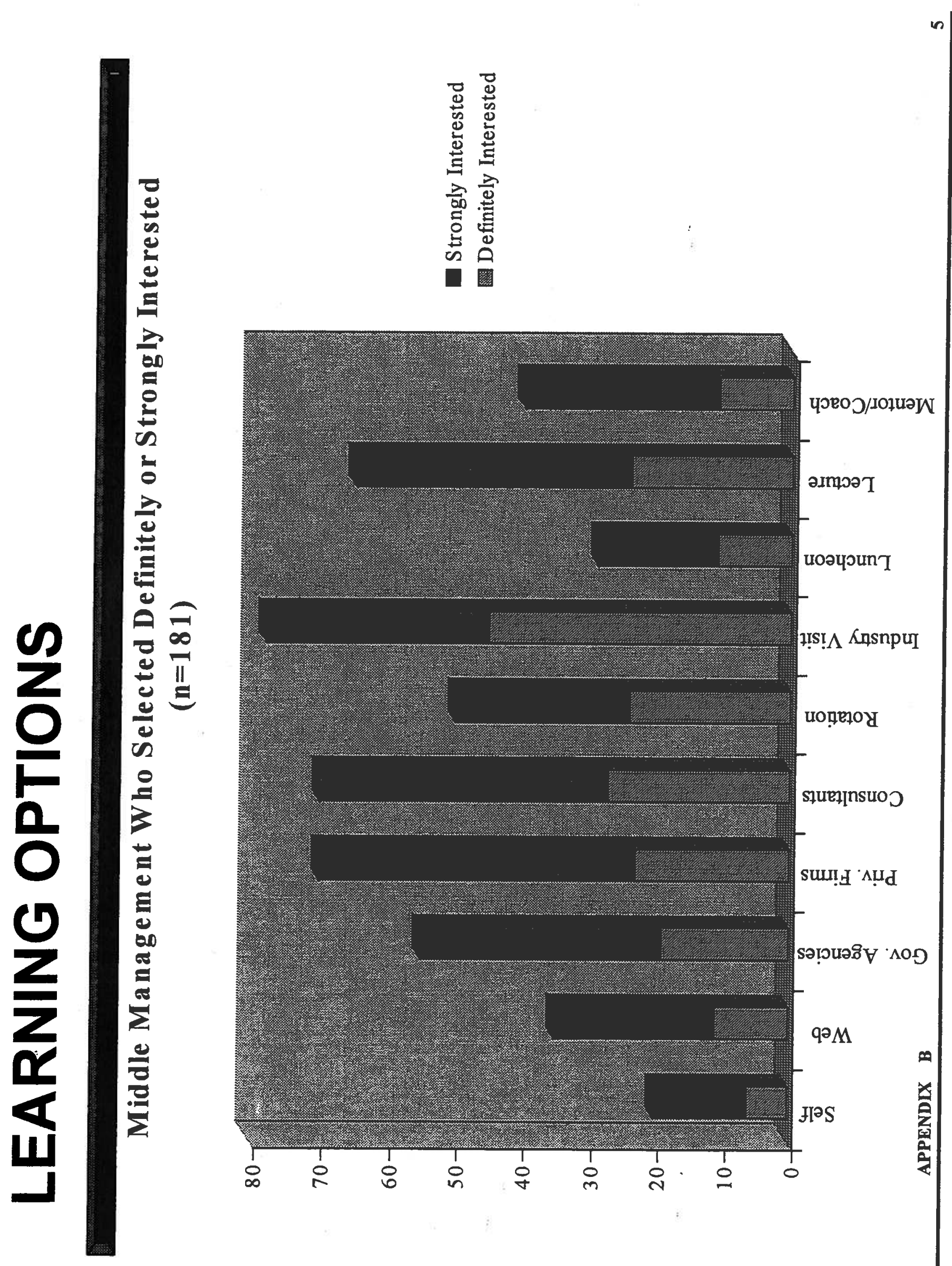



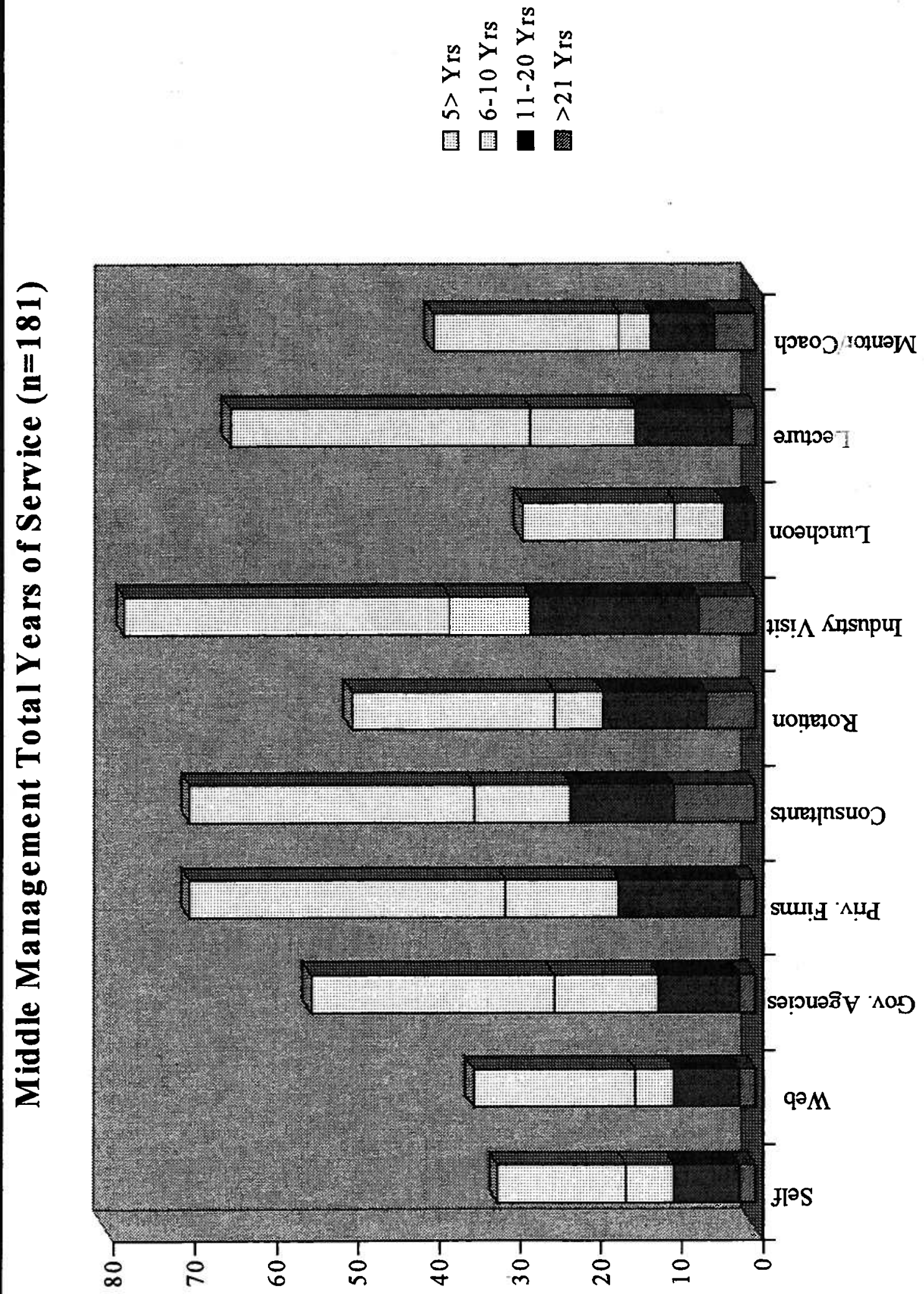


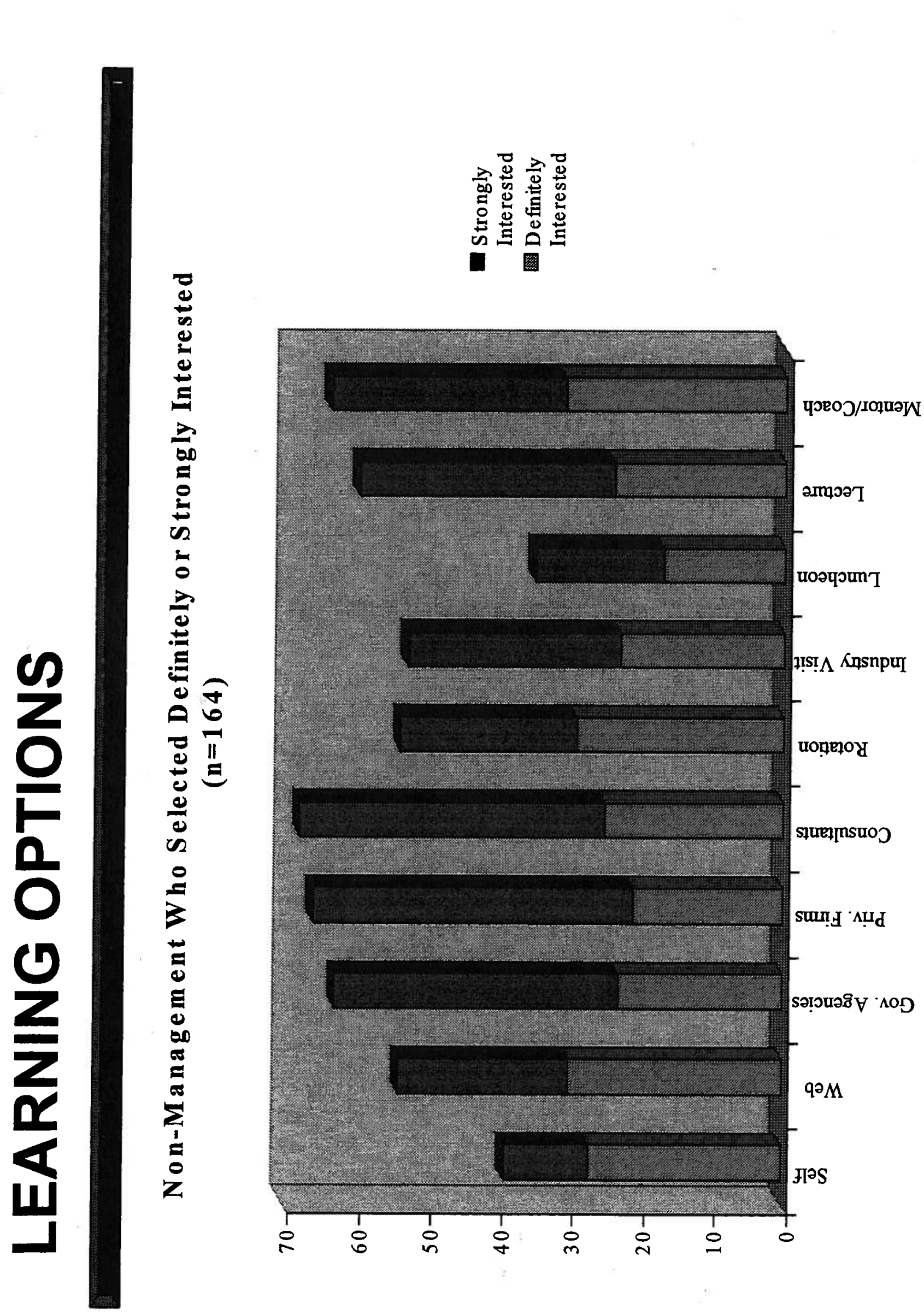




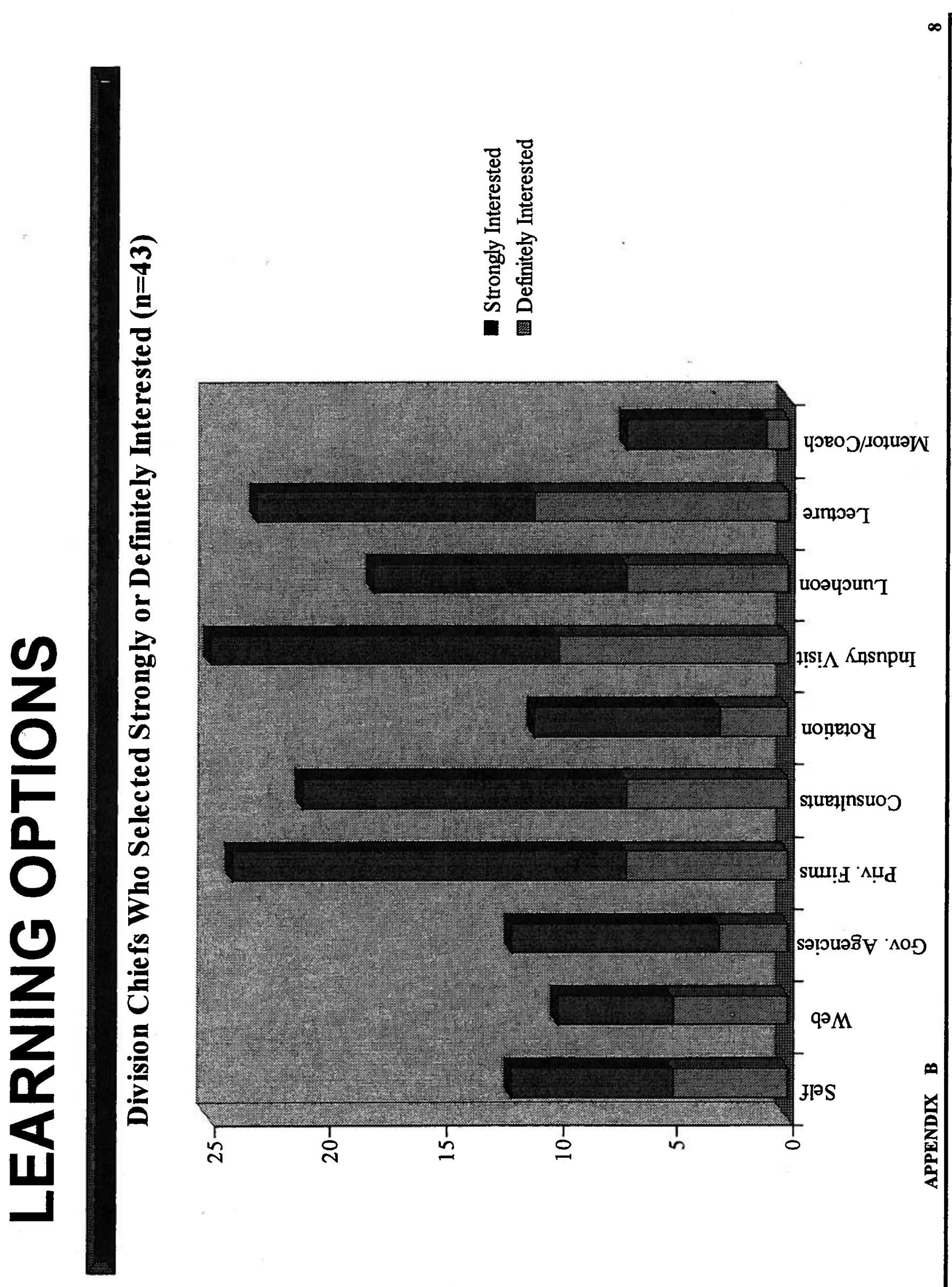




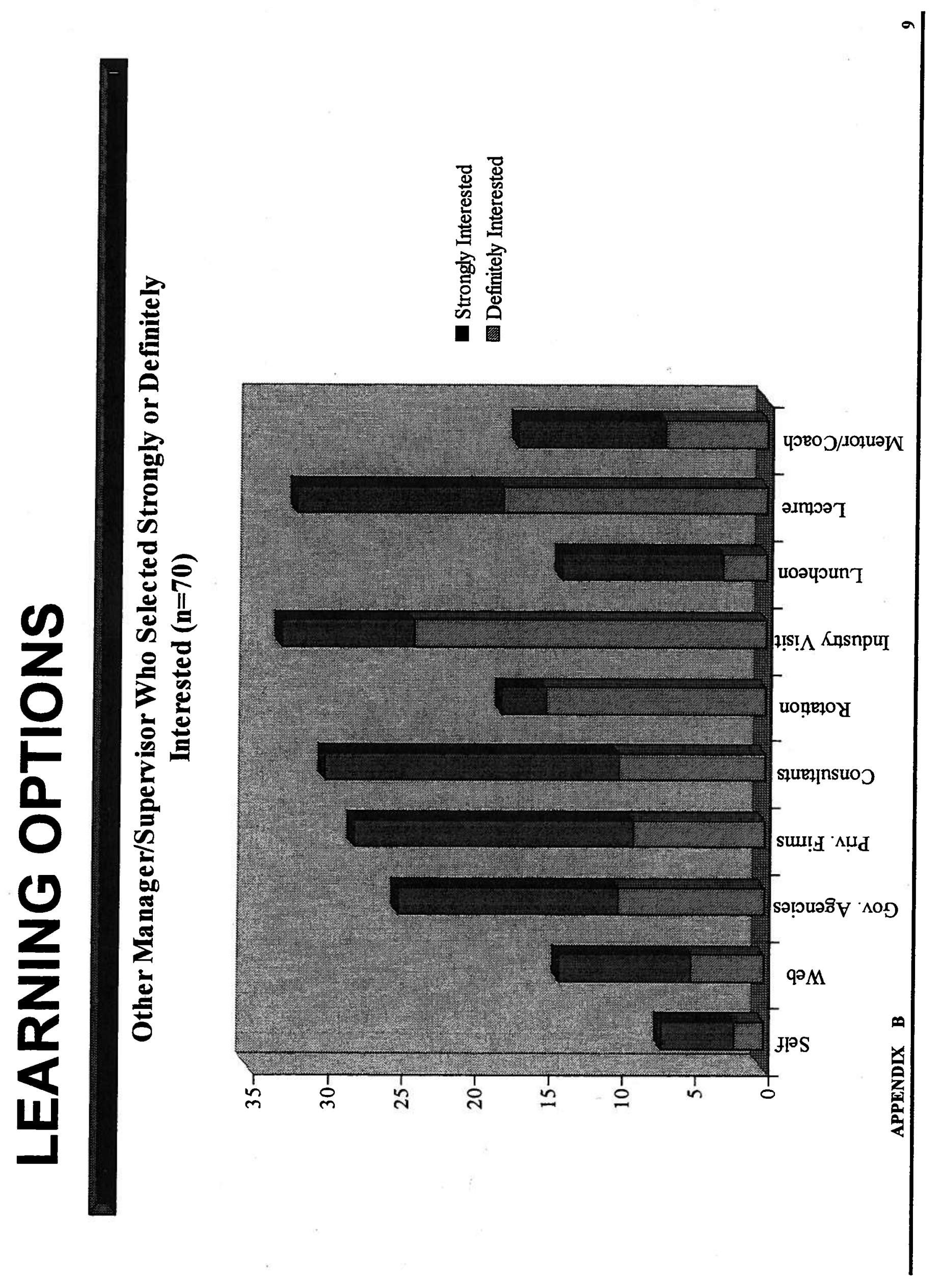



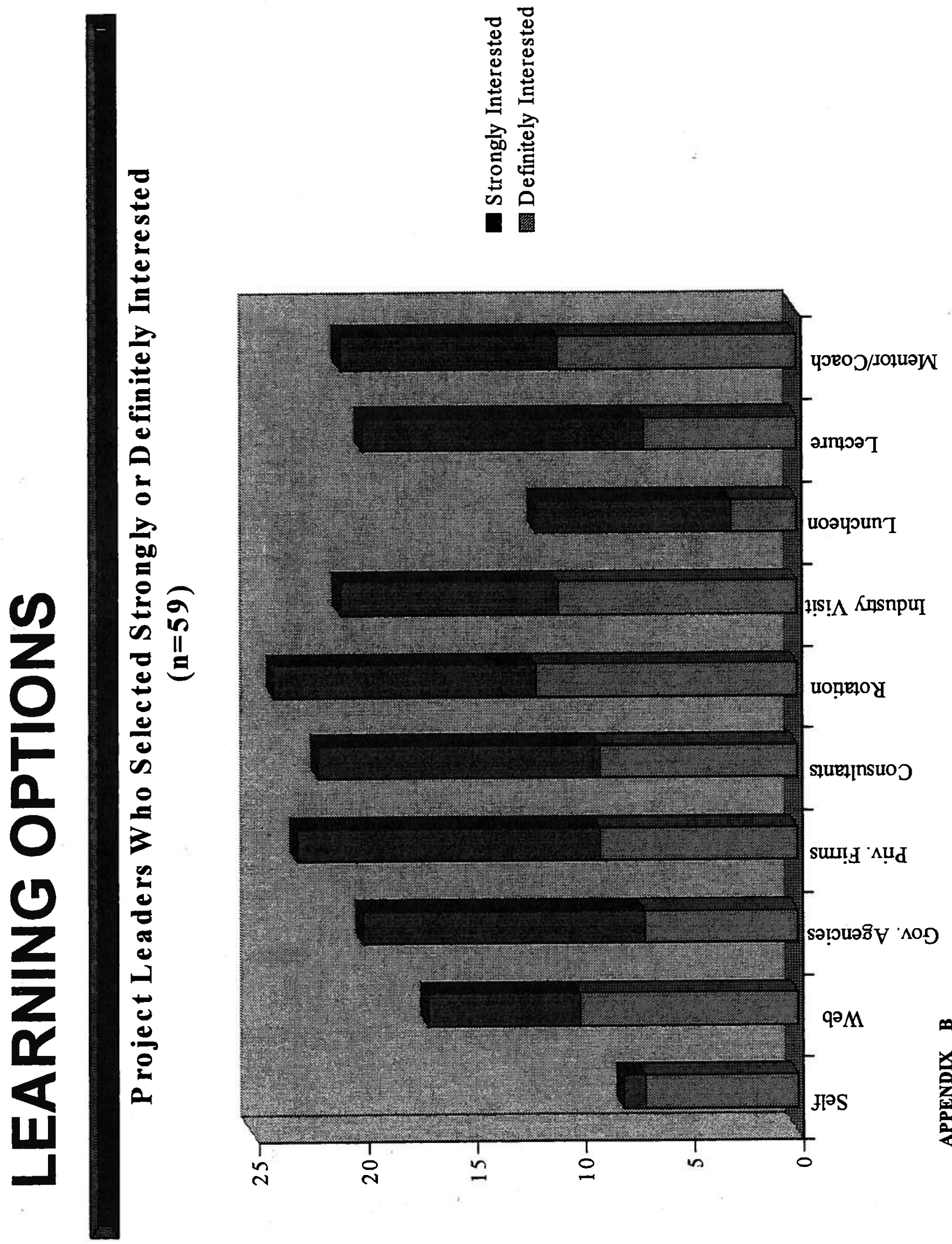


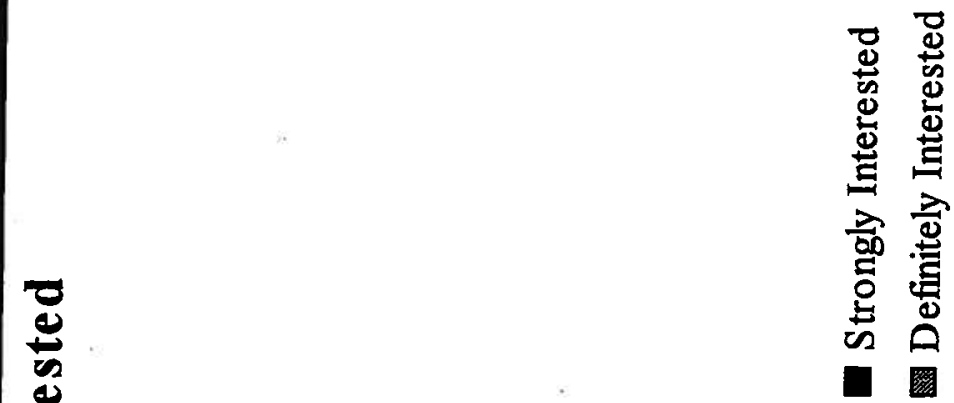

บวะ0ว/Д0ุUәW

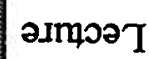

noəyoun 1

IIS! $\Lambda$ KnsnpuI

uopeq0y

squeł [nsuoj

SuUt: 'Aud

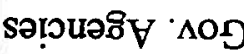

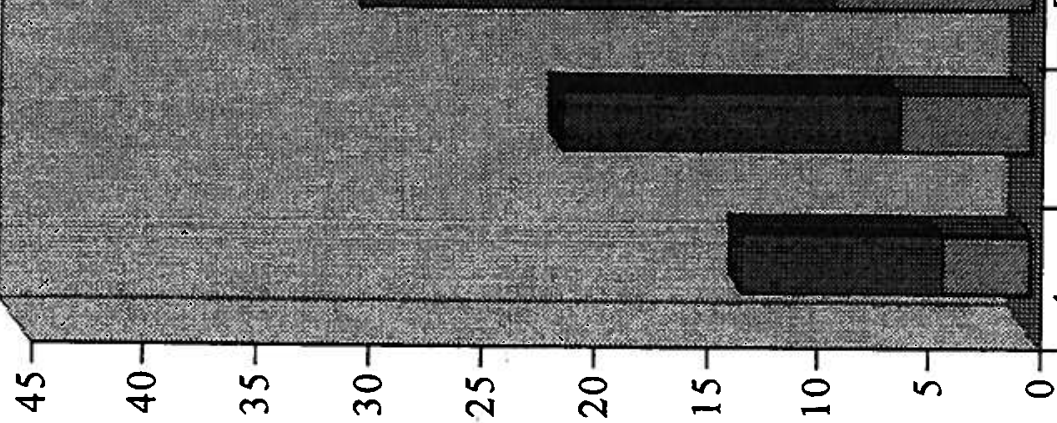




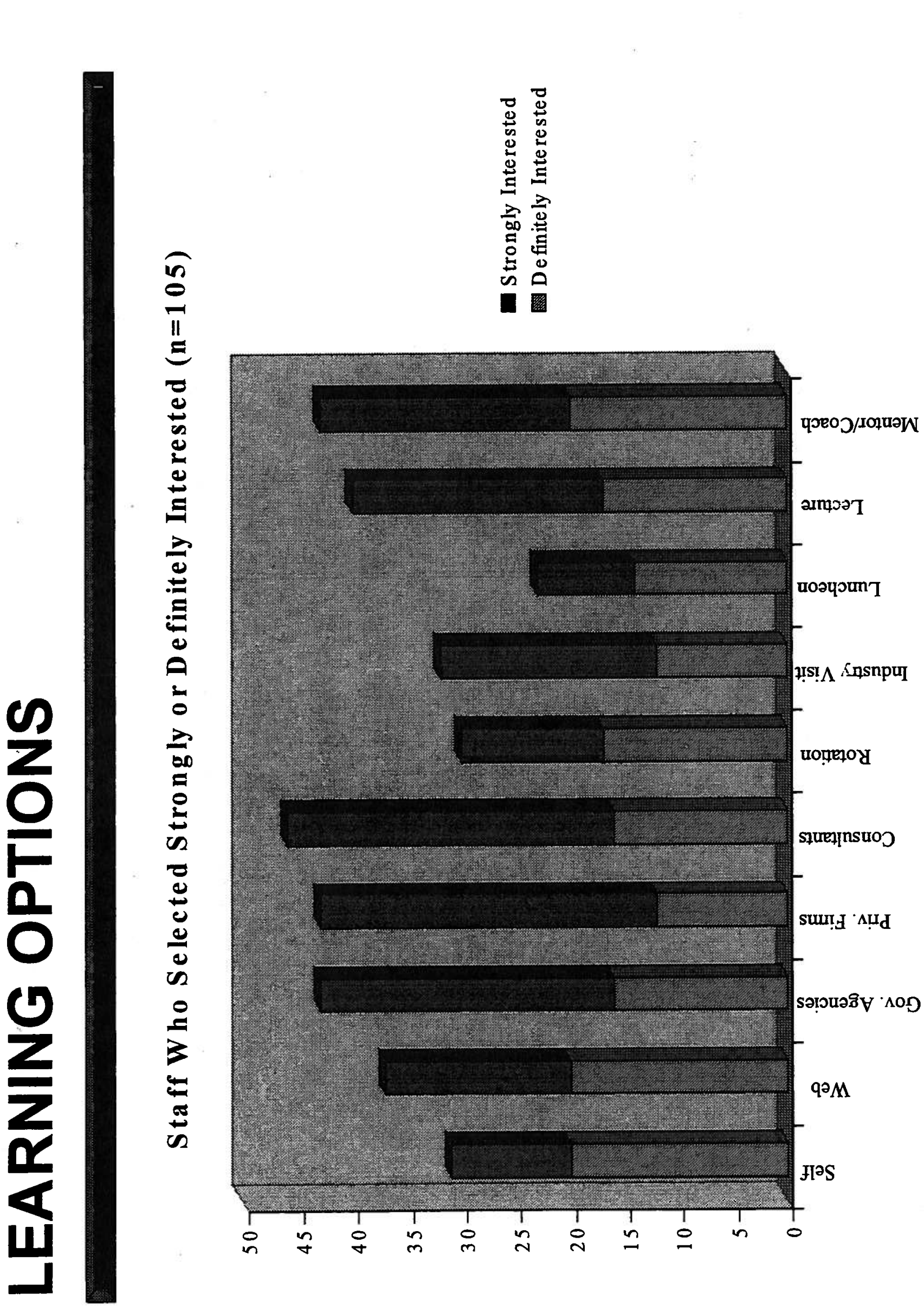




\section{APPENDIX C}

\section{UNABRIDGED COMMENTS}

November 30, 1998 
The Following Are in response to Question 6: "Are there any additional items that you feel should be added to Tables 4 and 5 above?"

- Perhaps the most important topic is the implementation of a strategy or achieving a vision. Certainly, some of the needed skills are represented in the list, but I feel the topic should be explicitly considered in order to identify all the elements necessary to implement a strategic plan successfully.

- Tables 4 \& 5 emphasize training and skills but not incentives. Management creates the environment and the reward structure, but does the federal bureaucracy and the unbelievable personnel rules allow the managers to manage!?! Can we establish a demo project that sets NIST as the leader in re-inventing the role of the federal manager?

- Tables 4 \& 5 need to address some meaningful measures of impact/success

- Establishing and maintaining appropriate external relationships

- Developing and maintaining the above skills in subordinate leaders

- None

- Identifying needed activities for the office, learning to set priorities and say "no", to interact effectively with other units at NIST (and in the government), and to do more with less

- You may wish to separate skills required at higher management levels from those of the first line supervisor (performance plans are done by the latter, not the former, for example - but the former is more critical in setting priorities for the direction of the unit

- Effective verification of industry needs

- Serving outside customers effectively

- From my experience, some NIST managers have a very narrow view of their work and how their work should support activities beyond those of their internal interests. Consequently, they are unwilling to undertake work that has a broad impact on national objectives additionally, there is a lack of cooperation and communication among some offices, which interferes with department objectives. Understanding other NIST, national or departmental objectives should be required of managers . 
- Stop talking about and do it (well)!

- At my career stage, I am not likely to find courses the most valuable use of my time. Hence, this response does not represent my evaluation of the importance of management training. I have found such training to be very valuable and feel it is essential for potential, new, and mid-career managers to have excellent training readily available and encouraged.

- Minimize the top down stuff

- Make it excellent, stimulating, and mostly voluntary

- It is needed

- None

- My responses on "I would take training to improve this skill" are based on the assumption that the training is good. In my experience to date, this has not been the case. Much more effort must be made to ensure that the training is directed toward the staff and issues of a high quality research institution. It must be meaningful and not be simplistic or based on processes that managers/leaders have little or no contact with

- We need it desperately, not only for existing managers, but also for our up-and-comers

- It's needed

- Definitely needed. Most good technical people are trainable in management, but not many are natural leaders.

- It could be better. Personnel could offer courses more than once a year since so many of us are on travel and have trouble attending then. I like the idea of web-based improvement courses, as well as luncheon sessions and discussions. Learning the problems that others have and how they solve them is very useful - and is a form of mentoring that is outside the employee/supervisor relationship. I've long thought that division/office chiefs, and then group leaders need a more formal forum where they can discuss ideas important to people at their particular level within NIST

- Thanks for sending this survey!

- Inadequate at present. Instead of over-analyzing the problem, I suggest that we find out how organizations that we respect do it. We especially need some fresh voices from the outside, from industry, in particular. 
- I marked "interested" in rotating assignments, even though I don't anticipate moving soon. I have had rotating assignments before, and I think they are vitally important to developing managers for lots of reasons: to give them broader perspective and organizational savvy, to let other managers see their capabilities, and to learn new skills. In my opinion, some managers do not take their performance evaluation responsibilities seriously enough. There is a lack of feedback to and insufficient development of, employees. Similarly, too much poor performance is accepted because the managers don't make the effort to correct employee performance problems. I think they need a course on their responsibilities.

- Understanding NIST/DOC personnel procedures - rules and regulations

- Ethics

- Knowledge of job functions (while taken for granted this should be acknowledged to be the top priority)

- Legal implications and potential impacts on NIST and on myself when implementing federal and state regulatory requirements

- Cost benefit analysis

- Managing $\mathrm{R} \& \mathrm{D}$ in a federal lab

- Managing OU information systems. Note: participation in training would be contingent on the fact that it was based on private sector performance - not traditional training that I have experienced here at NIST

- There are some management problems peculiar to NIST that should be addressed. The ideal NIST employee is a Nobel prize winner who contributes in an important way to the growth of the U.S. economy. For the rest of us, research and economically important applications are a trade-off that is not easily made.

- Assistance in helping to improve the ability of managers to make value-added decisions, and build high-performance programs

- There are too many items in $4 \& 5$. Still, the following skills are needed: measuring pre/post public benefit/economic impact and measuring customer satisfaction/feedback

- ATP is very unique, and therefore, because of budgetary pressures, uncertainties make management decisions difficult. This may change in the future, but until then, any skills which alleviate stress would be important to have additional education. Training example: women's executive leadership program

- Stress management classes 
- Training on how to interview and orient new employees

- Include memos and email under written communication

- Include making presentations under oral communication

- Training on any special problems females or minority managers/supervisors may encounter

- Listening skills, customer satisfaction skills (i.e.,, Are the folks you deal with happy with the service/info they receive from your division)

- Dealing with supervisors (i.e., The counter part of effectively delegating tasks). The persons I supervise should be trained to negotiate unreasonable assignments (not that I do that).

- None

- No. The list is comprehensive.

- No additional items to be added.

- I would like to see NIST boulder and Gaithersburg work closer together on projects that impact both sites. I would also like to see NIST management more involved in the excellence in government fellowship or OPM management development centers by providing additional funding for select managers to participate.

- We need more money for training. There is a lot of talk about schools, but there never seems to be enough money.

- Training budgets are always underfunded

- I have had the opportunity to participate in many leadership courses including Comsci, FEI, etc. They have been very useful. Unfortunately, I did not have the opportunity to go to the Kennedy school at Harvard, which I understand is excellent.

- When I became a supervisor, I was unable to get accurate information and guidance from my supervisors. Personnel issues were a minefield since no one seemed to know the correct answer to my questions. I learned by trial and error, making a lot of mistakes, which was extremely frustrating and discouraging. All new managers need to be briefed by personnel staff on the proper procedures for promotions, handling grievances, position descriptions, etc. To enable them to efficiently and effectively supervise. 
- Hit and miss at best. Only deals with procedures. Sorely needed.

- I participated in Comsci and think it is an excellent program

- As a member of the SES, I don't think that rotation or alternative assignments and diversity of experiences is either encouraged, or supported by the culture at NIST indeed, I think the culture discourages it. An institutional sabbatical program which encouraged inter-agency/departmental, and non-governmental assignments once every 5 to 7 years would go a long way to change the culture if people were encouraged and expected to participate.

- This initiative is long overdue! I have felt for years that we reward some of our most competent scientists by promoting them into management and then fail to give them the support, training, and skills to become good managers. A good scientist does not automatically mean this person is a good manager.

- It should be more accessible to targeted staff members who are not supervisors

- No. It is creative and plentiful

- NIST should establish certain training and mentoring programs aimed at specific needs of minority groups

- Training should be ongoing. Should not wait for problems to occur training is sought. The same opportunities offered in Gaithersburg need to be offered in boulder; meaning the employee should not have to relocate to Gaithersburg to be able to develop their management/leadership skills. Courses should be offered more frequently in boulder.

- Managing R\&D projects is different than managing a cooperative agreement or a services contract. Courses in the area of managing $r \& d$ in a federal laboratory environment, which discuss appropriate measures of success are needed. Also, managing information systems in the NIST culture, which discusses issues such as integration, total cost of ownership, etc.

- Many of the business-related courses I took when I received my MBA would be useful even in a lab environment

- Currently, I would rate it as extremely low quality based on my personal experience with private sector, fortune 500 , high performing companies

- This effort is a very positive direction for NIST. But, it is a long term effort with payoff in the future.

- Attention to diversity is important in identifying candidates for developmental training in leadership/management positions. 
- While I have not looked specifically, there are very few opportunities that are obvious

- The current "supervisory" training addresses the requirements for managing "government employees", but not good management practices. I have worked for both Administration and ATP while at NIST. Administration has taken the action of training its supervisors/managers internally, which is a great asset to the organization. Since the training is done internally, employees are able to interact with employees from other divisions, but within the same OU. I am presently attending a 4-day Covey training which is being conducted by admin employees, and I think this has been a positive experience and hope admin continues in this direction.

- It's not very visible. I don't see much organizational value placed on it. I don't see much evidence of my leaders using, supporting, or participating in activities. The few requirements seem to be focused on conveying procedures; not on developing skills.

- I have found the NIST management update series to be useful. However, it involves travel time as I am at NIST north. A couple of times, I went to a class only to find it had been canceled. I recommend general notification, e.g., email in the morning when classes are canceled.

- The number of courses required of new managers is crushing. The current format of occasional short seminars may work well for people adjacent to 101 , but creates a strain for those people who need to drive and find parking or wait for the shuttle. Before adding any new training, management should streamline the existing courses so that it can be completed over the course of 1 or 2 weeks.

- It could use more PR to let folks know about it, recognize its value

- No additional comments

- Benchmark against other world class organizations; e.g., GE, IBM, bell labs. There isn't much that has depth.

- The management development series that is offered currently has many positive features. The main issue is that some of the current managers do not utilize these training opportunities. Some of these managers need to be mandated to take these courses to help them in performing management duties. They could use more people friendly skills though instead of poly-pro.

- I find that many of the managers do not have the people skills necessary to manage people and communication becomes a huge block when a decision is needed. There seem to be instances throughout NIST that a technical staff member is excellent in their field and the only way to give them more financial reward is to make them a 
manager. Unfortunately, in many of the cases, the "people" skills needed for management are not in the skill set of the person being placed in that position.

- Being a supervisor for only a few months, I have not had enough time to evaluate what is available.

- Aside from the multitude of required classes on subjects that should be covered in the Administrative Manual, it's non-existent

- There needs to be more management/leadership training

- Metrics for success. With the emphasis on planning and measuring outcomes, how do we measure success in a research environment. I can measure success in a production environment such as calibrations.

- Program quality assessment, self appraisal

- Upper management should be planning succession long before it becomes an issue. Thus, training should be done before, rather than after, the fact.

- Science and technology policy issues and their effects on NIST activities

- Trouble is to find time for training. I would favor 1 hour training sessions over lunch time

- How to determine the true costs of operations, such as, the costs of having a physicist be the system administrator of a computer, or a chemist be responsible for the operation of a computer network, or an engineer manage world wide web pages, and how to alert upper management to these costs when decisions are made to augment or reduce them.

- Dealing with multiple tasks/prioritization

- Saying "no" to a multitude of requests for time

- Presentation skills, particularly in getting outside financial support for projects

- Skills in dealing with managers of other government agencies to seek their support for projects

- The above may or may not be related to marketing and promotion above, depending on how you define marketing and promotion. 
- Additional items: key factors managing and delivering a service and market/customer orientation. "customer" and "service" are two important factors omitted in the list above. All of NIST provides a service of some sort to its customers.

- Building skills to improve chances of entering Senior Executive Service

- Improving use of electronic communications (internet, www, etc.) In management

- Basic learning skills (reading, writing, math, PC operation) to allow those lacking prerequisite knowledge and abilities to survive

- Talent and passion for scientific research. It will be hard to lead the very highly talented scientific staff at NIST if you do not share their enthusiasm and absolute joy of doing this kind of work.

- None

- Can not think of any

- None

- Value of various management levels at NIST.

- In Table 5, I strongly suggest decomposing "developing strategic plans, a vision and setting goals" into three distinct items. I believe that goal setting skills are critical at every level of management. Strategic planning is a specialized activity that should be undertaken by executive teams. Developing a vision is a creative process based in part on analysis and in part on intuition. Developing a vision, the creative process, can be as important at the project level as it is at the strategic level.

- Consortium building or alliance networking strategies

- Prioritizing tasks

- Performing multiple complex tasks simultaneously

- Determining areas of responsibility

- Computer skills

- E-mail skills/internet skills

- Contracting skills 
- Procurement skills

- Safety management skills

- Dealing with technical issues outside of personal area of expertise

- Dealing with your management (most of the items above relate to your staff, not so much with communicating and effectively interacting with your management team)

- NIST is a technical organization, and we should strive for technical excellence. This means that we need to get our folks motivated to conduct world class research. I believe we can make this happen. This will require creative management techniques (given our budget constraints).

- Interactions as liaison with higher management.

- I have not had much experience, for example, dealing with poor performers, so it is hard to honestly evaluate my skill level (although I am confident I would be able to handle the situation)

- Learning how to see issues from the viewpoint of supervisors above me

- Managing with ambiguous authority

- Working in effective management teams

- Results oriented planning and leadership

- How to effectively use the internet to sell products or services and provide public information

- How to develop measures of program effectiveness

- I support the effort. 
- Focus on the early stage managers

- Build skills for others based on employee/supervisor perceptions

- Universal training topics to be avoided like plague

- Long term (greater than 8 hours) to be incorporated very cautiously

- I think overall it's been pretty good. There have been a few cases where management has set requirements that may have been questionable to make mandatory such as "managerial grid". (I personally found it quite interesting but not always in a planned way. When a team member, a VP from Aetna, went bipolar on us because "he no longer needed his lithium" we had a lot of unplanned experience in conflict resolution). The culture has always supported training. It might be helpful if there was bundling, e.g., 1 day of internet, 1 on the new processing and 1 on other NT tools as a package. Have to get up inertia fewer times.

- To my knowledge, it has been non-existent

- Would like NIST to offer more leadership development opportunities to managers

- None

- Not a present NIST concern. Must have a way of getting new, younger blood into the organization at all levels before any attempts will have any meaningful impact

- With respect to rotational assignments, it appears that the opportunities to get leadership experience in different labs is very limited. Opportunities are typically: Your own lab, ATP, program office. You may want to consider mechanisms for details to other laboratories. It would probably help to promote inter-laboratory collaboration. Please call if you wish to discuss this idea further

- Also, my responses to some questions were based on the fact that I have taken courses in a number of areas. For example, our division had training for a number of staff on "managing change." I personally felt that the course was a waste of time. Thus, there are potentially other questions with respect to each topic area - have you taken training in this area? Did you consider the training valuable? Would you consider taking additional training in this area?

- To have quality management requires attracting motivated and empowered individuals into these positions. Unfortunately, this type of individual is perceptive enough to see that there is no incentive to being a manager (group leader, even division chief) at NIST. You are offered administrative, financial, and personnel headaches - significant responsibility - with a joke $3 \%$ differential and lost opportunities for professional 
recognition. Do you wonder why the staff complain about the quality of management? They know they are smarter than we are.

- Management emphasis has to be a vertical chain. Fairness and equity is important throughout the organization. Creating a climate that management excellence is appreciated rather than despised is more important than individual training.

- Management courses offered in the past at NIST have been inefficient in time management, i.e., The courses are about twice as long as really needed. Also, almost all, if not all, of the material covered by the presenters could be obtained from the written material provided, and in a very short time. The oral presentations themselves have been almost useless.

- There is none of any real value. Most management courses are for business or supervisors of low level people - not our problem. The method of choosing managers is haphazard at best, and, once they are in place, they are never removed no matter how incompetent they prove to be. Training in a technical discipline in no way prepares one to be a manager. Anyone who lusts after a management job should never be allowed to have it. Most people who turned out to be the best managers took the job because they couldn't stand to work for whoever was second choice. Just some random thoughts from an old, old supervisor.

- I believe there should be more opportunity to branch out to different fields. For instance, one should be able to obtain personnel knowledge, procurement knowledge, accounting/budgeting knowledge, etc. To qualify for a senior management advisor position. My division is micro-managed, so regardless of how much education one obtains, it does little good in the actual work environment.

- Most of the classes I have taken at NIST in management/leadership have been very good -- the instructors have been excellent, and the material has been relevant.

- I feel that many of the questions deal with management skills but that equally important is the development of leadership skills, which I do not equate with management skills. I am not sure how one develops those skills, but I think they are vital in an institution such as NIST. Yet most courses address management (not leadership).

- This area has been at a minimal level for several years. A revitalization may help inject new enthusiasm and effectiveness.

- It seems to me that the opportunity and responsibility for improving management practice and skills resides at the OU level. Ray Kammer has the option of directing the OU directors to lead by example and to develop the necessary skills in their managers. It seems that good managers are characterized by their attitude about managing as much as anything else. The attitude is what is most important, not courses. Mentoring 
by selected managers recognized for their abilities and success is the best approach, I think.

- Most of it is worthless, but I admit that I do not know what an effective management training course would look like.

- I have concerns about the fact that NIST seems to think that management and leadership are one and the same. In an institution such as this one, that is not the case. Most of the courses you listed have to do with developing management skills but not leadership skills.

- We need a variety of courses for supervisors and managers as you have mentioned in the checklist above to develop different skills, particularly in the area of dealing with diversity issues such as changing the negative and conceited attitudes of supervisors/managers toward women, minority, secretaries, etc.

- In management training, it seems that there is a lot of "soft" knowledge. It is difficult to sort through the fluff to determine which training experiences are of significant value.

- Required management courses have ranged from bureaucratic to excellent. The best have been by outsiders. External instructors often focus on one or two vital elements/day. They hammer their points home with exercises and drills. For example, good external courses have covered (I) short presentations without visuals, (II) handling protected classes of employees, (III) matching management style to employee capabilities and (IV) presenting technical material. Internal courses too often emphasize many "rules of process" to be digested: these rules and reg. May be important, but the courses tend to be less effective.

- One real disappointment has been with personnel management training. Even following all the taught rules for managing poor performers, it sometimes seems hardly worth the effort. This part of training should give truly honest and candid indications of the difficulty-of-process attached to various adverse personnel actions.

- To attract NIST time-scarce managers, the management/leadership development education must provide very high-quality, high-credibility presenters and learning experiences. Expected utility for the managers must be high.

- Perhaps NIST or DOC could develop a leadership-building program similar to Montgomery county's leadership Montgomery. Only a small number of potentially great leaders are developed through programs like Comsci and others. NIST should have its own program for developing leaders from within.

- NIST needs to improve its management/leadership development program. Too often NIST managers lack management skills. 
- Many of the items/courses I feel are important are already being offered at NIST, but I find it difficult to allocate the time for them. Thus, solutions such as the lunch-time series mentioned in the forms might be just what I need.

- Providing a local series of leadership/management programs to address employee performance standards, managing problem employees and information on the HR support provided by NIST

- I was a first line manager at GE before joining NIST. I had gone through many of GE's excellent management training classes. I rated many topics as important but expressed low interest in participating in training. This contradiction is because I don't feel like repeating the class again. But I think it is important for new managers to go through management training (any kind). I also like to take refresher courses.

- Focus on technical output, the quality "at the bench", rather than the management side. Management deals with the process to achieve a product. For the most part, have management step aside and support the product, the output, rather than stepping in the way under the guise of "helping".

- At a seminar a few years ago, I remember well the admonition of the Director of Research at Bell Labs (now Lucent Tech.): My motto as a technical manager is to "hire the best people I can and get out of their way". This is idealistic perhaps, but I think it is a good attitude to emulate, rather than to hire the best and then tell them how to do a good job, or be more efficient, or. . e.g., support the technical staff's skills rather than trying to operate in a mode of "improving" those skills.

- Managers seem to be burdened with too many administrative details to be effective leaders. For instance, the perennial problem of having to "balance the books" seems to erode their ability to motivate the troops. Any training provided by NIST should address the present state of affairs.

- I think that the required "core courses" for new managers are very useful. Would like to see them expanded and more available to managers as they move through their careers.

- Many technical staff members at NIST feel that insignificant personal and/or monetary incentives exist to warrant serious consideration of a career choice in management. The non-technical challenges inherent in such positions are perceived to be both overwhelming and undervalued. To effect real positive change, I feel current management must focus on acknowledging the personal motivations of the staff by (re)considering the incentive issue and the (mis?)perceptions of the staff. The proper approach and balance to this tasks will then enable the subsequent educational and training mechanisms that will invigorate the leadership potential at NIST. 
- I regard management and leadership as two different disciplines. NIST offers nominal (i.e., Barely adequate) management training and virtually no leadership training inhouse. However, NIST has done a good job at providing access high quality management training.

- The two week OPM seminar for new managers that I took in Lancaster, pa was very well done. I recently completed an executive $\mathrm{ms}$ in technology management at UMD that was, for the most part, very good. Both of those training programs were supported by NIST. I also took part in the first conference of the national performance review at hunt valley in 1994 where world class business consultants presented their views on how the federal government can leverage lessons learned from the private sector.

- I applaud this new effort at management development. What is missing still is a program to identify and motivate staff to become future managers. My observation is that very few scientists at NIST have a desire to become group leaders or higher, and most must be pushed into it. This is so because the staff sees little positive personal benefit from becoming a manager. Turning this attitude around is a major challenge, and may be impossible with the present salary and management structure at NIST. It would be informative to survey the present group leaders to discover how many of them sought the position, and how many find the job rewarding and/or challenging.

- There is far less management training here at NIST than I have seen elsewhere in private industry.

- Most of the training courses, at least for new group leaders, are an agony to attend. Only one or two I have attended have been worthwhile. For instance, what are we doing getting training for inputting the position descriptions? The GL's should have a 20 minute intro on the principles, and the secretaries should learn the inputting details.

- Mentoring would be great if it ever took place, especially for a young ambitious female manager with SES aspirations

- Most of the managerial training courses I have attended at NIST were very useful

- Opportunities outside of NIST are not as accessible

- I strongly agree that NIST does a poor job of training managers/supervisors in the parts of the job that matter the most - setting goals and priorities, managing scientists, marketing, etc.

- It spends most of its training time teaching supervisors to do paperwork the right way, which doesn't get to the heart of NIST's mission 
- This not only slows down the building of quality leadership, but it also sends the wrong signals about priorities

- Training and mentoring opportunities would be very helpful for new supervisors, and could also benefit ones who have been at it for awhile

- In addition, a formal mechanism for staff to provide feedback about their supervisor to their second level supervisor could help the development of better managers, if handled well

- Why does my lab chief need to have his performance plan done in august when we don't do the staff until Sept (appraisal part) and October (planning part)? Since every level up the food chain depends on what is going on at the preceding level, this process is inverted as it stands now.

- The mandatory training I've been taking has not been very good. Some classes are a waste of time.

- Also, is there a way to find out which classes I've already taken? The names of some classes change over time, so I'm not sure if they're the ones I took a couple of years ago.

- Perhaps videotape courses, since it's been difficult for me to complete the mandatory sequence. There are only 1 or 2 opportunities in a year to take the courses, and often there are conflicts.

- There is no management/leadership development program at NIST.

- Managers should be evaluated on effectiveness and rated accordingly.

- Here are a few audio tapes/books I found interesting: built to last, fifth discipline, on communicating, one minute manager, individualized corporation, leadership engine, intellectual capital, the goal. The library needs to buy lot more on these topics.

- Should have more frequently during the year (we managers have to manage our time).

- I think the issue of developing strategic plans, visions, and setting goals is one of the most important topics to be addressed at NIST. Many members of the staff seem to lack a clear notion of who we are and what we are supposed to do.

- My comment to this forum is that this process (strategic plans, visions, and setting goals) transcends all levels of the organization. I am surprised that there are not well established processes for dialogue between the staff, management program office, etc. 
- Most of our planning seems reactive, not proactive (e.g., A rush call from the program office for a paragraph on what we might do on topic $\mathrm{x}$ ).

- Many courses are geared to the model office environment. This is not the norm for NIST.

- Need more education/training of senior managers on how to lead, motivate, team build and build morale

- Should ask the question if respondent has already had NIST's or other formal training, and to what extent

- I've always had the feeling that it takes a certain type of personality to be a manager. If a person doesn't have these characteristics, will "training" make a difference? I have taken most of the required training courses, but I still feel that I'm not a good manager. Basically, I get more joy out of doing the work rather than delegating the work.

- If NIST wants to improve management, I think it should be conducting a survey of the NIST employees, not the managers. From such a survey, we might learn the weaknesses in our current managers.

- There isn't any!

- NIST would be much better off if it eliminated the "supervisory training courses" -which involve telling managers the rules -- and replace these with education on how to be a good manager. Rules and procedures can always be picked up as they're needed, as long as the division has a good resource person.

- To be effective at NIST, education needs to be grounded to real data (in other words, backed by studies and statistics). Fluffy training will just be perceived as a waste of time.

- Current management education is mostly focused on the mechanics of the process rather than achieving results

- Diversity of management levels and responsibilities means that mechanics focused courses are not particularly useful

- Presently, it is non-existent

- Further the micromanagement at the OU director level is both contemptible and counterproductive

- Both the Lab Council and E-board are studies in how not to manage 
- Teamwork seems unimportant; cross-OU partnerships are subjected to unseemly scrutiny. NIST is one organization, not eight feuding kingdoms.

- Good management skills do not appear to be highly valued. Training is haphazard, and courses that I've taken are weak. NIST-policy training does not cover much that is actually relevant to real problems. Upper management provides almost no feedback (other than providing few tangible rewards for assuming management responsibilities!)

- I think NIST does a good job of providing a wide range of educational opportunities for managers.

- Lack of SES career development 
The following are in response to Question 7: "Do you have any comments regarding management/leadership education at NIST?"

- Am aware of very little, with some prominent exceptions

- Glad NIST management is realizing management is a learned skill. For too long, governmental people have been made managers because of grade or technical skill without mgmt training, development, or mentoring.

- Yes, course on development of the whole person should be offered

- A program like Anthony Robbins teaches would be the best

- Technical project management scheduling, budgeting, goal setting, etc)

- Skill in building and maintaining alliances

- Dealing with outside constituencies

- Career development for self and others

- Setting priorities is vitally important since there is never enough time to get everything done

- Importance of the manager keeping everyone informed

- Unfocused

- Moving in right direction. More would be better

- Unaware what NIST currently offers

- Difficult to find worthwhile NIST offerings for those who have private experience and/or an MBA. Many training opportunities do not assume their participants have this background.

- Main problem with this survey is that respondents are expected to be familiar with meanings of "conflict resolution", "organizational skills", or "team building" in order to answer whether interested and how they would rank themselves in that skill

- Seems as though the least training is provided to first-line managers (group leaders) who have direct contact with staff and require, perhaps, the greatest interpersonal skills. 
- Most of our managers have little or no training to be managers. They are researchers put in manager positions, wanting the money but not the work of a manager. We need managers who are just going to be managers.

- NIST managers need the most training in interpersonal management skills

- Cover message from director is right on

- This survey assumes I have an interest in becoming a manager, and I do not (I act for group leader in his absence)

- Would be interested in higher level internet training that covers management of an entire web site

- Would also be interested in project management development education for project managers

- Very glad to see an interest at the highest levels in continuing to improve management and leadership skills here at NIST

- In past, management training has been limited to how the NIST system works. It is good to see interest in real management skill development. Most NIST managers have either poor people skills or poor business skills. Most have good technical skills, but often in a narrow field because most have $\mathrm{PhD}$ 's. Policy of requiring division chiefs to have PhDs can be counterproductive in some OU's.

- I feel that managers should be evaluated on these skills in their performance plans, and that training sessions should be available to everyone at a certain level or above at NIST. For the scale, perhaps AP-III and above. Managers currently do not value employees' time spent on these types of training opportunities. Alternative, all performance plans at or above a certain level could have points assigned to completion of training in the areas described above.

- I am taking you at your word about informal mentoring. I think formal mentoring is a bit ridiculous. It is not clear there is any.

- The idea that $R \& D$ cannot be managed has been used as a "cop out". Further, technical people tend to have very little interest in or respect for management and management skills.

- Definitely needed. Cannot assume that staff from a technical background have or will easily learn management skills when they become managers. The successful completion of a series of mandatory management skill classes should be a part of the probation period of a new manager. 
- This survey is a good first step

- For close to 5 years I have been an Sr. Project Leader and have been pondering whether those "Management Update Series" classes announced in the technicalendar are open to all employees or only to the chosen ones

- Are you supposed to educate yourself to be a manager after being selected to be one, or should you try to do it before and look as a "pretender"?

- I don't see how one can learn management skills from books, videos, and other "dry" materials. It is an interactive position, and training should reflect that with opportunities to get feedback and ideas from other people.

- The government has become too bound within itself, and outside influences are drastically needed, i.e., The idea about the outside training programs.

- Sensitivity

- The e-mail mentioned that the survey would assess current and future resources, but the survey did not address current resources available. Also, SAO

- Sampling other NIST staff seems unnecessary for this type of survey. Allowing all NIST staff who are interested to take this survey would provide more information, especially since at the beginning of the survey, you already weeded out your random sample by asking people who may be interested to take the survey, as opposed to asking all "randomly selected" staff to proceed. The survey is not expensive to implement, so I am unsure what you are gaining by a random sample. Just some thoughts ... I know that a lot of forethought went into this, so I am not sure I am not simplifying the situation, not being aware of the full intent of the survey.

- Your question should address both those who are and those who have been in management positions. Since I fall in the latter position, I have to answer "no" to questions I probably should say "yes" to

- There are those who fall into the category of managers on an unofficial basis, but are not officially "project leaders" for example

- Encouraging positive interactions among team members rather than ignoring or setting members in competition with each other

- I believe you covered all the pertinent topics

- Program articulation - the ability to articulate a technical program such that others (staff, upper management, congress, presidential appointees and the executive branch management, ...) understand the program 
- Anti-team player recognition -- I noticed that frequently people who take actions that promote themselves at the expense of others and team goals are promoted, even to upper level management. A course that deals with how technical management can recognize this behavior and at least not promote the behavior would be welcomed.

- Development of other leaders

- Working with "volunteers". I spend an incredible amount of time working with volunteers in professional organizations, in regional groups gathering support and coordinating getting work done without people getting paid for it directly by NIST to meet NIST objectives.

- Table 4: informal and anonymous peer and underling review, placed confidentially through a third party to manager. Not to be used to rate the manager, but to help develop management skills in a way that is just between the manager and the third party. The confidential third party could make and take training suggestions. Therefore, criticism could be filtered and used constructively.

- Table 5: prioritization of projects

- Table 5: managing conflicting personnel interests

- Table 5: managing conflicting project interests

- Table 5: managing conflicting leadership interests

- Promoting group loyalty

- Identifying, understanding, and catering to the customer. (this is part of strategic planning, but I don't think it is done very well here at NIST, and therefore, should be emphasized).

- Maintaining a professional atmosphere and empowering employees to want to succeed by not treating them like cheaters or children

- I would add a line item that addresses the enhancement of "interpersonal skills" which is essential for effective leadership

- The perception of favoritism in making it available has hindered its acceptance among the general staff

- As a non-manager and a NIST employee for over 30 years, and having served under several managers, I feel that most were in serious need of training! 
- Please find a way to compensate the great scientists at NIST without having to make them managers. I have seen many examples of very intelligent men and women placed in managerial roles with "no" managerial skills whatsoever. NIST loses twice when this happens. We lost a staff member who no longer does science, and we lost by having an ineffective manager. I think we should look for those with managerial skills who have a great appreciation for the sciences.

- I think there should be a way to "strongly encourage" (if not mandate) managers to attend a certain \# of management classes/year

- Some managers do not belong in management positions. I think it would be good to have a pre-management program which will help to assess whether employees have the skills to be an effective manager. To many times, employees are made managers -- and they turn out to be lousy. Then, nothing gets done about it. A pre-mgmt program may help to eliminate putting non-manager types into the position to begin with.

- I know NIST has tried in the past to implement a mentoring program and there was not a lot of success stories, but I still feel it is an extremely important program to help develop careers, especially for women and minorities who are not as comfortable and/or familiar with the "networking" and "old boys network" philosophy of seeking promotions. Please keep trying!

- NIST needs more programs on diversity, treating others with dignity, and proper and improper behavior for managers. People skills should be just as important when selecting new managers, as are technical capabilities. A manager manages both people and projects, and you cannot empower your people to do excellent work on projects without having the abilities to make his/her workers feel appreciated and able to keep their self respect.

- I have been very fortunate in that all of my supervisors at NIST have helped me further my education. I have appreciated this immensely and am very interested in taking additional classes at NIST. whenever possible.

- I like the idea of allowing non-managers to attend management/leadership development sessions

- None at this time

- It is good that you are soliciting information on this survey from all levels of management as well as non-management levels. Targeting the importance of each item listed is crucial to the success of any program

- Thank you for letting me participate 
- Seems very much needed, especially delegation, communication and empowerment skills in this group

- Group would function more happily and more efficiently with better intergroup and leader/team communications which are at present negligible or absent

- I feel that management/leadership training should be offered not only to currently management/leaders but to other employees that are interested in advancing their careers in these types of fields

- I believe there would be a strong interest

- NIST is very lacking in good management/leadership. We could learn a lot from private industry on this topic.

- NIST has a very open environment which should be encouraged and works well for some individuals but many more people require stronger leadership and more management. It is good to see that this area is being addressed.

- I feel that the opportunity to participate in management/leadership development education should be extended to all employees that desire to become managers. I also believe that all managers should be required to complete a management track prior to being considered for management level positions. Currently, management/leadership development education is only available to those persons who are present managers. I think that it is too late to train someone to become an effective and successful manager after they have assumed the role of a manager. I believe a manager should definitely be involved in continuing education courses to further develop their skills and keep abreast of new developments in the management arena

- Improving the management at NIST is a valuable project. My experience so far is that management at NIST is inferior to what I experienced in industry. This is an important problem to work on - kudos!

- Some concepts embraced at the laboratory level; e.g., Development of an atmosphere of inclusion and opportunity, are slow in trickling down to the division and individual project levels.

- The dated concepts of handling workers who treat co-workers rudely, who have somehow achieved "idiosyncrasy credits" that cause their interpersonal problems to be overlooked because they are valued for other "contributions" to the organization should be abandoned in favor of a zero-tolerance policy with regard to workplace aggression and sexual harassment. (ref. Washington post, 12jul98, pg. H01). Otherwise, the perception that "unacceptable behavior is acceptable if --- likes you" quickly pervades the OU. 
- Sub-optimal managerial techniques such as exclusion, shielding from opportunity, obvious disrespect and subtle harassment are extremely contagious. They are readily transferred from management to the staff at large.

- I would suggest being careful with the understanding of the "team" approach. There seems to be a push for team operation in situations where the concept does not apply. There seems to be too much "management" and not enough research/production/science carried out in some areas at NIST. Management can't do research because of time/responsibilities required by "management".

- NIST is loosing good staff due to over-management

- I find that I have been able to use leadership development skills of others in professional organizations and in collaboration and partnership with other federal and state agencies as well as in a nonofficial capacity in NIST work where I am responsible for leadership development - yet wonder about the lack of potential of using these skills on the job within NIST

- Also, my greatest area of passion, outside of the technical work I do is in leadership development -- not "management" -- and would love to get a $\mathrm{PhD}$ in this area

- I feel that any management/leadership development education being offered at NIST should be mandatory for any employees already in a management/supervisory position or who are being considered for such positions.

- More management/leadership development classes should be offered at NIST for folks not currently in management or supervisor positions. These folks should be able to attend these classes with the full support of their supervisor.

- We must genuinely enforce the development of NIST minority employees to be technical and not administrative managers.

- I welcome the opportunities for management education \& training development at NIST. The numerous categories listed in table 4 show how extensive training could be. While all managers should be able to receive refresher training in any area at their own discretion, I think core training (possibly a week-long course covering multiple key categories) should be required of new managers. The primary outcomes of the core training should be instruction, empowerment, and support.

- The NBS mandatory training for new group managers in the early 1980 's was very valuable. But much of that training had a limited shelf life. Managers should be required to take refresher training to stay current on essential, administrative information on budget, personnel, procurement, etc. 
- Managers who don't grasp the "leadership 101" part of training the first time probably never will. Leadership training is essential for an organization, but it is not a panacea for ensuring excellent leadership.

- This survey should not be sent to persons who are not managers or supervisors. It is irrelevant.

- All items in Table 5 are important at some level, and the relative importance probably depends on the particular supervisory/leadership task that is required. I do think that I personally would rate well in most of the areas listed in table 5. However, in many of these areas I am untested, and therefore, don't feel able to give a genuinely accurate indication. I would generally be interested in improving areas where I perceive a weakness, but until that day when I'm asked or required to act in such a capacity, I can't give an accurate indication.

- Needs to be continued and constantly updated to better serve the fast-paced and changing/challenging world in which we live.

- I am relatively new to NIST and the management/leadership development educational process. I currently feel that the opportunity exists for those who want to strive to receive education and training in any area, but I feel that in some divisions, only certain courses are allowed or certain classes are approved for one who wishes to pursue their education. If classes or the education is being offered, anyone who wants to take it to better themselves should be allowed to take the course.

- I'm glad to see a focus on management/leadership development education!

- I'm very glad that a survey has been done concerning this topic. I will be interested in learning the results.

- NIST courses are often listed (and encouraged) for managers only. Why not allow all NIST employees to attend 1 class every $1-2$ years? We would all benefit.

- For the chosen few or not much use if no chance to advance

- Managers should take a course in people skills. Having the smarts and ability to manage is not all that should be considered for the position. We have a manager who has all those qualities, but when it comes to treating the employee's, there is a lack of respect. Focus should be on all of these skills, not just a part of them

- I think it is needed. Managers and non-managers should have these educational opportunities.

- I definitely would like to see an increased effort in this department. I would like to further my career here at NIST, and management skills are vital to that goal. I hope to 
see more training programs in the future for both current management and for people looking to get into management. Effective leadership requires training, and to remain a world-class leader in technology, we will certainly need the leaders to take us there.

- Based on past supervisors I have had at NIST, it seems that management/leadership development training has been ignored or placed as a low priority. I have rarely seen/heard of one of my supervisors going to some development/training program or courses. However, when I did work at another governmental agency, there was mandatory supervisory training for new supervisors. Existing supervisors were also required to take so many hours each year. Maybe this is in place at NIST also, but as I stated, I have seen only $2-3$ instances in the past 10 years.

- I think it would be a nice idea to implement a management/leadership development program at NIST, especially one that would target individuals who might be interested in becoming managers. This should probably include courses on project leadership (I took several project leadership courses some at my last job that were very informative).

- Web and self-study materials are of limited value since it is difficult to set aside the uninterruptable time necessary to actually complete them.

- Please accept my somewhat nostalgic comments on this survey; as I approach the end of my career at NIST, I am not strongly motivated to take advantage of this new initiative. I only wish it had been conducted 10 years ago. I have not observed, in my 13 years at NIST, shining examples of first-level management development opportunities. This is perhaps the result of the "pyramid effect". Nevertheless, all of you reading these comments, have my sincere best wishes for a successful initiative. It's spotty. It seems to be depended upon individual motivation, which I suppose is appropriate. I would love to see more emphasis placed on the development of effective leadership abilities with focus on managing and valuing people, not solely technical research efforts.

\section{Somewhat longer response to questions 6 and 7:}

- After strategic planning, the single most important responsibility of a manager is setting priorities, using stated, rational criteria, among important activities competing for a limited budget. I find it interesting that this topic is not explicitly included on the list. Perhaps it was subsumed in project management skills or in decision making. But priority setting is so important that it merits a line of its own. The lack of uniformly good priority setting throughout the organization is, in my view, the single most important shortcoming of NIST. It is why NIST has not optimized its impact with its present budget. NIST managers often attempt to export priority setting to management levels above or below their own. Some exporting to management levels below their own is good management (delegation). But most exporting to levels above their own is bad management. 
A major example is the pursuit of additional resources from a higher level for new work, instead of the use of priority setting to identify lower priority work that could be terminated to enable support of new work of higher priority. In a well-managed organization, requests for additional resources (including agency initiatives) should be made only for work of lower priority than any other work presently underway. Work of higher priority should be supported by terminating or phasing out work of lower priority. This doesn't mean RIF actions. Good managers plans these changes in advance, with their staff, and provides maximal opportunities for staff to move to new areas and to retrain, if necessary.

The practice of priority setting using stated, rational criteria must start at the top of the agency if it is ever to succeed throughout the agency. If management levels below the top perceive that decisions on their resources are being made at the top using less than stated, rational criteria, they will not bother to feed rational argument up the chain of command. Instead, they will seek to discover the basis that is being used for making decisions and will try to respond accordingly. One hopes that they won't have to consider bases such as these: ingratiating themselves to the next higher level; yelling the loudest; arguing that all organizational units should have the same level of resources because that is only "fair"; and other arguments that have little to do with a distribution of resources that optimally meets the needs of nit's customers.

Another topic of importance is determining the needs of the customer. This didn't make the list above but may have been subsumed in other topics. This information should be the driving force for priority setting. But too often at NIST, studying the needs of the customer is given a low priority. Such study may be considered boring. After all, "we already know what we want to do." Further, studying those needs may be considered threatening, because it can lead to the discovery that we are not doing the most important work and, therefore, that we should change. We need to stop looking at industry's needs as just an "opportunity, should we choose to respond" and to start looking them as a "responsibility to respond".

\section{ResponseTwo of somewhat longer comments on Questions 6 and 7.}

- One of the most important improvements needed at NIST is a better climate for projects that cross organizational lines. Increasingly, the problems that NIST must solve to serve its customers require multi-disciplinary approaches to resolution. Unfortunately, the need for collaboration is sometimes converted into a battle for turf. Too often, this tendency leads to keeping others out of an area in which help is needed if NIST is to meet the customer's needs. The customer is the loser in this process.

For similar reasons, NIST also needs increased flexibility to reorganize in order to bring diverse skills together for a number of years to promote focus, coordination, and priority setting within a given area. There is no need for NIST to have multiple, uncoordinated efforts in a given area. Sometimes the need for competition is raised as 
a rationale for multiple efforts. But industry has too many needs requiring NIST for NIST to afford the luxury of internal competition.

One possible way of advancing collaboration might be to start rotating high-level managers among the laboratories. The managers would hopefully begin thinking of themselves in a NIST-wide context instead of in a single-organization context. The purpose would be to have them learn more about each other's work and to come to understand better the importance of that work. Another purpose would be to expose them to other management styles. The level of the managers to be rotated would need to be considered, since such rotation is no simple matter. Such rotations, or perhaps exchanges, would be most important among or between organizations with common customers.

Another dimension of need is for NIST managers to learn more about economically efficient practices that are essential for survival in the private sector. Many NIST managers have never worked in the private sector. This fact, combined with the lack of a profit motive in government, has led to inefficient practices. Some services provided at NIST are woefully slow; some may be unnecessary. Empowerment is sometimes seen as a threat to control instead of as a tool for improving efficiency. Staff time is sometimes treated as a sunk cost. Meetings that are too long and too frequent are held without ever putting a dollar cost on the labor hours consumed and lost to useful work. Paperwork is sometimes generated with just as little thought. One is tempted to say that NIST staff should be given a cost center or two to bill for all activities of these kinds that take them away from their work. It would be interesting to see how high the cost really is.

This matter of etficiency is so serious at NIST that I have come to cringe whenever I hear the word "excellence" touted at a goal. Excellence is clearly essential for our core mission in providing and maintaining the fundamental standards. But, too often, the pursuit of excellence at NIST is implicitly used as a justification for not delivering on the schedule the customer needs and at the level of quality that the customer needs. The adage "the excellent is the enemy of the good" merits further consideration in NIST management training. Often what industry needs from NIST is something good now not something excellent later. We need to start identifying early in a project what level of performance is needed, and when, to be most helpful to our customers.

Another phrase that raises concern whenever I hear it is "reserve funds". While there are justifiable reasons for reserve funds, I worry that managers keeping reserve funds may spend more time managing the distribution of the reserve funds than the distribution of the total resources for which they are responsible. Too often reserve funds translate into micro-management, a desire to manage at a level of generality below the level that is appropriate. Thus the management of reserve funds can become one expression of the always a group leader syndrome at NIST; this is the failure of NIST managers to move to a higher level of generality as they move up the management chain. Some of this tendency seems to result from the fact that most 
NIST managers were bench scientists or engineers earlier. They love science and technology. They may have become managers reluctantly. They want to continue to dabble at the lower levels that are closer to the technical work that they liked better.

Taking the broad view, the needs for NIST's contributions in metrology are so obvious, and the credit that NIST would receive for meeting those needs better is so potentially great, that about the only real threat to NIST's continued welfare as an organization is its own performance. The new emphasis on management quality, evident in the existence of this questionnaire, can be the start of a major advance for NIST. Bravo to all supporting this effort.

Being a good manager is very difficult. Managers need a much broader background, viewpoint, and skill set than laboratory research requires. The rest of us need to respect our managers for their willingness to take on the responsibilities, to make the tough decisions, and just to put up with incredible diversity of the rest of us. We need to support them, too; and we owe them additional training to help them cope successfully. Good quality training is a win-win situation for managers, staff, NIST's customers, and the taxpayers 
